\title{
HYDROGEN ENERGY ASSESSMENT
}

\author{
F.J. Salzano and C. Braun, Editors
}

September 1977

Prepared for the

OFFICE OF THE ASSISTANT ADMINISTRATOR

FOR PLANNING AND ANALYSIS AND THE

DIVISION OF ENERGY STORAGE

UNITED STATES DEPARTMENT OF ENERGY

BY THE

NATIONAL CENTER FOR ANALYSIS OF ENERGY SYSTEMS

BROOKHAVEN NATIONAL LABORATORY ASSOCIATED UNIVERSITIES, INC.

UNDER CONTRACT NO, EY-76-C-02-0016 WITH THE

UNITED STATES DEPARTMENT OF ENERGY 


\section{DISCLAIMER}

This report was prepared as an account of work sponsored by an agency of the United States Government. Neither the United States Government nor any agency Thereof, nor any of their employees, makes any warranty, express or implied, or assumes any legal liability or responsibility for the accuracy, completeness, or usefulness of any information, apparatus, product, or process disclosed, or represents that its use would not infringe privately owned rights. Reference herein to any specific commercial product, process, or service by trade name, trademark, manufacturer, or otherwise does not necessarily constitute or imply its endorsement, recommendation, or favoring by the United States Government or any agency thereof. The views and opinions of authors expressed herein do not necessarily state or reflect those of the United States Government or any agency thereof. 


\section{DISCLAIMER}

Portions of this document may be illegible in electronic image products. Images are produced from the best available original document. 
BNL 50807

UC-94d

(Energy Storage-Chemical - TID-4500)

\title{
HYDROGEN ENERGY ASSESSMENT
}

\author{
F.J. Salzano and C. Braun, Editors
}

Contributors
M. Beller
N. Bhagat
A. Doernberg
H. Davitian
K. Hoffman
W. Sevian

September 1977

This report was prepared as

spensored by the United Stutes an account of work

United States nor the United States Det. Neither the

Energy, nor any of United States Department of

conttractors, subcont their employees, nor any of theit

any warrats, expractors, or their employees, makes

liability ory, express of implied, of assumes any legal

or useful responsibility for the accuracy, completeness

process diss of any information, apparatus, product or

infringe privately owned rights.

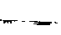

Prepared for the

OFFICE OF THE ASSISTANT ADMINISTRATOR

FOR PLANNING AND ANALYSIS

AND THE

DIVISION OF ENERGY STORAGE

UNITED STATES DEPARTMENT OF ENERGY

BY THE

NATIONAL CENTER FOR ANALYSIS OF ENERGY SYSTEMS

\section{BROOKHAVEN NATIONAL LABORATORY}

ASSOCIATED UNIVERSITIES, INC.

UPTON, NEW YORK 11973 


\section{N O T I C E}

This report was prepared as an account of work sponsored by the United States Government. Neither the United States nor the United States Department of Energy (DOE), nor any of their employees, nor any of their contractors, subcontractors, or their employees, makes any warranty, express or implied, or assumes any legal liability or responsibility for the accuracy, completeness or usefulness of any information, apparatus, product or process disclosed, or represents that its use would not infringe privately owned rights.

Printed in the United States of America Available from

National Technical Information Service

U.S. Department of Commerce

5285 Port Royal Road

Springfield, VA 22161

Price: Printed Copy $\$ 6.50$; Microfiche $\$ 3.00$

May 1978 
Page

HYDROGEN TECHNOLOGY OVERVIEW..................... 1

SUMMARY .................................... 4

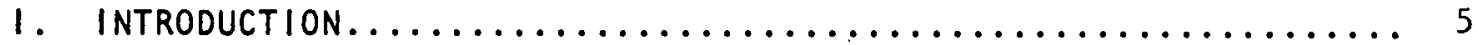

11. POSSIBLE HYDROGEN APPLICATIONS AND CURRENT STATUS

OF RELEVANT TECHNOLOGIES ........................ 8

111. CURRENT AND FUTURE DEMAND FOR INDUSTRIAL HYOROGEN......... 17

A. Historical Background..................... 17

B. Current and Future Demand................... 17

C. Resource Implications of Industrial Hydrogen Demand...... 24

IV. NEW HYDROGEN APPLICATIONS IN THE NATIONAL ENERGY SYSTEM...... 28

V. RED COST-BENEFIT STUDY...................... 47

A. Market Penetration of Advanced Hydrogen Production Technologies............................ 48

B. Hydrogen Production by Coal Gasification.............. 49

C. Hydrogen Production by Water Electrolysis............ 51

D. Comparison of Projected Benefits and Relationship to RED Funding on Hydrogen Production............... 52

REFERENCES $\ldots \ldots \ldots \ldots \ldots \ldots \ldots \ldots \ldots \ldots \ldots \ldots \ldots \ldots$

BIBLIOGRAPHY ............................ 64

APPENDIX A

HYDROGEN PRODUCTION METHODS AND COSTS................67

A. Introduction.......................... 67

B. Natural Gas Reforming and Partial Oxidation of Hydrocarbons.............................67

C. Hydrogen Production by Coal Gasification............. 74

D. Hydrogen Production by Water Electrolysis............. 75 
TABLE OF CONTENTS (Cont'd)

Page

E. Thermochemical Hydrogen Production................. 90

F. Additional Hydrogen Production Methods............... 91

APPENDIX B

COST EQUATIONS USED IN ESTIMATING HYDROGEN PRODUCTION COSTS.... 92

\section{LIST OF TABLES AND FIGURES}

Table $1 \quad$ Hydrogen - Current Sources and Uses $-1973 \ldots . . . \ldots . .19$

Table 2 Projections of Future Demand for Industrial Hydrogen... 20

Table 3 Literature Survey of Future Industrial Hydrogen

Demand Projections........................ 21

Table 4 Energy Resource Requirements for Industrial Hydrogen

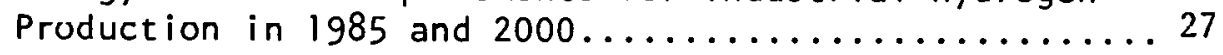

Table 5 Synthetic Fuel Cost Computations - Cost to Final Distributor........................... 30

Table 6 Hydrogen Applications - Current and Potential.......32

Table 7 Energy Requirements for Subcompact Passenger Vehicle Operation............................. 39

Table $8 \quad$ Vehicle Operating Cost Comparison............. 40

Table 9 By-Product Gases From Major U.S. Industries

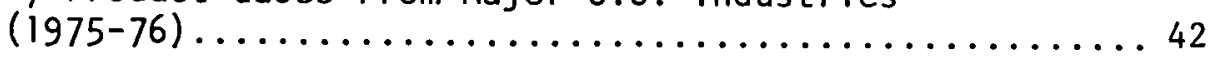

Table 10 Estimated Maximum Potential Penetration of Hydrogen Into the National Energy System in New Applications.... 46

Table 11 Summary of BNL Cost Benefit Calculations Related to Improvements in Hydrogen Production Technology........50

Table A-1 Computation of Hydrogen Production Costs by Various Technologies in the Years 1985 and $2000 \ldots \ldots \ldots \ldots . \ldots 71$

Table A-2 System A - Projected off-Peak Energy Costs..........79 


\section{LIST OF TABLES AND FIGURES - (Cont'd)}

Table A-3 New York Power Pool - Off-Peak Energy Costs vs.

Demand Level.......................... 80

Table A-4 Hydrogen Production Costs 1975 Dollars............ 85

Table A-5 Electrolytic Hydrogen Production Costs 1975 Dollars.... 86

Table A-6 General Electric SPE Electrolysis System Hydrogen Product Cost for Various Operating Modes....... 87

Figure 1 Production Costs Including 15\% DCF Return for

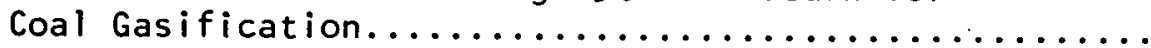

Figure A-1 Approximate Current Hydrogen Prices $(1974) \ldots \ldots \ldots \ldots 6$

Figure A-2 Current Hydrogen Production Processes.............. 70

Figure A-3 Hydrogen Manufacturing Costs - Midcontinent Location.... 73

Figure A-4 Cost of Coal-Derived Hydrogen as a Function of the Gasification Efficiency and the Lignite Cost.......... 76

Figure A-5 Hydrogen Manufacturing Costs - New Coal Gasification.... 76

Figure A-6 Cost of Off-Peak Nuclear Electrolytic Hydrogen as a Function of the Off-Peak Power Cost, and the Electrolyzer Efficiency....................... 82

Figure A-7 Hydrogen Manufacturing Costs - Electrolysis.......... 89 
Presently, hydrogen is used for various industrial purposes, primarily as a chemical commodity and minimally as a fuel. Within the last five years it has received worldwide attention and many people advocate extensive federal programs to make hydrogen a universal fuel.

A key focus of any federal hydrogen program should be to assure essential industrial supplies for all applications, while conserving scarce fossil fuels. For present applications, hydrogen is derived from natural gas and residual oil, which is expected to be in short supply in the near term. An alternative hydrogen source is required and coal is the most likely candidate. It is also clear that hydrogen must eventually be produced from nonfossil energy resources. A convincing argument can be made that some smaller fraction of the industrial hydrogen produced in the future will be supplied from electrolytic sources, most likely nuclear-derived electric sources. In circumstances where purity is of prime importance and cost secondary, electrolytic hydrogen sources may be favored. The need to supply these industrial requirements for high purity hydrogen will be important and in some cases may be critical.

The role of hydrogen within the national energy system in the next 30 years is strongly tied to the development of the domestic synthetic fuels industry, based on coal. The near term extensive use of hydrogen as an energy carrier depends on a large-scale economical production capacity which would be based primarily on coal gasification. However, other products of the gasification process, such as methane or methanol, may prove cheaper to produce than hydrogen and are more compatible with the existing transmission and distribution (TED) infrastructure. These fuels would then be the preferable products of the gasification technology. In the near term, coal could be the principal raw material for hydrogen production for its conventional industrial markets, instead of the scarce natural gas and the expensive residual oil, which could be used to fill other more important end-use demands within the national energy system. 
However, other coal-based fuels will hinder the penetration of hydrogen into new energy sectors as an independent energy carrier. Only when nonfossil-based large-scale hydrogen manufacturing technologies based on nuclear or solar resources are developed, will hydrogen be able to compete with natural or synthetic fossil fuels for applications in all the energy sectors.

It has been stated that hydrogen is a potential replacement for natural gas because it is easily produced from coal and is clean burning. However, the transition from natural gas to hydrogen would involve substantial changes and additional investment in the natural gas transmission and distribution systems and end-use devices because the present systems and devices are not totally compatible with the use of pure hydrogen. Also, synthetic natural gas, i.e., methane, can be produced from coal easily and at a similar cost to hydrogen. Thus, the current emphasis that federal coal gasification programs place on methane production is sound. For the future, natural gas TED companies should consider developing new systems which are equally compatible with synthetic natural gas (SNG) and hydrogen for use in existing pipeline systems.

It has been argued that hydrogen can be derived from nuclear, solar, and wind or other nonfossil resources and used for a wide range of residential, commercial, and industrial fuel applications. The applications include transportation for air and ground as well as stationary fuel uses. These are all qualitative arguments based on speculative economics, which do not always objectively examine competing alternatives to the various applications considered. Although the case for these applications, and the extent to which hydrogen will be used, tends to be overstated it is highly likely that a number of them will materialize in some regions of the U.S. at a significant demand level. In almost all cases, the viability of these applications depends on the further refinement or development of various key technologies which are essential or relevant to the end uses. Generally, the relevant technologies are in the areas of hydrogen production, storage, materials for transmission and distribution, and end-use applications, in addition to direct high efficiency electric conversion devices, e.g., fuel 
cells. Much of the additional supporting technology, e.g., pipeline fabrication, compressor design, etc., is essentially available from the commercial sector.

Any federally funded Hydrogen Technology Development Program must focus on the total range of prospective applications and must endeavor to deliver the key critical technologies to allow the widest application range. As in ongoing efforts DOE should continue to examine present and future economic and technological circumstances to define very specific system applications for hydrogen in the near and long term. Because it is both difficult, and unwise to conduct a broad, unfocused Hydrogen Technology Development Program, the current DOE program must focus on the most feastbile near-term applications and sources of supply.

$-3-$ 
The purpose of this assessment is to define the near term and long term prospects for the use of hydrogen as an energy delivery medium. Possible applications of hydrogen are defined along with the associated technologies required for implementation. A major focus in the near term is on industrial uses of hydrogen for special applications. The major source of hydrogen in the near term is expected to be from coal, with hydrogen from electric sources supplying a smaller fraction. A number of potential applications for hydrogen in the long term are identified and the level of demand estimated.

The results of a cost benefit study for RED work on coal gasification to hydrogen and electrolytic production of hydrogen are presented in order to aid in defining approximate levels of RED funding. A considerable amount of data is presented on the cost of producing hydrogen from various energy resources. A key conclusion of the study is that in time hydrogen is likely to play a role in the energy system; however, hydrogen is not yet competitive for most applications when compared to the cost of energy from petroleum and natural gas. 


\section{INTRODUCTION}

The idea of using hydrogen manufactured from nuclear energy and other nonfossil resources as a universal fuel (Hydrogen Economy Concept) to serve industrial, stationary, and transportation applications appeals to the frontier instincts of all technologists. However, one must carefully weigh this alternative by taking a practical, rational view of where, how, why, and at what cost hydrogen can be produced and used in the energy system, in addition to the timing for its implementation in various end-use applications. This study, which focuses on the time frame year 1980 to 2000 , considers production technologies and end-use applications which could materialize in this period.

Clearly, to the user electricity is a clean and convenient form of energy which can be derived from nuclear and other nonfossil resources. It will always fulfill a unique and essential role in the energy system; however, electricity is not the best, most practical, or even the most economical form of transportable energy for all domestic and industrial applications, certainly not within the time frame considered here.

The existing energy system is heavily committed to the direct use of storable-portable fuels. In the near term, the need to supply these fuels to various demand sectors is obvious. In the absence of a readily available and inexpensive domestic fossil fuel supply, it is desirable to manufacture substitute synthetic fuels without relying on the availability of a fixed carbon source such as limestone or $\mathrm{CO}_{2}$ in the air. Hydrogen readily lends itself to this application as a basic fuel form and as a source of other liquid synthetic fuels.

The conditions described above are not yet fulfilled and the exact time when the necessary economic conditions will exist is obscure. However, it is generally agreed that these conditions will eventually prevail and a number of near-term applications will exist.

In the near term, hydrogen production will be limited by available energy sources. Coal is a likely choice to replace part of the natural gas and residual oil feedstocks presently utilized for hydrogen production; 
however, for some applications the use of excess (off-peak) nuclear capacity will also be desirable. The course of the energy system's future development must follow a logical, natural path which is compatible with a flexible fuel and electricity mix. Additional sources of storable and portable fuels will be required, and the introduction of hydrogen will be feasible for some applications.

Any long-term view of the system must recognize the significant growth of nuclear energy--both fission and possibly fusion--in the electric utility industry and this energy-source's potential to help fill the gap between general purpose fuel demands and the domestic petroleum and gas supply. The less desirable alternative of imported oil may require the United States to pay significant economic penalties and compromise our international political independence. Strategies which would offset these undesirable effects at reasonable cost, even to a small degree, should be seriously considered. Furthermore, in the face of these difficulties, i.e., the need to import large quantities of oil, the United States should encourage development of alternate non-nuclear energy sources such as solar, wind, ocean thermal, and geothermal. If it is desirable to deliver energy from these sources in forms other than electricity, hydrogen is the key.

Even in the enhanced exploitation of coal, which will be required in the near term, the question of what clean energy form coal should be converted to arises; the alternatives are methane (synthetic natural gas), liquid hydrocarbons, or hydrogen. Obviously, there will be a need to produce and deliver all three types of fuels; however, the production of any of these is dependent on the intermediate production of hydrogen. The most likely situation is that all three forms will be exploited to overcome the oil and natural gas supply problem faced by the United States over the next 20 - 30 years. Another alternative that must be considered in any analysis of the cost and impact of hydrogen production is the potential of deriving oil from shale and tar sands and its eventual cost in competition with the systems described.

In the near term, two applications of hydrogen are technically possible using off-the-shelf components or components involving a limited amount 
of development work. The first and most likely alternative is the use of hydrogen as a medium for delivering nuclear or other base load electricity to selected applications as a supplement to the natural gas supply. It has been suggested that concentrations up to $10 \%$ by volume can be injected into existing natural gas lines without changes in FPC regulations regarding Btu content or adjustment of end-use devices. Such an application would allow nuclear or eventually solar energy to flow into the gas system. The recent natural gas shortage of winter 1976/1977 has served to emphasize the nearterm need for all forms of supplemental gas supplies, and hydrogen can be considered, together with propane, liquid natural gas (LNG), and SNG from naphtha, as such near term sources. The other application is convenient and flexible hydrogen production by utilities for special industrial applycations or its use as an energy storage medium to meet peak demands in fuel cells or in super heat turbines at central stations. Nuclear or solar derived hydrogen is a storable and readily available energy form which can be used to give versatility and flexibility to the national energy system.

$-7-$ 


\section{POSSIBLE HYDROGEN APPLICATIONS AND CURRENT STATUS \\ OF RELEVANT TECHNOLOGIES}

The concept of using hydrogen as a synthetic fuel, derivable in the near term from coal and in the long term from nuclear or renewable energy resources, is attractive for the following reasons:

- Hydrogen is essentially clean buming; its main combustion product is water.

- Hydrogen may be substituted in almost all applications where a reducing gas is required, such as in the metallurgical industry, with minor modifications to existing processes.

- Hydrogen can be produced from domestic resources, such as nuclear fission, fusion, geothermal; it can also be produced from renewable resources, such as solar, ocean thermal and wind energy, by the simple technique of water electrolysis.

- Hydrogen can be readily produced from coal, which will be an important fuel resource in the near term; thus, hydrogen production makes coal and nuclear energy compatible as energy sources for both gaseous or liquid fuels, and for electricity, which can feed a common energy supply system.

- Hydrogen produced from any primary energy resource could be delivered at a cost-per-unit heating value similar to electricity, and in some cases, perhops slightly cheaper.

- Hydrogen can be converted to a variety of other fuel forms such as methanol and comonia.

- Hydrogen production is an attractive use for intermittent primary energy sources such as solar or wind power which may be difficult to interface with a continuous energy demand.

- Hydrogen can be used for transportation applications (such as in land and air vehicles where the respective advantages of clean 
burning and high Btu content per unit weight are attractive features) where it can be substituted for hydrocarbon liquid fuels derived from oil.

Research and development of hydrogen technologies can be broken down into the following basic areas:

- Production

- Storage (including production of derivative synthetic fuels)

- Transmission and Distribution

- Electric Conversion (fuel cells and turbines)

- Transportation Fuel Applications

- Stationary fuel Applications (residential, commercial and industrial)

- Specialized Industrial Applications

- Materials Problems

- Systems Analysis

- Support Activities

A more detailed breakdown of all the possible program activities for each of the above major areas is given below. Research and development in all of these areas is not appropriate for the DOE organization and part of these RED activities are being carried out by the private sector.

A. Production

1. Water Electrolysis

2. Thermochemical Production

3. Biological Production (including from solid waste)

4. Photochemical Production

5. Production of Derivative Synthetic Fuels

a. Ammonia $\left(\mathrm{NH}_{3}\right)$ and derivative $\mathrm{N}_{2}-\mathrm{H}_{2}$ fuels

b. Methanol $\left(\mathrm{CH}_{3} \mathrm{OH}\right)$

6. Coal-Derived Hydrogen as an Interim Source

B. Storage

1. Metal Hydrides

2. Cryogenic Liquid

3. High Pressure Gas

4. Underground Bulk Storage 
C. Transmission and Distribution

1. Large Pipeline Systems

2. Transmission of the Cryogenic Liquid

3. Problems in Local Distribution

D. Electric Conversion

1. Electric Energy via Hydrogen Storage Systems

2. Fuel Cell Systems and High Temperature Turbines for Use in Electric Generation

E. Transportation Fuel Applications

1. Aircraft (liquid only)

a. High Performance Turbines

b. Airframe Development

2. Commercial Vehicles and Automobiles

a. Portable Storage Tanks for Automotive Systems

b. Advanced Propulsion Systems

F. Stationary Fuel Applications

1. Industrial Fuel

2. Reducing Gas

3. Coal Gasification and Liquefaction.

4. Refinery Operations

5. Residential or Commercial Fuel

G. Materials Problems

H. Systems Analysis Studies of Hydrogen's Role in the U.S. Energy Economy

I. Support Activities

1. Safety

2. Monitoring

3. Implementation

4. Legal and Institutional Problems

It is beyond the scope of this study to give a comprehensive summary of all the relevant technologies. This study was intentionally limited to production and utilization technologies that could be commercialized through moderate level RDED programs before the year 2000 , and more specifically, 
during the next 15 years. This scope rules out a detailed analysis of the thermochemical, biological, and photochemical hydrogen production methods which are all at a laboratory development stage. Likewise, large hydrogen pipeline systems and large-scale residential/commercial heating applications are expected to only marginally impact the national energy system before the year 2000. A comprehensive discussion of the long range hydrogen energy system concept has been carried out in a number of previous studies which are cited in the References and Bibliography.

A short summary describing the current status of the relevant technologies is given below.

\section{Production}

1) Water Electrólysis - This is a commercial art practiced on a small scale in the process industry. Commercial plants can be purchased and exist in sizes up to 100 megawatts. Costs are in the vicinity of $\$ 320 / \mathrm{kW}$ of output using current Lurgi technology and could be reduced by a factor of two with research and development. Efficiencies presently achieved are about $65 \%$ and in some cases efficiencies as high as $80 \%$ are now claimed. In principle, these can be in the vicinity of $90 \%$ to $95 \%$. The annual demand for electrolytic hydrogen is about $1 \%$ of the industrial hydrogen demand and amounts to $0.3 \times 10^{12} \mathrm{Btu} / \mathrm{yr}$.

2) Thermochemical Production - Laboratory and analytic engineering studies are in progress to demonstrate feasibility. However, commercial applications are not expected before the year 2000.

3) Biological Production - Limited laboratory studies are in progress.

4) Photochemical Production - Limited laboratory studies are in progress.

5) Production of $\mathrm{NH}_{3}$ and $\mathrm{CH}_{3} \mathrm{OH}$ - Industrial processes which make use of atmospheric $\mathrm{N}_{2}$, or supplies of $\mathrm{CO}$ or $\mathrm{CO}_{2}$ to produce these fuels respectively, presently exist. The hydrogen source for these applications is mostly steam reforming of natural gas and partial oxidation of residual oil.

6) Coal-Derived Hydrogen - Coal gasification and liquefaction processes presently under development involve hydrogen production as a first step. Hydrogen and $C O$ mixtures were produced from coal 150 years ago, and distributed in the U.S. cities as town gas; some such systems exist in the world 
today. DOE has recently shown interest in the design of a coal-derived hydrogen plant, which will be integrated with a synthetic fuels production complex.

Storage

1) Metal Hydrides - High storage densities of hydrogen can be achieved (as great or greater than liquid hydrogen). Development of this storage technique is under development in DOE laboratories.

2) Cryogenic Liquid - This highly advanced technology was originally developed for space and high energy physics studies. Application is limited by safety considerations and costs.

3) High Pressure Gas - This is a costly form of hydrogen storage, but a readily available technology.

4) Underground Bulk Hydrogen Storage - This technique is commonly used by the natural gas industry. It is not presently used for hydrogen, but it is believed that selected geological formations can be engineered for hydrogen storage.

Transmission and Distribution

This is an available technology. A few industrial hydrogen pipelines exist in the world today, e.g., in the Galveston Bay area of Texas and the Ruhr Valley in Germany. Some materials problems may exist under special conditions. The cost of long distance hydrogen transmission is estimated to be approximately three times the cost of natural gas transmission which averages 3 cents $/ 10^{6}$ Btu per 100 miles.

Electric Conversion

Fuel cells which could achieve efficiencies of up to $60 \%$ are under development by United Technologies Corporation in cooperative programs with electric utilities, EPRI, and DOE. A $40 \mathrm{MW}$ demonstration plant is scheduled to operate within a utility environment by 1982. This plant will be fueled by distillate oil which will be reformed to hydrogen. The basic fuel for these systems is hydrogen which is expected to be produced from fossil fuels in the fuel cell system.

Existing gas turbine systems can be readily adapted to accommodate hydrogen. General Electric Corporation claims that using hydrogen, turbine efficiencies above $60 \%$ could ultimately be achieved. 
Transportation Applications of Hydrogen

Internal combustion engines can and have been easily converted to burn hydrogen. The process is slightly more complex than conversion to natural gas. The main obstacle to implementation in ground transportation systems is the problem of storing sufficient hydrogen in the vehicle to provide a minimum range of about 300 miles. A small hydrogen-fueled prototype bus with a 100 mile range has been produced by Mercedes Benz in Europe; it uses metal hydride storage. Similar projects have been developed by Billings Energy Corporation in Provo, Utah.

It is envisioned that liquid hydrogen can readily serve as fuel for aircraft applications. The high heating value per unit weight of hydrogen can increase the range of existing aircraft by $30 \%$. Advances in the performance of turbine systems burning hydrogen can make additional improvements in range. NASA has operated a large B-52 bomber in the air with one engine fueled by liquid hydrogen. This is one of the most likely large-scale applications of liquid hydrogen in the commercial sector, but it is controversial, due to safety and economic considerations.

\section{Stationary Fuel Applications}

The industrial uses of hydrogen are well known, and in combustion applications hydrogen can be substituted for natural gas with minor burner modifications. Hydrogen can be added to natural gas up to levels of $8-10 \%$ without any modification of the end-use combustion device. A near-term application of electrolytic hydrogen as a natural gas supplement is now being evaluated by a group of industry, utilities, and DOE representatives.

Hydrogen can be substituted in almost all metallurgical applications where a reducing agent ( $\mathrm{CO}$ or coal) is required, including the reduction of iron ore.

Materials Problems

Hydrogen has been shown to cause embrittlement of some metals used for containers, but the exact magnitude of the problem is yet to be defined. A great deal of industrial experience with hydrogen in connection with oil refinery operations exists, and the problem has relevance to the present interest in the development of coal gasification and liquefaction processes. 
There has been an ongoing weapons-related program on materials for hydrogen containment systems and much of this experience can be related to broader hydrogen energy uses.

Systems Analysis

A number of studies have been conducted under sponsorship by AEC, ERDA, NASA, EPRI, SRI, IGT, universities and various gas and electric utilities; these are included in the 1 ist of References.

The major conclusion of this review of relevant hydrogen technologies is that a DOE Hydrogen RDED Program should stress the development of new, improved production processes. The emphasis on hydrogen production stems from the need to supply the projected future demands for industrial hydrogen and from the desirability of releasing the current natural gas and oil hydrogen feedstocks to other end-use applications within the national energy system. Additional RDED programs in the areas of hydrogen storage, materials, and end-use devices are required to support and complement the hydrogen production research. Long range hydrogen supply processes should be evaluated separately in the context of DOE's overall long range RED programs.

The present United States consumption of industrial hydrogen is at a level of $0.8 \times 10^{15} \mathrm{Btu} /$ year $(0.8 \mathrm{Quad})$ or $2.58 \times 10^{12} \mathrm{sCF} /$ year. Industrial hydrogen demand is expected to grow to levels of 1.4 Quads/year and 2.7 Quads/ year or $4.3 \mathrm{TCF} /$ year and 8.3 TCF/year, by the years 1985 and 2000 , respectively. The current demand for hydrogen in the petrochemical industry is $1.4 \mathrm{TCF} /$ year and is expected to grow to $1.5 \mathrm{TCF} /$ year by 1985 , and remain at this level until the end of this century. Ammonia and methanol production now require 0.34 Quad per year and 0.12 Quad per year, respectively. Hydrogen requirements for ammonia production are projected to reach $1.7 \mathrm{TCF} /$ year and $2.8 \mathrm{TCF} /$ year in 1985 and 2000. Hydrogen requirements for the production of methanol and other chemicals could reach $0.68 \mathrm{TCF} /$ year and $1.9 \mathrm{TCF} /$ year in the same representative years. The ammonia industry is expected to be the largest single market for industrial hydrogen by the end of this century. Both the ammonia and the total demands for industrial hydrogen are expected to triple, compared with current production, in the next 25 years. 
The current, most economical hydrogen manufacturing processes are steam reforming of natural gas and partial oxidation of light and heavy petroleum fractions. Industrial hydrogen costs in 1975 varied between $\$ 1-4 / 10^{6} \mathrm{Btu}$, depending on the availability and price of natural gas or residual oil and on the hydrogen purity desired. Resid partial oxidation processes are about 20 percent more expensive than natural gas reforming, due to the larger plant investment required. The expected hydrogen production costs by 1985 (1975 dollars) are in the range of $\$ 4-5 / 10^{6} \mathrm{Btu}$ for natural gas reforming and $\$ 5-6 / 10^{6}$ Btu for resid partial oxidation. This is based on the current DOE projections of fossil fuel prices. The same DOE forecasts project a continuing decline in the U.S. gas and petroleum supplies, i.e., $-2.8 \% /$ year and $-1.5 \% /$ year, respectively, during the period 1990-2000.

Coal-derived hydrogen could become a major source of industrial hydrogen beyond the year 1980. Using the current Koppers Totzek gasification process, coal derived hydrogen costs will be about equal to the cost of resid partial oxidation by 1985. Advanced Koppers Totzek pressurized gasification process could lower the cost of coal-derived hydrogen to the level of natural gas reforming costs, i.e., $\$ 4-5 / 10^{6}$ Btu.

The utilization of off-peak electric power to produce industrial hydrogen is the likeliest route for water electrolysis technology. Unused base load electricity can power electrolyzers to average load factors of 0.3-0.45. Some hydrogen storage is then required to provide a continuous supply. Electrolyzer operation at higher load factors will result in higher on-peak electricity costs. Current Lurgi electrolys is technology is expected to provide hydrogen in a cost range of $\$ 9-12 / 10^{6}$ Btu. Advanced electrolysis technology with $7 \mathrm{mills} / \mathrm{kWh}$ off-peak power is projected to supply hydrogen at $\$ 6 / 10^{6}$ Btu. Hydrogen production with spinning reserve electric power is potentially the most economic water electrolysis method. This concept assumes off-peak electricity rates, utilized at very high load factors. Hydrogen production costs of $\$ 4 / 10^{6}$ Btu can be projected for this concept. 
A cost benefit study for the projected improvements in industrial hydrogen production has been conducted as part of this study. For the purpose of this study, it was assumed that improved coal gasification and water electrolysis processes will be developed during the period 1977-1985. These technologies will penetrate the industrial hydrogen market and eventually supply the entire industrial demand during the period 2000-2010. A split of $99 \%$ coal-derived and $1 \%$ electrolytic hydrogen was maintained. In the case of coal-derived hydrogen, the capital cost of a $100 \times 10^{6} \mathrm{sCF} /$ day Koppers Totzek gasification plant could be reduced from $\$ 160$ to $\$ 130 \mathrm{million}$ dollars. Gasification efficiency was assumed to improve from $59.6 \%$ to $64.2 \%$. The results of the RDED effort carried out in 1977-1985 are both a cheaper cost of coal-derived hydrogen and reduced coal mining requirements. In the case of electrolytic hydrogen, it was assumed that RDED would result in reduced electrolyzer capital costs (from $\$ 320 / \mathrm{kW}$ to $\$ 150 / \mathrm{kW}$ ) and in improved electrolysis efficiency of $90 \%$, compared with the current level of $75 \%$. The benefits of installing advanced vs. current technologies for the production of future industrial hydrogen were accumulated and discounted at a factor of $10 \%$. The cumulative discounted benefits attributed to the successful completion of the RDED programs in coal gasification and water electrolysis amount to $\$ 2.8 \times 10^{9}$ and $\$ 0.27 \times 10^{9}$, respectively.

These benefits could be utilized within the framework of a standard cost benefit methodology to estimate the appropriate funding levels for these two hydrogen production RDED programs. 


\section{A. Historical Background}

The first significant commercial use of hydrogen occurred in London, England, about 1800. It involved the use of manufactured coal gas consisting primarily of hydrogen and carbon monoxide for illumination. By 1900, the demand for manufactured gas in the U.S. reached 100 billion cubic feet. The principal process for manufactured gas production utilized the catalytic water-gas reaction between steam and red-hot coke to produce the gaseous fuel.

During the 1930 's, newly discovered natural gas sources penetrated the market for manufactured gas. Complete substitution for manufactured gas by cheap and plentiful natural gas occurred during the 1940's, aided by the extensive gas pipeline network laid over the same period. New hydrogen production processes, based on catalytic steam reforming of natural gas feedstocks, were developed. The ascendancy of natural gas as a primary energy resource has shifted the demand for hydrogen to the industrial-chemical markets where it is utilized as a unique chemical feedstock. Hydrogen is also produced by partial oxidation of heavy petroleum feedstocks and utilized in various refinery operations. Specific low level demands for high purity (99\%) hydrogen are met by water electrolysis.

B. Current and Future Demand

The current industrial uses of hydrogen are in petroleum refining and manufacture of ammonia, methanol, and other chemicals. These uses require hydrogen purity of $98 \%+$, which can be provided by the existing production processes, based on steam reforming of methane and partial oxidation of heavy oils. Ultra-high purity hydrogen $99.9 \%+$ is required for vegetable oil hydrogenation, semiconductor manufacturing, and iron ore reduction. Most of the large-scale industrial demands involve hydrogen production of the final product, the hydrogen being a "captive" intermediate of the production process. Only $5 \%$ of the current hydrogen demand, produced in part by water electrolysis, is sold commercially and referred to as "merchant hydrogen." Hydrogen demand projections have recently been reported in (1) and (2). 
The key to hydrogen usage projections through 2000 is the expansion of the petrochemicals industry and the domestic refining of crude petroleum. These industrial activities comprise most of the current volume of hydrogen usage, which is applied in welding, cooling, iron reduction, process heat, and as rocket fuel. The Brookhaven projections for growth in current hydrogen demand have been linked to a growth scenario; the one chosen here is a growth in energy consumption consistent with the new ERDA National Energy Forecast, specifically, the base case, Forecast 2 , (3).

The historic base is 1973, and the supply-demand data for that year is reported in Table 1 , based on $(2,4,5)$. BNL projections of future industrial hydrogen demand are summarized in Table 2, and other demand projections are reported in Table 3. Table 3 is included here to demonstrate the range of hydrogen demand projections that relate to current industrial end uses. The uncertainties in projecting future hydrogen demands for new applications will certainly be larger. A discussion of the projections of the various hydrogen demand categories follows.

Refinery Operations

Hydrogen is used to treat and upgrade crude oils by hydrotreating and hydrocracking processes. Hydrotreating is employed to desulfurize feedstocks, to hydrogenate olefins, and to treat lube oils and kerosene type jet fuels. The hydrocracking process is employed to upgrade the heavier, higher boiling hydrocarbons into more valuable, lighter fractions. A larger amount of hydrogen than is required for hydrotreating is consumed in this process. Hydrogen requirements average $250 \mathrm{SCF}\left(\mathrm{H}_{2}\right)$ /barrel oil for hydrotreating and $2500 \mathrm{SCF}$ $\left(\mathrm{H}_{2}\right)$ /barrel for hydrocracking. A good description of these processes is available in (6) and (2).

The projections of hydrogen demand in petroleum refining assume that 250 SCF of hydrogen are required per barrel of crude into a refinery, see (2). It is also assumed that all the domestic crude and $50 \%$ of the imports are refined in the U.S. In 1972, $47 \%$ of the imported barrels of petroleum were refined domestically (7). The 1973 hydrogen requirements for refinery operations were computed from the domestic and imported crude oil supply figures reported by FEA (8). Hydrogen demand projections for 1985 and 2000 are based on recent 
Table 1

HYDROGEN

CURRENT SOURCES - 1973

\begin{tabular}{|c|c|c|c|c|c|c|}
\hline Feedstock & $\begin{array}{c}\text { Natural } \\
\text { Gas }\end{array}$ & $\begin{array}{l}\text { Petroleum } \\
\text { Hydrocarbons }\end{array}$ & Coal-Coke & Water & Brine & Total \\
\hline $\begin{array}{l}\text { Production } \\
\text { Process }\end{array}$ & Steam Reform & $\begin{array}{l}\text { Petroleum } \\
\text { Refinery, Chemical } \\
\text { Plant Off-Gases }\end{array}$ & $\begin{array}{l}\text { Water-Gas } \\
\text { Reactions }\end{array}$ & $\begin{array}{c}\text { Water } \\
\text { Electrolysis }\end{array}$ & $\begin{array}{l}\text { Caustic/ } \\
\text { Chlorine } \\
\text { Electrolysis } \\
\text { By-Product }\end{array}$ & \\
\hline $\begin{array}{l}\text { Quantity } \\
\times 10^{15} \\
\text { Btu }\end{array}$ & 0.42 & 0.39 & .029 & .0003 & .0007 & 0.84 \\
\hline
\end{tabular}

HYDROGEN

CURRENT USES - 1973

\begin{tabular}{|c|c|c|c|c|c|c|}
\hline Use & $\begin{array}{c}\text { Ammonia } \\
\text { Production } \\
(3 / 4 \text { Fertilizer })\end{array}$ & $\begin{array}{c}\text { Petroleum } \\
\text { Refining } \\
\text { (Crack/Treat) }\end{array}$ & $\begin{array}{l}\text { Methanol } \\
\text { Production }\end{array}$ & $\begin{array}{l}\text { Hydrogenation } \\
0 \text { ils/Fats } \\
\text { Ore Reduction }\end{array}$ & $\begin{array}{c}\text { Miscellaneous } \\
\text { Welding, Cooling } \\
\text { Research } \\
\text { Rockets }\end{array}$ & Total \\
\hline $\begin{array}{l}\text { Quantity } \\
\times 10^{15} \\
\text { Btu }\end{array}$ & 0.34 & 0.34 & 0.12 & 0.01 & 0.03 & 0.84 \\
\hline
\end{tabular}


Table 2

PROJECTIONS OF FUTURE DEMAND FOR INDUSTRIAL HYDROGEN

$10^{15} \mathrm{Btu}$

\begin{tabular}{|c|c|c|c|}
\hline & 1973 & 1985 & 2000 \\
\hline 1. Refinery Operations & 0.34 & 0.51 & 0.50 \\
\hline 2. Ammonia Production & 0.34 & 0.54 & 0.92 \\
\hline 3. Methanol and Other Chemicals & 0.12 & 0.22 & 0.61 \\
\hline 4. Hydrogenation of $0 i l s$ & 0.005 & 0.01 & 0.03 \\
\hline 5. Ore Reduction & 0.006 & 0.02 & 0.03 \\
\hline 6. Other Uses & 0.03 & 0.07 & 0.19 \\
\hline Sub-Total Current End Uses & 0.84 & 1.37 & 2.28 \\
\hline 1. Space Shuttle & - & 0.0013 & 0.0013 \\
\hline 2. 0 il Shale Liquefaction & - & 0.037 & 0.16 \\
\hline 3. Coal Liquefaction & - & 0.023 & 0.23 \\
\hline $\begin{array}{l}\text { Sub-Total Current and Implied } \\
\text { Uses }\end{array}$ & 0.84 & 1.43 & 2.67 \\
\hline 1. Coal Gasification & - & 0.11 & 1.63 \\
\hline TOTAL & 0.84 & 1.54 & 4.30 \\
\hline
\end{tabular}


Table 3

LITERATURE SURVEY OF FUTURE INDUSTRIAL HYDROGEN DEMAND PROJECTIONS

$$
\underline{10^{15}} \text { BtU }
$$

\begin{tabular}{|c|c|c|c|c|c|c|c|c|c|}
\hline & \multirow{3}{*}{$\begin{array}{l}\text { YEAR } \\
\text { ORGAN IZATTION } \\
\text { REFERENCE } \\
\end{array}$} & \multicolumn{4}{|c|}{1985} & \multicolumn{4}{|c|}{2000} \\
\hline & & $J P L$ & IGT & EXXN & BOM & $J P L$ & IGT & EXXON & BOM \\
\hline & & $(1)$ & (3) & $(4)$ & (5) & $(1)$ & $(20)$ & (4) & (5) \\
\hline & 1. Refinery Operations & 0.66 & 0.25 & 0.28 & 0.47 & 0.78 & 0.45 & $0.58-1.65$ & 0.65 \\
\hline & 2. Ammonia Production & 0.73 & 0.46 & 0.54 & 10.65 & 1.73 & 1.20 & 0.90 & 1.03 \\
\hline & 3. Methanol and Other Chemicals & 0.22 & 0.10 & 0.29 & & 0.61 & 0.36 & 0.60 & \\
\hline & 4. Hydrogenation of $0 \mathrm{ils}$ & 0.01 & 0.007 & 0.01 & & 0.03 & & 0.03 & \\
\hline \multirow[t]{7}{*}{1} & 6. Other Uses & $\underline{0.15}$ & 0.04 & & $\underline{0.05}$ & $\underline{0.40}$ & $\underline{0.34}$ & & $\underline{0.12}$ \\
\hline & Sub-Total Current End Uses & 1.83 & 0.92 & 1.12 & 1.18 & 3.77 & 3.00 & $2.09-3.18$ & 1.83 \\
\hline & 1. Space Shuttle & 0.0013 & 0.0013 & & & 0.0013 & & & \\
\hline & 2. Oil Shale Liquefaction & 0.025 & 0.04 & & 0.036 & 0.10 & 0.41 & & 0.24 \\
\hline & Sub-Total Current and Implied Uses & 1.86 & 1.10 & 1.12 & 1.22 & 4.97 & 6.27 & $2.09-3.18$ & 2.42 \\
\hline & 1. Coal Gasification & & 0.48 & & 0.18 & $\underline{0.51}$ & 3.74 & & 2.28 \\
\hline & TOTAL & 1.86 & 1.58 & 1.12 & 1.40 & 5.48 & 10.01 & $2.09-3.18$ & 4.70 \\
\hline
\end{tabular}

(1) The range of values depends on whether residuum processing is done by coking or by hydrotreating. 
ERDA projections, (3) Scenario 2. In addition to domestic and half the imported oil supply, the projected supply of synthetic crude from shale oil and coal liquefaction were also included in the computation of refinery requirements for hydrogen. Should these synthetic liquid fuel supplies not materialize in the future, as reported in the ERDA Case 2 projections, then an equivalent amount of crude oil will have to be imported to meet the national energy requirements.

In terms of hydrogen demand, the synthetic liquid fuel industries require hydrogen; first, to produce the synthetic crude and then to upgrade it in the refinery to useful end-products. The inclusion of synthetic crude inputs in the computation of the hydrogen requirements for refinery operations implies further hydrogen demands for crude production; these are included in Table 2. It is interesting to note that hydrogen refinery requirements, including requirements to upgrade synthetic fuels, actually decline slightly between 1985 and the year 2000. This is due to the declining oil demand projected in Case 2 , which reflects moderate energy conservation efforts, the implementation of the new car mileage efficiency regulations, and moderate penetration of new energy technologies. The small reduction in refinery hydrogen requirements, $-0.16 \% /$ year, is in contrast to the demand growth rates reported in Table 3 .

\section{Ammonia Production}

Ammonia production requires between 70,000 and 80,000 SCF $\left(\mathrm{H}_{2}\right)$ per short ton of synthetic anhydrous ammonia. Three-fourths of the ammonia produced is used to make fertilizers; other uses include explosives, plastics, synthetic fibers, animal feed, pulp and paper, etc. It is assumed that ammonia production grows at the same rate as the petrochemicals sector, or $3.6 \%$ per year according to (3). The last nine-year growth rate of nitrogenous fertilizer was $9.3 \%$, but has dropped to $5 \%$ in the last five years. Two factors contribute to this decline, and the trend does not appear to reverse; first, cutbacks in foreign aid programs and second, the manufacture of ammonia abroad in OPEC countries where there are ample natural gas resources and no demand for them as fuel. Ammonia is also a by-product of coal gasification. Net hydrogen requirements for ammonia production should then be reduced by 
the amount of by-product ammonia available from coal gasification plants. However, it can be shown that the amount of captive hydrogen in coal-derived ammonia is less than $3 \%$ and $5 \%$ of the total hydrogen requirements for ammonia production in the years 1985 and 2000, respectively.

Methanol and Other Chemicals

Synthetic methanol production requires about $72,000 \operatorname{SCF}\left(\mathrm{H}_{2}\right)$ per short ton/methanol. Methanol is used mostly for the production of formaldehyde which, in turn, is important in the manufacture of several resins. Methanol is also used in the production of isoprene rubber, methyl bromide, acetic acid, and various esters. Additional refinery-produced chemicals that require hydrogen are cyclohexane, used in the production of nylons, aniline, naphthalene, hexamethylene diamine, oxo alcohols, and others. This industrial category is assumed to grow at the historical rate for chemicals of twice the GNP growth, (3), i.e., $7 \%$ per year.

Hydrogenation of Fats and 0 ils

High purity hydrogen is an essential component in the hardening of vegetable and fish oils used in the production of margarine, lard, shortening, and cooking oils. Only a few cubic feet of hydrogen are consumed per pound of product. Hydrogen demand is expected to grow at $7 \%$ per year (3). Ore Production

Metallurgical demands for hydrogen include direct reduction of ores, heat treatments, welding, and production of pure metals. The major demand is assumed to be the direct reduction of iron oxide ores to sponge iron. This process uses about $20,000 \mathrm{SCF}\left(\mathrm{H}_{2}\right)$ per short ton of iron produced. 0ther metals reduced by hydrogen include tungsten, molybdenum, and magnesium. Hydrogen is also used in the production of sintered metal parts, annealing and furnace brazing, high temperature plasma arc welding, and oxygen-hydrogen metal cutting. The overall growth rate of these hydrogen demands is estimated at $2.7 \%$ /year.

\section{Other Uses}

Additional small-scale demands for high purity hydrogen include cooling of large generators, motors, and frequency changers in electric utility systems. Hydrogen is used as a reducing atmosphere for brazing metals and silicon 
compounds utilized in solid state components, vacuum tubes, and lighting devices. Additional hydrogen uses include: glass manufacture via the floatgas process, oxygen-hydrogen glass cutting, artificial stone production, refrigeration, pharmaceuticals, and nuclear physics research using liquid hydrogen bubble chambers. These are hydrogen demands that typically have not yet reached saturation. They grow at a rate of $7 \%$ per year, faster than the GNP growth.

Space Shuttle

The future hydrogen requirements for the space shuttle program were obtained from NASA JPL projections, (1), Table $111-2$. Liquid hydrogen demand is estimated at $12 \mathrm{million} \mathrm{Kg} /$ year after 1985 , based on $60 \mathrm{flights}$ per year. NASA was interested in the construction of a coal gasification demonstration plant to help provide fuel for the space shuttle program. This plant would have converted 200 tons of coal per day into 30 tons of hydrogen per day (11 million SCF $\left.\left(\mathrm{H}_{2}\right)\right)$. This project did not materialize and NASA has signed a long range contract for hydrogen delivery, based on natural gas reforming.

0il Shale, Coal Liquefaction, and Coal Gasification

Hydrogen demands for oil shale and coal liquefaction are estimated at 1000 SCF $\left(\mathrm{H}_{2}\right)$ and 4000 SCF $\left(\mathrm{H}_{2}\right)$ per barrel of crude oil produced in each of these two processes, respectively. 1500 SCF $\left(\mathrm{H}_{2}\right)$ are required to produce 1000 SCF of $970 \mathrm{Btu} / \mathrm{SCF}$ syngas (2). These hydrogen markets are "captive," i.e., the hydrogen is produced and consumed within the confines of the synthetic fuel plants. The overall hydrogen requirements for synthetic fuels manufacture depend on the commercialization level of this industry. The current projections are based on the recent ERDA Case 2 estimates, (3). Future adjustments of the expected national fuels mix will greatly impact this category of industrial hydrogen demand. These hydrogen requirements will form large fractions of the future overall industrial hydrogen demand, even though the synthetic fuels will supply a relatively smaller fraction of the future liquid and gaseous fuels supply. The expected growth of the synthetic fuels industry between 1985 and the year 2000 will result in high growth 
rates of the hydrogen demands for oil shale and coal liquefaction, $10.4 \%$ per year and $16.6 \%$ per year, respectively. The demand for hydrogen in coal gasification is expected to increase at an even higher rate of $19.8 \%$ per year.

The overall growth rate of the current and the implied industrial hydrogen demands is estimated here at $4.25 \%$ /year. This is slightly higher than the $3.9 \%$ year growth rate estimated by the Exxon Company $(6)$. When the demand for hydrogen by the coal gasification industry is included in the computations, the BNL projections correspond to an annual growth rate of $7.1 \%$ /year, compared with the $6.6 \%$ year rate estimated by the Bureau of Mines (2).

\section{Resource Implications of Industrial Hydrogen Demand}

The future growth of the industrial hydrogen demand within the national energy system may require large-scale fuel consumption for hydrogen production. An assessment of the resource requirements for the projected hydrogen demand has been attempted here. Partial oxidation of fuel oil and steam reforming of natural gas, which are the current major production technologies account for $99 \%$ of the hydrogen supply according to Table 1 . The demand for electrolytic hydrogen may grow to $2 \%$ of the industrial hydrogen market by the year 2000, assuming no new applications, according to Table 2 . The resource requirements for supplying the industrial hydrogen demand projections of Table 2 during the years 1985 and 2000, are computed in this section. As a base case analysis, it is assumed that the production technologies mix until the year 2000, will remain essentially the same as in 1973. This computation does not take into consideration the possibility of substitution of hydrogen manufacturing technologies due to the changes in relative process economics and feedstock availability.

Based on the production mix distribution in Table 1 , it is assumed that the $1.37 \times 10^{15}$ Btu of industrial hydrogen demand by 1985 will be supplied $50 \%$ by steam reforming of natural gas, $49 \%$ by resid partial oxidation and $1 \%$ by water electrolysis. An additional amount of $0.17 \times 10^{15} \mathrm{Btu}$ will be produced by advanced coal gasification for captive use within the synthetic fuels industry. The fractional distribution of hydrogen production by process 
technology in the year $2000\left(2.28 \times 10^{15} \mathrm{Btu}\right)$ is $50 \%$ from steam reforming, $48 \%$ from partial oxidation and $2 \%$ from electrolysis. An additional $2.02 \times$

$10^{15}$ Btu of captive hydrogen will be produced by coal gasification. The amount of hydrogen produced by each method in the years 1985 and 2000 , assuming continuation of current production trends, is shown in Table 4. Hydrogen Production Efficiencies as reported in Table A-1 (Appendix A) are:

$\begin{array}{ll}\text { Steam Reforming of Natural Gas } & 70.2 \% \\ \text { Partial 0xidation of Residual 0il } & 82.7 \% \\ \text { SPE Water Electrolysis } & 90.0 \% \\ \begin{array}{c}\text { Improved Koppers Totzek Coal } \\ \text { Gasification }\end{array} & 64.2 \%\end{array}$

Based on these conversion efficiencies, the resource requirements to produce industrial hydrogen, assuming the continued existence of the current production technologies mix in the future, are shown in Table 4. The fractional resource requirements for hydrogen production compared with overall demand within the national energy system are also shown. Total energy resource requirements are obtained from the ERDA Forecast 2 data, (3). The resource requirements and partial utilization figures are then modified to account for the use of coal, gas, and oil in electricity production. The correction is minimal for natural gas and crude oil, reflecting the displacement of these fuels out of the electric energy sector. The future large-scale penetration of coal into the electric sector results in relatively large fractions of coal dedicated to hydrogen production out of the total non-electric demand for coal. In general, continued reliance on natural gas and oil as the main energy resources for industrial hydrogen manufacture will require less than ten percent of the projected demands for these fuels even by the year 2000 .

The relatively small resource fraction still has a large monetary impact. At $\$ 2.41 / M$ Btu cost of natural gas to utilities (see (3) Appendix B - Fuel Prices), the dollar value of the 1.62 Quads of natural gas that could be required for industrial hydrogen production is $3.9 \times 10^{9}$ in 1975 dollars. The cost of oil required for hydrogen production by partial oxidation will reach $\$ 4.2 \times 10^{9}$ assuming a unit oil price of $\$ 3.15 / \mathrm{M}$ Btu by the year 2000 . 
The total cost of the 3.15 Quads of coal. required for the synthetic fuels industry by the year 2000 is only 2.5 billion in 1975 dollars (at a unit price of $\$ 0.80 / M$ Btu to industry). This indicates the incentive of shifting to coal as a principal raw material for industrial hydrogen production by the year 2000 .

Table 4

ENERGY RESOURCE REQUIREMENTS FOR INDUSTRIAL HYDROGEN PRODUCTION IN 1985 AND 2000

(Hydrogen Demand Supplied by Current Mix of Production Technologies)

\begin{tabular}{|c|c|c|c|}
\hline & 1985 & 2000 & \\
\hline \multicolumn{4}{|l|}{ Hydrogen Production by Technology $\left(10^{15} \mathrm{Btu}\right)$} \\
\hline Natural Gas Reforming & 0.69 & 1.14 & \\
\hline Partial Oxidation & 0.67 & 1.11 & \\
\hline Water Electrolysis & 0.01 & 0.03 & \\
\hline \multicolumn{4}{|l|}{ Coal Derived Hydrogen: } \\
\hline oil Shale and Coal Liquefaction & 0.06 & 0.39 & \\
\hline Coal Gasification & 0.11 & 1.63 & \\
\hline \multicolumn{4}{|l|}{ Resource Requirements for Hydrogen Production } \\
\hline Natural Gas $\left(10^{15}\right.$ Btu $)$ & 0.99 & 1.62 & \\
\hline Crude 0 il $\left(10^{15}\right.$ Btu) & 0.81 & 1.34 & \\
\hline Electricity $\left(10^{9} \mathrm{kWh}\right)$ & 29.3 & 87.9 & \\
\hline Coal for Liquefaction ( $\left.10^{15} \mathrm{Btu}\right)$ & 0.09 & 0.61 & . \\
\hline Coal for Gasification ( $10^{15}$ Btu) & $\underline{0.17}$ & $\underline{2.54}$ & \\
\hline Total Coal Requi rements $\left(10^{15} \mathrm{Btu}\right)$ & 0.26 & 3.15 & \\
\hline \multicolumn{4}{|l|}{ Fraction of Total Resource Use (Percent) } \\
\hline Natural Gas & $4.03(4.61)$ & 7.92 & $(8.70)$ \\
\hline Crude $0 i^{(1)}$ & $2.05(2.21)$ & 3.58 & $(3.62)$ \\
\hline Electricity & 0.91 & 1.42 & \\
\hline Coal $(1)$ & $1.25(4.97)$ & 7.58 & $(14.96)$ \\
\hline
\end{tabular}

(1) Numbers in brackets refer to fractional resource requirements computed for total resource use outside of the electric energy sector 
The future market for hydrogen can be divided into two parts--historical markets and potential new markets. The expected future growth of historical hydrogen demand was discussed earlier. In most of the potential new market areas, hydrogen is only one of several possible energy forms (energy carriers) that can be employed. A key issue in assessing hydrogen's potential role in the national energy system is its ability to compete successfully with other energy carriers in a given application. The various methods which can be used to produce hydrogen and the associated costs are given in Appendix A. Table A-1 summarizes the basic cost data used in this study.

Beyond these more conventional markets, hydrogen can prospectively emerge as an energy carrier within the entire energy system. In the very long range an entire energy economy based on nuclear or other inexhaustible energy resources and hydrogen, can be conceived; e.g., (9) and (10). Before this ultimate or "exponential" energy system is achieved, it is important to investigate the likeliest routes for hydrogen penetration into the energy supply markets as an energy carrier. This can be done by conducting an economic comparison of hydrogen in the particular applications considered, with the likely or more conventional alternatives.

To aid in clarifying the relative economics of hydrogen use compared with alternatives, allowed or target costs have been identified for potential applications of hydrogen based on the estimated costs of other energy carriers that could be employed in those applications. The allowed costs represent an estimate of an upper bound on the cost of hydrogen, if hydrogen is considered a competitive energy carrier for use in a given application. The target cost is adjusted to account for the difference, if any, in the relative end-use efficiency of hydrogen compared with the alternative carrier. It does not include the effect of differences in the costs of end-use devices or differences in the costs associated with the conversion of pre-existing transmission/distribution networks, or the construction of new networks that may be necessitated by the introduction of a new energy carrier. 
The data base employed in the BNL Energy System Optimization Model,

and (12), was used to develop the target costs. Costs associated with the production, transport/transmission, and distribution of hydrogen, methane, methanol, low Btu gas, and gasoline synthesized from coal and for gasoline synthesized from shale oil, were summed to yield the costs of the energy carriers to final distributors. A listing of these costs is shown in Table 5. The allowed hydrogen costs were computed for various potential applications as a product of the cost of the alternative energy carrier times the relative energy efficiency of hydrogen in each application.

Relative efficiency advantages were assumed for hydrogen for use in fuel cells ( $20 \%$ improvement over methane), aircraft $(10 \%$ improvement over synthetic fuels), residential/commercial heating and hot water $(5-10 \%$ improvement over natural gas if non-vented catalytic burners are employed, recovering part of the latent heat of vaporization), and vehicular applications ( $10 \%$ compared to synthetic liquids assuming metal hydride storage of hydrogen). Electricity was assumed to be significantly more efficient than hydrogen in vehicular applications; relative hydrogen efficiencies of $25 \%$ to $60 \%$ compared with that obtained with electricity were employed, the range resulting from different power plant combinations.

The target costs are shown in Table 6 , in which current and potential future hydrogen applications are listed with future applications categorized by the earliest time period during which initial application can be expected. In general, an application listed under a later utilization period required a greater number of new technologies or more extensive alterations of the energy production/transmission/distribution/end use system. The use of hydrogen appeared to be less favorable compared with the alternatives, than for an application listed under an earlier period. The nature of the application (i.e., chemical or fuel), the approximate volumetric hydrogen requirement, alternative energy carriers or processes, and research and development needs, are indicated for each application. The cost of the alternative carrier, the relative energy efficiency advantage of hydrogen and the allowed costs (in the column headed "Required $\mathrm{H}_{2}$ Cost Less Than') are shown where applicable, beside the alternative carriers listed under each application. 
Table 5

SYNTHETIC FUEL COST COMPUTATIONS - COST TO FINAL DISTRIBUTOR $\left(\ln \$ / 10^{6} \mathrm{Btu}\right)$

\section{Production}

Refining Syn-Crude

to Gasoline

Transport or Transmission Coal $(400-1500 \mathrm{m.})$

Gas $(400-1500 \mathrm{~m}$.

Distribution

Industria

Residential \& Commercial

TOTAL

Industrial

Residential \& Commercial

$\left.\begin{array}{ccc}\begin{array}{c}\text { Hydrogen } \\ \text { (Coal) }\end{array} & \begin{array}{c}\text { Methane } \\ \text { (Coal) }\end{array} & \begin{array}{r}\text { Methano } \\ \text { (Coal) }\end{array} \\ \hline 2.55 & 3.05 & 4.40 \\ .23-.75 & .25-.75 \\ .30-.90 & .10-.30 \\ & & \\ .12 & .11 \\ 80 & .76\end{array}\right\}$

80

$2.90-3.50$

$3.60-4.20$

$3.25-3.70$

$3.85-4.30$
6.16

Low Btu G
$($ Coal $)$
2.35

$.20-.57$
.15
.97

.97

2.70-3.10

$3.50-3.90$

Notes:

1) Transport costs for hydrogen, methane, low Btu gas, show range in costs as function of distance.

Transport costs for coal adjusted to reflect $65 \%$ conversion efficiency to hydrogen, methane, and $87 \%$ to low Btu gas. Transport and distribution of methanol assumed to cost twice as much as gasoline due to $50 \%$ reduction in volumetric heating value from gasoline to methanol.

2) Distribution costs for hydrogen assumed to be $10 \%$ higher than for methane and $35 \%$ higher for low Btu gas (by extrapolation of methane-hydrogen cost-to-heating value relation).

3) 1985 Costs in 1975 dollars.

4) Recent estimates by the Federal Energy Administration ( 8 ), indicate that these costs may be too low by about $\$ 1.0 / 10^{6}$ Btu.

Source: 8NL Data Base, Reference (11) and (12). 
A comparison of the allowed hydrogen costs in Table 6, with the cost of hydrogen produced from coal as given in Table 5, indicates that the use of hydrogen offers a significant operating cost benefit only in the electric utility fuel cell application.

The applications of hydrogen in the electric and gas utilities sector are varied and depend upon the appropriate combination of production, storage and utilization technologies applied in each case. In the near term, the development of advanced electrolyzer technology makes the concept of natural gas supplementation feasible. In the intermediate term, 1985-2000, the additional development of fuel cell and storage technology will enhance the economics of hydrogen as an electric energy storage medium. In the long range, use of hydrogen as an intermediate fuel in the "electric-gas energy transformer" may permit a greater integration of the electric and gas utility sectors. Hydrogen may prove to be a route to seasonal energy storage in the utility systems. The range of possible applications indicates the main advantage in utilizing hydrogen--the flexibility of the operation in the production, storage and conversion uses within and between both the electric and gas sectors of utilities. A short discussion of near term hydrogen applications in these areas follows.

Natural Gas Supplementation

The main thrust of this concept is to generate electrolytic hydrogen, using the cheapest mode of operation as discussed above, and to use the product hydrogen for supplementation or peak shaving in the gas sectors. The hydrogen content should not exceed $15 \%$ of the natural gas volume. This concept has been investigated by an Ad Hoc Committee on Hydrogen as a Natural Gas Supplement, set up by representatives of electric and gas utilities, National Laboratories, ERDA, IGT and EPRI. The status of this activity has been reviewed in Reference (13) and the economics of this concept have been discussed extensively (14). The major advantages of this concept are:

- No large scale pure hydrogen, transmission, distribution and storage facilities would be required as long as the electrolyzers are dispersed in modules of about $5 \mathrm{MW}$ capacity along the natural gas grid (200-300 psig). 
Table 6

HYDROGEN APPLICATIONS - CURRENT AND POTENTIAL

Competitive Carrlers and Processes, Target Hydrogen Costs, RSD Requirements

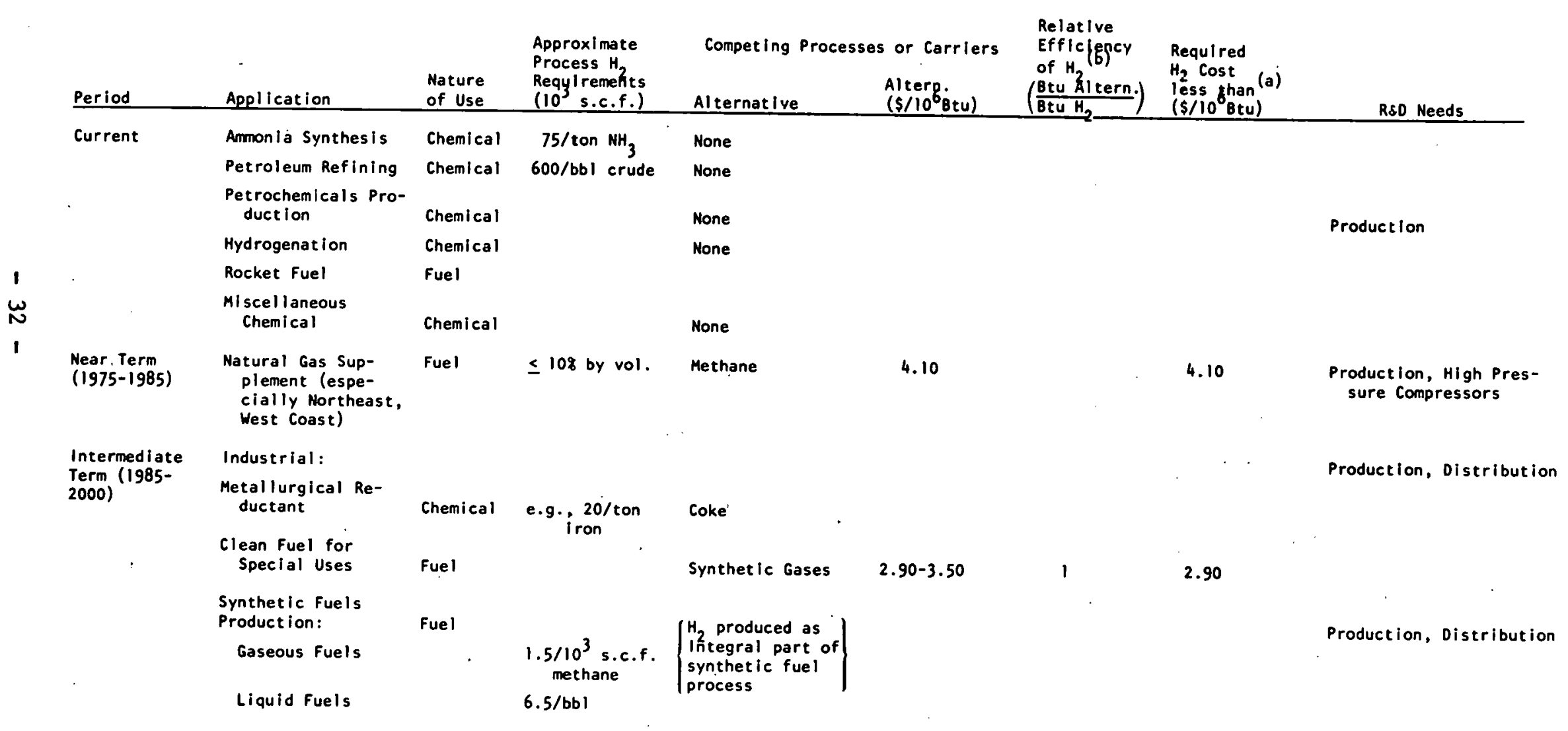


Table 6 (Cont'd.)

HYDROGEN APPLICATIONS - CURRENT AND POTENTIAL

Competitive Carrlers and Processes. Target Hydrogen Costs, RSD Requirements

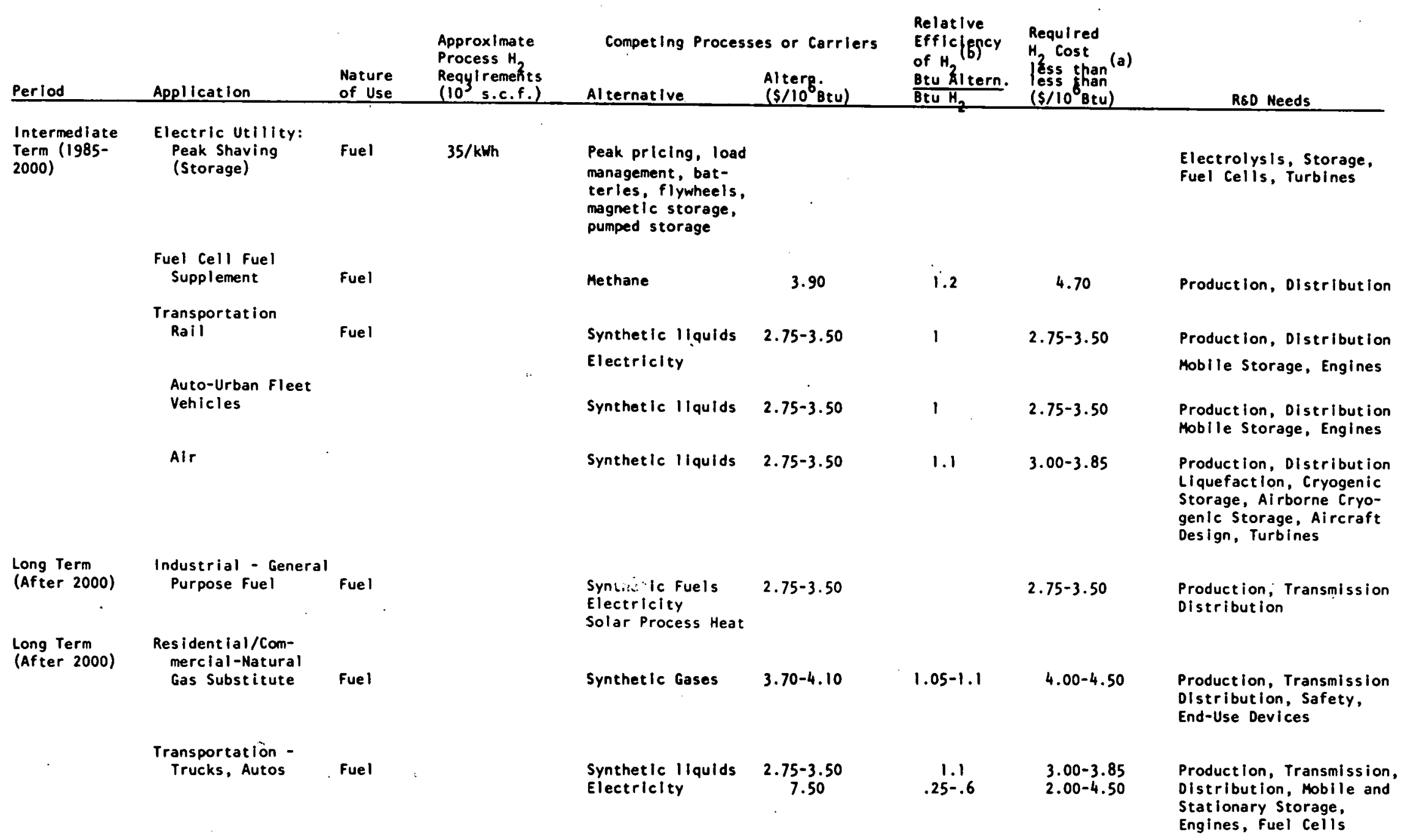

(a) Cost below which hydrogen becomes competitive (= (cost of alternative) $x$ (relative efficiency))

(b) Relative end-use device energy efficiency of hydrogen compared to alternative 
- The electrolyzers can be located at electric substations throughout the utility network. The existing electric transmission and subtransmission facilities and the gas grid would be better utilized, inereasing the Btu's delivered along an existing system right-of-way.

- A modest alleviation of the natural gas curtailment problem may accrue in areas where this concept is implemented. The improvement in the gas supply situation is, however, limited by the availability of electrical energy to power the electrolyzers.

- This would promote better use of existing base load plants during periods of low electric demand (off-peak power). The higher load factors achieved may eventually make it possible to increase the base load portion of the installed electric capacity. This applies to all types of low incremental costs (fuel $O$ and $M$ ) base load plants only, i.e., nuclear, geothermal, solar or fusion, but does not apply to fossil-fueled power plants.

The costs for natural gas blending with electrolytic hydrogen, shown in Table A-1 or A-6 should be compared with costs for propane blending at $\$ 4.5-5 / 10^{6}$ Btu during peak gas demand periods. Electrolytic hydrogen would be competitive with synthetic coal gas products even for higher off-peak costs shown if system impacts are considered, such as:

- Reduction in electric transmission losses due to improved reactive control

- Reduced spinning reserve losses

- Reduced gas peak-shaving requirements (reduction in storage inventory)

These additional credits could reduce the cost of hydrogen production by another $\$ 0.5-1 / 10^{6} \mathrm{Btu}$, particularly for combined electric and gas utilities. This. would be based on minimizing overall costs for both the gas and the electric systems.

The commercialization of this concept will depend upon achieving the target production costs of electrolytic hydrogen, shown in Tables $A-1$ and A-4. However, implementation of this concept is a first step toward a more 
integral role of hydrogen as an energy storage medium in the operation of electric and gas utilities.

Hydrogen Energy Storage Concepts for Utility Applications

The concept of hydrogen as an electric energy storage medium has been discussed extensively; e.g., (9), (15), (16), and (17). The more advanced concepts of utilizing hydrogen to effect energy transfer between the gas and electric sectors of joint utilities were reviewed in (18) and (19). The entire field of electric energy storage has recently been reviewed, (20), (21), and the various energy storage technologies including hydrogen were compared on a uniform basis and ranked accordingly.

The general conclusions related to hydrogen energy storage systems are as follows.

- Hydrogen energy storage systems are most attractive for weeklycycle operation and, in fact, one of the only alternatives for seasonal energy storage. This is due to the separation of the storage and energy conversion functions. A recent concept developed at Brookhaven National Laboratory considers the closed cycle electrolysis and recombination of hydrochloric acid. This concept offers greater flexibility in terms of reduction in component requirement and greater decoupling between the storage and conversion functions (22).

- Hydrogen energy storage requires three separate equipment components for electrolysis, hydrogen storage, and reconversion to electricity. Several hydrogen-halide concepts now being considered (22) will require only two components, the electrolysis and conversion functions which are combined in the same module. several different combinations of electrolysis, storage, and conversion equipment will be come available in 2985. These modules can be co-located or dispersed throughout the electric and gas substation networks of joint public utilities (29) and (23). This decentralized location capability may entail some system credits that have not yet been extensively quantified, except by the work of $R$. Fermandes (29), (23), and (24). 
- The flexibility of the hydrogen energy storage concept is obtained at a price. The overall capital cost requirement for the three components of this system is larger than the capital cost of several competing technologies. The overall conversion efficiency (electric-to-electric) is quite low and ranges between $40 \%$ and $55 \%$, due to conversion losses in each module of the hydrogen system. Land requirements may be relatively large compared with other dispersed storage technologies when operation on the transmission substation is desired. The engineering requirements of combining the three components of the hydrogen system may make this concept cumbersome to install in real electric utility networks.

- The economic advantage of hydrogen electric energy storage systems is not unique, compared with other alternative intermediate load storage technologies. Based on detailed production cost computations (2l), hydropumped storage and thermal oil storage are more attractive than hydrogen systems, while hydrogen is slightly more attractive than compressed air storage and advanced batteries. Given that no clear cut economic advantage for hydrogen energy storage systems was obtained in a generic study such as (2l), Zocal situations which involve specific utility credits due to operational flexibility must be considered when choosing the optimal intermediate load storage technology to be installed in the utility system.

Hydrogen Use in the Transportation Sector

Hydrogen use as a chemical fuel for transportation has long been considered because of the r. iatively nonpolluting and environmentally beneficlal aspects of burning hydrogen. The energy crisis has focused attention on hydrogen applications in the transportation sector as one way to reduce the national requirements for crude and distilled oil products. Ground transportation applications of hydrogen have been reviewed extensively in (1), (25), (26), (27), (28), and also (29), (30) and (31). 
The principal drawbacks to the use of hydrogen in ground transportation include:

- Hydrogen's physical properties, especially the very low density in both liquid and gaseous states and the very low temperatures associated with liquid hydrogen, increase the requirements for hydrogen storage. Gaseous hydrogen storage in metal hydrides require a bulky and heavy module that must fit in standard size vehicles. Liquid hydrogen storage poses severe cryogenic probZems, results in an appreciable energy loss in liquefaction (33\% of initial hydrogen energy content), causes difficult volume reduction problems for the on-board vehicular storage systems, and may cause unacceptable safety hazards in accident situations. Pressure bottling of gaseous hydrogen results in relatively large volume occupied per unit energy stored and may also pose safety hazards on impact. The engineering design problems associated with fitting hydrogen storage into vehicular systems are difficult though not insurmountable. Several hydrogen vehicular demonstration projects are now being carried on (32).

- Widespread use of hydrogen as an automotive transportation fuel will be seriously inhibited by the lack of an adequate logistics system. The entire infrastmucture of hydrogen production, liquefaction, storage, and distribution steps must be re-created as long as alternative hydrocarbon fuels are available for the existing fuels distribution system. This can be achieved only at a large capital expenditure.

- When considering alternative synthetic fuels for transportation applications based on coal or oil shale feedstocks, no clear cut economic advantage for hydrogen can be identified. Coal or oil shale conversion to gasoline or diesel-like fuels is cheoper than conversion to hydrogen fuel. 
The operating cost advantage indicated in Table 6 for surface transportation applications of hydrogen compared with synthetic fuels is considerably diminished or reversed by the higher capital costs associated with metal hydride storage systems compared with the costs of conventional tank storage of liquid fuels. Electricity is likely to offer significant operating cost benefits compared with hydrogen in ground transportation systems unless highly efficient mobile hydrogen fuel cells are developed.

The only new large-scale production technology of hydrogen until the end of this century is based on coal conversion. However, it is more economical to convert coal to hydrocarbon-based fuels, both in terms of production costs and adaptability into the existing fuel logistics infrastructure. Should future large-scale production technology of hydrogen, based on thermochemical or electrolytic methods coupled to inexhaustible energy resources such as solar or advanced nuclear reactors materialize, then the economic viability of hydrogen as a transportation fuel vis-a-vis hydrocarbon-based fuels, will change. A recent energy balance and economic comparison of a hydrogen powered car vs. an electric car, internal combustion engine and hybrid systems, has been prepared by Exxon Research and Engineering Company, (33), and is shown in Tables 7 and 8 . The relative efficiency and cost disadvantages of hydrogen cars compared with other alternatives are clearly demonstrated.

Aircraft applications of hydrogen have also been extensively reviewed in (1), (25), (28), (34), and (35) and (40). Basic observations made regarding the use of hydrogen in ground transportation also apply for aircraft applications, though in a less severe fashion.

Assuming that coal is the energy raw material, the cost and efficiency supplying kerosene-like fuel from coal are similar to those of supplying liquid hydrogen. The volume and weight reduction problem per unit of energy delivered are less severe in aircraft compared with automotive applications. An overall reduction in gross take-off weight by a factor of $26 \%$ compared with conventional jet-fueled aircraft was estimated by Brewer, $(87)$. Conversion of the airline distribution system from jet fuel to hydrogen is easier compared with the ground transportation logistics system, due to the 
Table 7

ENERGY REQUIREMENTS FOR SUBCOMPACT PASSENGER VEHICLE OPERATION

\section{Vehicle Type}

Vehicle Weight, Ib

Energy Consumption at the Wheels, kWh/mile (I)

Energy Consumption at $A C$ Outlet or Service Station Pumps, kWh/mile (1)

Coal Required at the Mine, Assuming Coal as Primary Energy Source (LHV Basis):

$\mathrm{kWh} / \mathrm{mile}$

kBtu/mile

Equivalent Gasoline Consumption at the Service

Station Pump:

Gal./mile

Miles/gal.
Hydride Storage

Hydrogen Car

Battery Powered
Electric Car
Internal Combustion
Engine Car

Present

Engine

Tech.

2850

0.23

$1.40(2)$

4.5

15.0

0.071
2650

0.21

0.42

1. 3

3.0

10.5

1.7

6.0

0.050

20
Gas Turbine/Electric Hybrid Car

Present Expected

Engine Engine

Tech. Improve.

$2500 \quad 2500$

0.20

0.18

Note:

(1) Average estimaced consumption, based on the EPA urban driving cycle.

(2) $1.40 \mathrm{kWh}$ of electric energy are required to produce the $1.05 \mathrm{kWh}$ of hydrogen needed, on the average, to drive this vehicle for a mile according to the EPA driving cycle. 
Table 8

VEHICLE OPERATING COST COMPARISON

Vehicle Type

Vehicle Weight, Ib.

Operating Costs (3)

Hydrogen cost, e $5 c / \mathrm{kWh}$ of $\mathrm{H}_{2}$ (1)

Electric energy cost, e $3 \mathrm{c} / \mathrm{kWh}$

Gasoline/turbo fuel cost, e $1.20 \$ / g a l l o n$

Hydride/battery depreciation (20\%/year)

Total "Fuel" Related Costs

Vehicle depreciation, ex hydride/battery (10\%/year)

Repairs \& maintenance

allowance

Insurance (5\%/year on total purchase price)

Total Vehicle Operating Cost, c/mile
Hydride Storage Battery Powered Hydrogen Car

Electric Car

2850

2650

Internal Combustion

Engine Car

Present Expected

Engine Engine

Tech. Improve.
Gas Turbine/Electric Hybrid Car

Present Expected

Engine Engine

Tech. Improve.

Notes: (1) Approximately $4 \mathrm{k} / \mathrm{kWh}$ of the $5 \mathrm{c} / \mathrm{kWh}$ total cost of hydrogen represents the cost of electric energy for electrolysis, at an assumed off-peak rate of $3 \mathrm{k} / \mathrm{kWh}$. The remaining $1 \mathrm{c} / \mathrm{kWh}$ of hydrogen represents

(2) These operating costs are based on Fe/Ti hydride storage. Should the present RsD efforts on Mg hydrides be successful, the "fuel" related costs and the total operating cost could be reduced to $6 \mathrm{c} / \mathrm{mile}$ and lc/mile, respectively.

(3) Based on 10,000 miles/year average driving.

(4) If the cost of electric energy were increased from $3 \mathrm{~s} / \mathrm{kWh}$ to $5 \mathrm{c} / \mathrm{kWh}$, the operating costs for a hydrogen car. 
greatly reduced number of storage units involved. A recent IGT report for NASA Langley Research Center (28) and (40) indicated that coal-derived hydrogen may be economically justified for future aircraft larger than the Boeing 747. Improved hydrogen production technologies, based on renewable energy resources, may make hydrogen a preferred general aviation fuel beyond the end of this century. Hydrogen Use as a Fuel in the Residential, Commercial and Industrial Energy Markets

The eventual use of hydrogen as an energy carrier utilizing its heat content of $325 \mathrm{Btu} / \mathrm{SCF}$ or $52,400 \mathrm{Btu} / 1 \mathrm{~b}$ has been considered extensively by various proponents of advanced versions of the hydrogen economy concept. Most of these applications are based on two major premises: cheap hydrogen production technologies based on renewable energy resources will become available, and fossil energy raw materials will reach a state of near depletion which will result in high fuel prices and low availability. These two basic assumptions will not materialize before the end of this century. Future projections regarding the evolution of the U.S. energy system over the next the next 50 years border on pure speculation. Therefore, the discussion in this section is limited to two basic observations regarding the industrial use of by-product gases and large-scale production of hydrogen from coal.

The production and avallability of by-product gases from major U.S. industries in 1975-1976 is shown in Table 9, based on data supplied by H. G. Corneil of Exxon Research and Engineering Company (41). These byproduct gases which contain hydrogen are now utilized as industrial boiler fuel for in-plant low temperature process heat applications. This indicates that hydrogen is and can be utilized to supply industrial process heat. The essential starting point for utilizing various gas mixes containing hydrogen and hydrocarbons as industrial fuels already exists. Low or intermediate Btu coal gasification to supply hydrogen-rich gas mixes for industrial process heat is now being considered (42), (43) and (44), by private industry and by $D O E$, respectively. This is the mechanism whereby hydrogen can be introduced into the industrial process heat supply market 
Table 9

BY-PRODUCT GASES FROM MAJOR U.S. INDUSTRIES (1975-76)

\begin{tabular}{|c|c|c|c|c|c|c|}
\hline & $\begin{array}{l}\text { Petroleum } \\
\text { Refining }\end{array}$ & $\begin{array}{l}\text { Ethylene } \\
\text { Plants } \\
\end{array}$ & $\begin{array}{l}\text { Caustic } \\
\text { Chlorine } \\
\text { Plants } \\
\end{array}$ & $\begin{array}{l}\text { Coke } \\
\text { Ovens } \\
\end{array}$ & $\begin{array}{c}\text { Blast } \\
\text { Furnaces } \\
\end{array}$ & Total \\
\hline Heating Value, Btu/SCF & 1000 & 500 & 315 & 520 & 90 & - \\
\hline \multicolumn{7}{|l|}{ Production } \\
\hline SCF $/ D \times 10^{6}$ & 2740 & 870 & 350 & 2630 & 23000 & 29000 \\
\hline $10^{15} \mathrm{Btu} / \mathrm{yr}$ & 1.00 & 0.16 & 0.04 & 0.50 & 0.75 & 2.45 \\
\hline \multicolumn{7}{|l|}{ Availability } \\
\hline$S C F / D \times 10^{6}$ & 1370 & 870 & 350 & 1320 & 9100 & 13000 \\
\hline $10^{15} \mathrm{Btu} / \mathrm{yr}$ & 0.50 & 0.16 & 0.04 & 0.25 & 0.30 & 1.25 \\
\hline
\end{tabular}

Composition, Vol\%

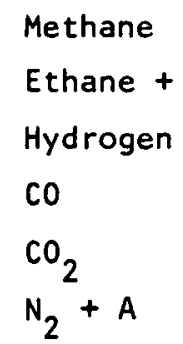

$\begin{array}{r}60 \\ 19 \\ 18 \\ - \\ - \\ 3 \\ \hline 100\end{array}$

$\begin{array}{r}20 \\ 2 \\ 78 \\ - \\ - \\ - \\ \hline 100\end{array}$

\begin{tabular}{lr}
- & 29 \\
- & 3 \\
95 & 50 \\
- & 10 \\
- & 3 \\
- & 5 \\
\hline 100 & 100
\end{tabular}

\begin{tabular}{rr}
- & - \\
- & - \\
3 & - \\
26 & - \\
13 & - \\
58 & - \\
\hline 100 & -
\end{tabular}


in the near term. As coal supplies dwindle; and nonfossil-based hydrogen production processes are commercialized on a larger scale, pure hydrogen fueling will replace the various hydrogen-hydrocarbon gas mixes now being utilized or being considered for near term applications.

The relative economics of manufacturing high Btu synthetic gases and hydrogen from coal using several current and advanced gasification processes has been reviewed in (41), based on uniform ERDA cost evaluations, References (45) and (49), and the results are plotted as a function of coal prices in Figure 1. The gas product costs are based on ERDA supplied plant costs and efficiencies. These should not be compared with the BNL cost estimates in Table A-1, which are based on more recent Exxon cost and efficiency projections. Figure 1 should be considered for comparative purposes only.

Based on the discussion in this section, upper bound estimates of hydrogen penetration into new markets within the national energy system have been computed and are shown in Table 10. In 1985, assuming only small start-up in hydrogen introduction to new applications, the incremental hydrogen demand is $41 \%$ of the projected hydrogen requirements in current industrial activities and in coal gasification. Most of the incremental hydrogen demand will be obtained from coal gasification. The problems and prospects of coalderived hydrogen have been discussed above and they account for the low initial hydrogen penetration rate into the new energy applications. Although the electrolytic hydrogen requirements in the electric sector are quite small, percentage-wise, they still amount to ten times the projected demand in conventional industrial applications, reported in Table 2. Thus, this projection is contingent on the timely development of advanced water electrolysis equipment and its introduction into the electric utilities sector.

The greatest potential demand for hydrogen in new applications by the year 2000 is as a source of industrial process heat and of residential space heat. For this to occur, a large-scale low and intermediate Btu coal gasification industry connected to regional and local distribution systems will have to materialize. This demand should be considered in addition to the captive hydrogen demand for high Btu pipeline gas, reported in Table 2. A very large-scale penetration of hydrogen into the residential, commercial, 
and industrial sectors must await the development of new hydrogen production technologies based on thermochemical water splitting with High Temperature Gas-Cooled Reactors (HTGR's) or solar heat sources. The same general comment also applies to hydrogen utilization in the transportation sector. The hydrogen penetration rate in this sector is assumed. lower compared with process heat applications due to the more severe logistics problems associated with the introduction of hydrogen into this energy sector. Hydrogen penetration into the aviation energy market is assumed somewhat greater than into ground transportation. This is a reflection on the graater ability of the aircraft transportation sector to adjust to hydrogen fuels, compared with ground transport.

A word of caution regarding this market penetration projection is now due. In most applications, hydrogen costs are roughly comparable as seen in Table 6 . Since the operating cost comparisons do not reveal a well defined advantage or disadvantage for hydrogen compared with the likely alternatives, the use of hydrogen as an energy carrier will be determined by factors other than operating fuel costs. In particular, the relative ease and cost of introducing a hydrogen production/transmission/distribution/ end use network compared to the alternatives is likely to be the key factor in determining whether or not hydrogen will play a role in a given application. In this regard, it is important to note that the pre-existence of transmission/distribution networks for electricity, methane, and hydrocarbon liquids will, in general, place these energy carriers in a competitively advantageous position compared to hydrogen. 


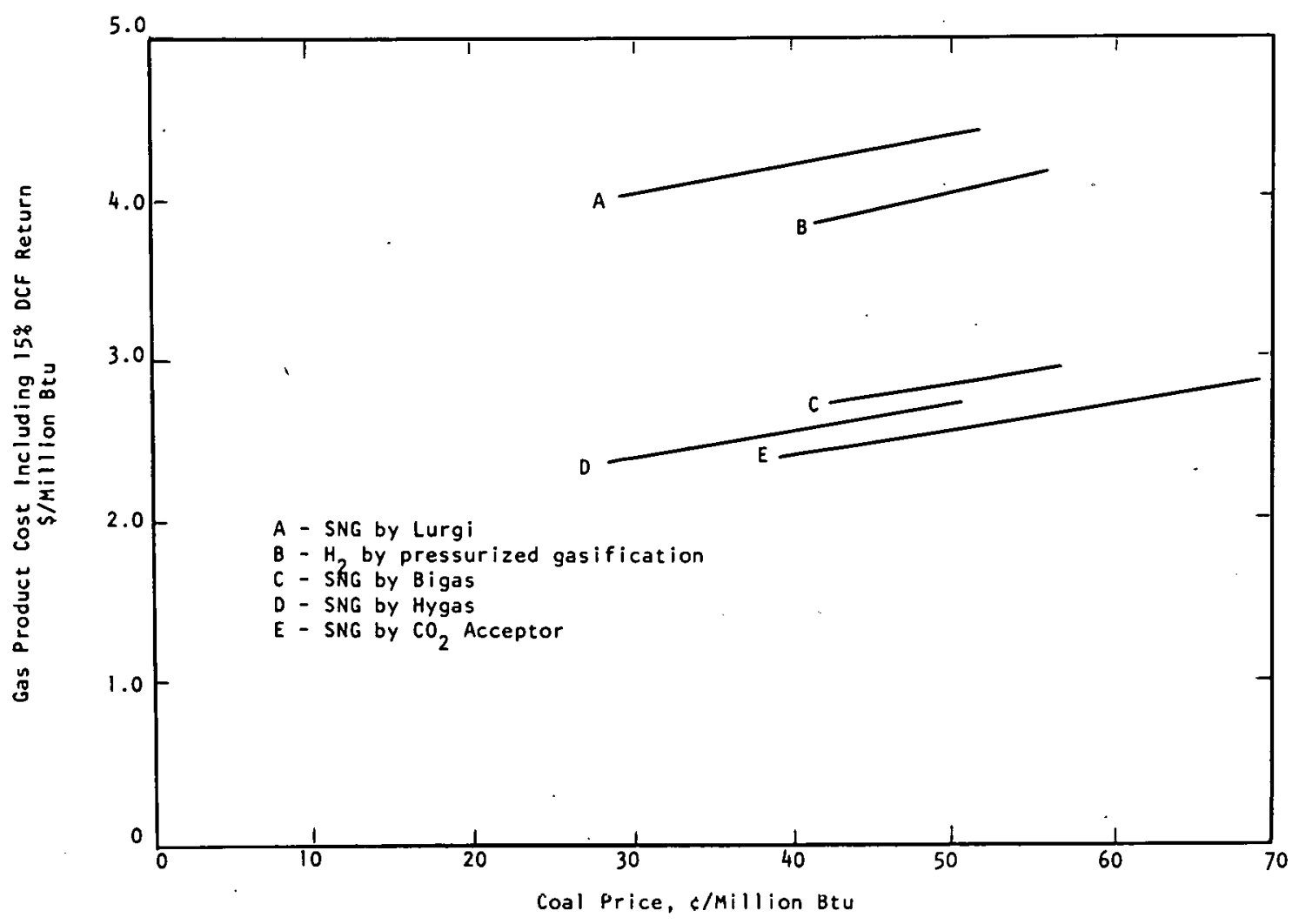

Figure 1. Production costs including 15\% DCF return for coal gasification. Hydrogen by pressurized gasification. SNG by several processes. Data from ERDA economic studies. 
Table 10

ESTIMATED MAXIMUM POTENTIAL PENETRATION OF HYDROGEN

INTO THE NATIONAL ENERGY SYSTEM IN NEW APPLICATIONS

$10^{15}$ Btu Hydrogen

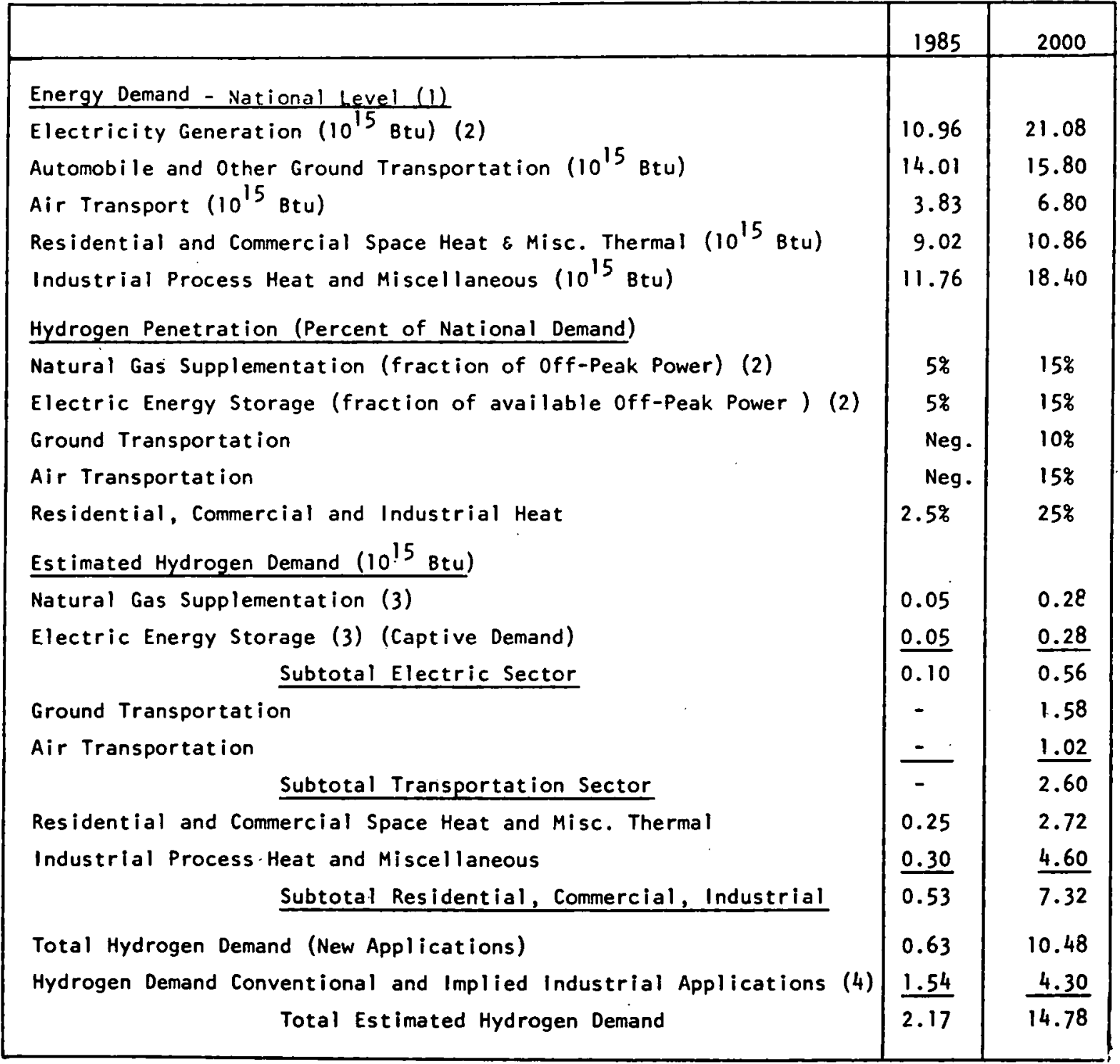

1. National energy demand and electricity supply projections obtained from ERDA Scenario 2 (the nominal case), (3).

2. Hydrogen supplementation of natural gas and electric energy storage activities assumed to consume, each 5 and 15 pe-cent of the available off-peak power supply by the years 1985 and 2000 , respectively. The available off-peak energy is projected as $10 \%$ of the direct electricity generation for load, based on the analysis of Public Service Electric and Gas, (21).

3. Assumed hydrogen production efficiency by advanced water electrolysis of $90 \%$.

4. From Table 2 . 


\section{RED COST-BENEFIT STUDY}

A cost-benefit study has been performed here to estimate the benefits to the national energy system from the commercialization of advanced water electrolysis and coal gasification technologies for hydrogen production. The general cost-benefit methodology has been applied only to these processes because they have the most detailed and reliable predicted cost and performance data.

The basic assumption of this cost-benefit study is that RDED programs carried out during the period 1975-1985 will result in technological improvements which will be implemented within the national energy system over the 25-year period, 1985-2010. The potential benefits during the later period from commercialization of advanced vs. conventional hydrogen production processes are measured in cost reductions and energy resource savings. These cost and resource savings are related to supplying the projected demand for industrial hydrogen in the time frame considered.

To compare the cumulative stream benefits (savings in production costs) and expenses (RDED programs costs) which accrue over different time periods, both monetary streams are discounted to the same year--1975 in this case. A discounted benefit-cost comparison tends to underscore the value of the benefits which occur 20 to 30 years into the future. The cumulative cost of the RDED program which is expected to be carried out in the immediate future is affected to a smaller degree by the discounting process. A $10 \%$ discount rate, which is the OMB recommended rate for government agencies during the budgetary allocation process, is assumed here as the basic discount rate. According to OMB (50) this discount rate represents an estimate of the average rate of return on private investment, before taxes and after inflation. As a parametric analysis, the hydrogen production costs and expected savings were discounted to the year 1975 using the discount rates of 7.5 and 12.5 percent per year. The cumulative discounted benefits could be related to an allowed RDED total program cost by specifying a benefit/cost ratio, when both savings and allowed expenses are discounted to the same basis year. Alternatively, if the cost of the RDED 
program is specified and the expected benefits are estimated, it is possible to compare the computed benefit/cost ratio with similar figures obtained for other RDED programs, to assess the relative value of the proposed program.

This analysis presupposes that crude oil and natural gas will be replaced as hydrogen feedstocks, as a matter of national energy policy. In this respect, this analysis differs from the cost-benefit study performed in the Exxon report (6) and (8) which used the more restrictive assumption of production process substitution only in cases where direct economic advantage can be identified. The cost-benefit study does not measure the incremental benefits to the national energy system from releasing the natural gas feedstocks to other and more important end-use applications.

The cost savings computed here thus underscore the national benefits of developing and commercializing new hydrogen production processes, based on abundant energy resources.

The basic study assumptions and the hydrogen production technologies data are discussed in the next three sections. The results of the costbenefit study are then reviewed.

A. Market Penetration of Advanced Hydrogen Production Technologies

This analysis is limited to hydrogen manufacture for industrial purposes only, for which relatively reliable demand projections exist, e.g., Table 2 for BNL estimates, Table 3 for other sources. It is assumed that the current hydrogen production methods based on natural gas reforming and resid partial oxidation will be phased out between the years 1985-2000. New production technologies based on coal gasification and water electrolysis will be introduced over this period to offset the need for importing natural gas or petroleum supplies. Complete substitution of the current production technologies is assumed to occur during the period 2001-2010. Two processes are considered for each basic hydrogen production method: conventional and advanced Koppers Totzek coal gasification technologies, Lurgi type and Solid Polymer Electrolyte (GE Company process) water electrolysis systems.

As shown in Table 2, the demand for industrial hydrogen at the current end uses grows at an annual exponential rate of $3.45 \%$ per year, while electrolytic hydrogen requirements increase by $7.60 \%$ per annum. It is assumed 
here that these growth rates computed for the period 1985-2000, will also be maintained in the following period of 2001-2010. Thus, electrolytic hydrogen forms $0.7 \%$ of the total industrial hydrogen requirement by the year 1985, and this fraction increases to $1.94 \%$ of the projected demand by the year 2010 . The non-electrolytic industrial hydrogen demand is being penetrated by the coal gasification technology, starting at essentially zero implementation level by 1985 and achieving full substitution of the existing production processes by the year 2000. A summary of the basic results of the computations is provided in Table 11 and a discussion of the basic assumptions regarding the technological improvements in the new hydrogen production processes now follows.

\section{B. Hydrogen Production by Coal Gasification}

Coal-derived hydrogen is assumed here to be produced either by a current or an advanced Koppers Totzek process. The advanced process includes pressurized gasification and results in both capital cost savings and improvements in plant capital investment. The total reduction in hydrogen production cost is shown in Table A-1, which is discussed in Appendix $A$ of this study. As seen in Table $A-1$, coal-derived hydrogen from conventional and advanced K-T gasification, costs $\$ 5.12 / M M B t u$ and $\$ 4.46 / M M B t u$, respectively, by 1985 , and $\$ 5.25 / M M B t u$ and $\$ 4.59 / M M B t u$ in the year 2000 . The reduction in hydrogen cost is due mostly to the reduction in the capital cost component. The improvement in gasification efficiency results in reduced coal requirements for hydrogen manufacture. Relatively modest efficiency improvements are assumed here based on the Exxon study process description, (6), i.e., from $59.6 \%$ to $64.2 \%$. A national averaged coal heat content of $21.4 / \mathrm{MM} \mathrm{Btu} /$ ton is projected here according to the base ERDA projections (3). Coal savings can be translated to monetary equivalents assuming coal prices of $\$ 0.74 / \mathrm{MM} \mathrm{Btu}$, by 1985 , rising to $\$ 0.82 / M M$ Btu by the year 2000 (3).

The incremental coal supply for the production of coal-derived industrial hydrogen amounts to $8.4 \%$ of nominal coal supply. This corresponds to $2.45 \%$ of the total energy resource supplies by that year. The national coal production by 1975 was $63.9 \times 10^{6}$ tons, according to the FEA data (8). The large 
Table 11

SUMMARY OF 8NL COST BENEFIT CALCULATIONS

RELATED TO IMPROVEMENTS IN HYDROGEN PRODUCTION TECHNOLOGY

All computed benefits expressed in billion 1975 dollars discounted to 1975

Net Benefits

\begin{tabular}{|c|c|c|c|c|c|c|}
\hline \multirow[b]{2}{*}{ Technology } & \multicolumn{3}{|c|}{ Period $1985-2000$} & \multicolumn{3}{|c|}{ Period 1985-2010 } \\
\hline & $\begin{array}{c}\text { Discount } \\
\text { Rate }=7.5 \\
\text { g/Year }\end{array}$ & $\begin{array}{c}\text { Discount } \\
\text { Rate }=10.0 \\
\% / \text { Year }\end{array}$ & $\begin{array}{c}\text { Discount } \\
\text { Rate }=12.5 \\
\% / \text { Year }\end{array}$ & $\begin{array}{c}\text { Discount } \\
\text { Rate }=7.5 \\
\% / \text { Year }\end{array}$ & $\begin{array}{c}\text { Discount } \\
\text { Rate }=10.0 \\
\% / \text { Year }\end{array}$ & $\begin{array}{c}\text { Discount } \\
\text { Rate }=12.5 \\
q / \text { Year }\end{array}$ \\
\hline
\end{tabular}

Improvement in Coal Gasification Technology (1) (6)

\section{Reduction in Coal Requirements
109 Ton Coal}

Savings from Reduced Coal Requirements (3) $10^{9} \mathrm{~s}$

0.10

0.39

0.10

0.10

0.25

0.25

0.25

Total Savings from Reduction in Coal-Derived

Hydrogen Cost $10^{9} s$

(4) (6)

2.75

1.95

0.16

0.70

0.40

0.24

Improvements in Water Electrolys is Technology Reduction in Electrolyzer Capital Costs $10^{9} \$(5)$

Total Savings from Reduction in Electrolytic Hydrogen Cost $109 \$$

$\begin{array}{ll}0.15 & 0.11 \\ 0.18 & 0.13\end{array}$

0.37

0.45
0.23

0.27

0.14
NOTES: (1) Gasification efficiency improved from 53.6 to 64.2 percent (Btu( $\left.\mathrm{H}_{2}\right) / \mathrm{Btu}(\mathrm{th})$. Hydrogen production costs reduction from $\$ 5.12 / \mathrm{MM}$ Btu to $\$ 4.46 / \mathrm{MM} B t u$, according to Table 5 data.

(2) Average coal heat content of $21.4 \mathrm{MM} \mathrm{Btu}(\mathrm{th} / \mathrm{ton}$ according to Reference (3).

(3) Coal Cost (including transportation) averaged as $\$ 0.74 / \mathrm{MM}$ Btu by 1985 and $\$ 0.82 / M M$ Btu by the year 2000 , according to Reference ( 3 ).
(4) Electrolysis efficiency improved from 74.7 to 90.0 percent $\left\{\mathrm{Btu}\left(\mathrm{H}_{2}\right) / \mathrm{Btu}(\mathrm{Sh})\right)$. Hydrogen production cost reduction from $\$ 9.05 / \mathrm{MM}$ Btu by 1985 to $\$ 5.61 / \mathrm{MM}$ Btu by the year 2000 as reported in Table 5 .

(5) Electrolyzer capital cost reduction from $\$ 320 / \mathrm{kW}\left(\mathrm{H}_{2}\right)$ to $\$ 150 / \mathrm{kW}\left(\mathrm{H}_{2}\right)$, according to Table 5 .

(6) All efficiency improvements and capital cost reductions result from an ERDA RDED program carried out during the period 1975-1985. 
amount of coal required to supply a relatively small portion of the national energy requirements is in itself a large incentive for the improvements in the hydrogen production efficiency, especially when legal, environmental, and institutional constraints on large-scale coal mining are considered.

The economic impact of improving coal gasification technology for hydrogen manufacture is quite pronounced. The detailed cost-benefit study computations indicate that the annual savings in the cost of the required coal supply by the year 2000 amount to $221.8 \mathrm{million} 1975$ dollars. The total monetary savings from the implementation of advanced vs. current gasification technologies for hydrogen production reach $1.5 \times 10^{9} 1975$ dollars. These figures relate to the production of coal-derived hydrogen for currently established industrial demands only. Should new applications for coalderived hydrogen, such as the synthetic fuels industry be considered, then the savings from improved production technologies will be correspondingly higher.

\section{Hydrogen Production by Water Electrolys is}

Two water electrolysis technologies were compared in this section: the current Lurgi system and the advanced Solid Polymer Electrolytic process, now being developed by the General Electric Company. It is expected that the DOE RDED program carried out between 1976 and 1985 will result in commercialization of the advanced electrolysis process during the period 1985-2010. The savings from implementation of advanced vs. current electrolytic hydrogen production technologies are computed. The differences in performance and cost characteristics between the two electrolysis technologies have been listed in Table A-1. Electrolyzer capital cost reduction from $\$ 320 / \mathrm{kW}\left(\mathrm{H}_{2}\right)$ to $\$ 150 / \mathrm{kW}\left(\mathrm{H}_{2}\right)$ is expected. This is coupled with improvements in electrolysis efficiency from $74.7 \%$ to $90.0 \%$. The combined effect of capital cost reduction and efficiency improvement is a reduction in the cost of electrolytic hydrogen from $\$ 9.05 / \mathrm{M} \mathrm{Btu}$ to $\$ 5.61 / \mathrm{M} \mathrm{Btu}$ by 1985 , and from $\$ 9.43 / \mathrm{M}$ Btu to $\$ 5.93 / \mathrm{M}$ Btu by the year 2000 , assuming operation with off-peak electric power. Electrolyzers are expected to operate 55 hours per week which corresponds to an annual average load factor of 0.33 . Nuclear off-peak power at an average cost of $8 \mathrm{mills} / \mathrm{kWh}$ is assumed available for 
electrolytic hydrogen production. Should an average nuclear-fossil off-peak power mix be considered, the fuel cust component of the electrolytic hydrogen will increase to $\$ 12 / M M B t u$ and $\$ 8 / M M B t u$, for current or advanced electrolysis technologies, respectively. In such a case, the projected savings from improvements in water electrolysis methods would be higher than reported in Table 11. As seen in Table A-1, about $80 \%$ of the reduction in electrolytic hydrogen production cost by current vs: advanced processes is due to the computed reduction in the capital cost component. This pattern is also evident in the results of the cost-benefit study reported in Table 11. The reduction in the investment related component of the hydrogen cost is so pronounced, both in Tables $A-1$ and 11 , since the concomitant improvement in electrolysis efficiency is also included in the computation of the capital cost component. The equations used in the hydrogen production cost computations of Table 5 and in the cost-benefit study are reported in Appendix $A$. As seen in equation (1) of Appendix $B$, the capital cost component of the electrolytic hydrogen price is directly proportional to the plant investment and inversely proportional to the electrolysis efficiency.

D. Comparison of Projected Benefits and Relationship to RDED Funding on Hydrogen Production

Based on the results of Table 11, it is interesting to note that while the electrolytic hydrogen demand is about $1.3 \%$ of the overall industrial hydrogen demand $(0.7 \%$ by 1985 , rising to $1.9 \%$ by 2010$)$, the cumulative discounted savings from improvements in electrolysis efficiency are almost $10 \%$. of the projected savings in the cost of coal-derived hydrogen. In an earlier draft of this report (51), it was assumed that electrolytic hydrogen amounts to $10 \%$ of the industrial hydrogen demand. It was then found that the monetary benefits due to improvements in coal gasification and water electrolysis technologies were quite similar. This pattern is explained by the fact that the expected reduction in the cost of electrolytic hydrogen due to the commercialization of advanced production technology is about ten times greater than the potential reduction in the cost of coal-derived hydrogen, as seen in Table 5. The state of water electrolysis technology development is such 
that revolutionary cost reductions (factors of 2 or 3 ) can be expected due to the implementation of new process technologies. Coal gasification for hydrogen manufacture is expected to experience only small decrements in capital cost, e.g., 20-30\%. The larger potential cost reduction in water electrolysis compared with coal gasification partially offsets the fact that only a relatively small amount of hydrogen will be produced by this process. Thus, a comparison of the RDED benefits from improvements in electrolysis and gasification technologies is very sensitive to the relative amounts of hydrogen produced by each process.

The detailed cost-benefit computations show that the annual savings from implementing advanced vs. conventional gasification technology for the manufacturing of coal-derived hydrogen amount to $1.95 \times 10^{9} 1975$ dollars by the year 2000. This should be compared with the cumulative discounted savings over the entire study period, 1985-2010, which corresponds to 2.78 $\times 10^{9} 1975$ dollars, discounted at $10 \%$ to 1975 . The cumulative discounted savings from the commercialization of advanced vs. current water electrolysis technology amount ot $\$ 0.18 \times 10^{9}$ and $\$ 0.27 \times 10^{9}$ by the years 2000 and 2010 , respectively.

This cost-benefit study primarily considers the differences between production costs at various technology development levels. One should also consider the absolute magnitude of the production costs. The benefits computed here only relate to industrial hydrogen production. Should water electrolysis and coal gasification processes be utilized for the production of hydrogen delivered to the non-industrial sectors, the computed benefits shown in Table 11 will increase proportionately. Using the benefit-cost study methodology, it is possible to parametrically arrive at allowed RDED program costs, based on the benefits computed above and on a specified benefit/cost ratio. The higher the value of the benefit/cost ratio, the smaller the allowed RDED funding level for a given amount of discounted savings.

The total savings due to the implementation of improved technologies for coal-derived and electrolytic hydrogen production amount to $2.78 \times 10^{9}$ 
and $\$ 0.27 \times 10^{9}$, respectively, according to Table 11 . Should a benefit/cost ratio of 10 be accepted, it follows that the allowed RDED funding programs for coal gasification and water electrolysis over the 10 year period 19761985 are about 280 million 1975 dollars and 27 million dollars. As a first approximation, the annual funding level within this period could be assumed to be one-tenth of the allowed cost of the entire RDED program. As such, the hydrogen from coal program could expand to an annual level of 28 million dollars, while the electrolytic hydrogen program could be funded at about $2.8 \times 10^{6}$ dollars/year. The previous draft of this report (51), which assumed a 10:1 split between coal-derived and electrolytic hydrogen demands, instead of the 100:1.3 ratio assumed here, resulted in an equal split of the allowed RDED funding between water electrolysis and coal gasification. The more conservative assumption regarding the industrial demand for electrolytic hydorgen results in a $10: 1$ split in funding levels in favor of coalderived hydrogen. This is due to the greater potential demand for coal gasification as a source for industrial hydrogen.

Should the lower discount rate of $7.5 \%$ per year be accepted as the nominal value, then the allowed annual funding levels could be increased by a factor of $60 \%$. Conversely, should the high discount rate of $12.5 \%$ per year be accepted, then the allowed funding levels could be reduced by approximately the same factor.

The evaluation of allowed funding levels mentioned above depends on the value of the benefit/cost ratio, given the amount of benefits computed in this study. A choice of a different benefit/cost ratio would have yielded another set of allowed RDED expenses. Thus, while the benefits from improved hydrogen production methods are based on technological data, the budget allocation process is in the hands of the policymaker. Based on the computed system benefits, a rational choice of RDED funding levels can be made. 


\section{REFERENCES}

1. Kelley, J. H., Laumann, E. A. Hydrogen Tomorrow - Demands and Technology Requirements. Report of the NASA Hydrogen Energy Systems Technology

Study. Jet Propulsion Laboratory, Pasadena, California, December 1975.

2. Adkins, D. C., Jaske, R. J. Hydrogen. A Chapter from Mineral Facts and Problems. 1975 Edition: Bureau of Mines Bulletin 667. U. S. Department of the Interior, Washington, DC, 1976.

3. U. S. ERDA - Office of the Assistant Administrator for Planning Analysis and Evaluation. Working Paper Forecasts and Scenarios 1985-2000 (Revised Draft). September 10, 1976.

4. Biederman, N., Darrow, K., Jr., Konopka,A. Utilization of Off-Peak

Power to Produce Industrial Hydrogen. Electric Power Research Institute, Final Report on Research Project 320-1, Palo Alto, California, August 1975.

5. Meadows, D. P., De Carlo, J. A. Mineral Facts and Problems 1970 Edition, Hydrogen Section, pp 97-109, U. S. Bureau of Mines Bullet in 650, Washington, D.C.

6. Corneil, H. G., Heinzelmann, F. J., Nicholson, E. W. S. Production Economics for Hydrogen, Ammonia, and Methanol During the 1980-2000 Period. Report prepared by EXXON Research and Engineering Company for Brookhaven National Laboratory. Linden, New Jersey, April 1977.

7. U. S. Bureau of Mines. Captive Hydrogen for Ammonia, Methanol Production and Petroleum Refining Prices. Bureau of Mines Data Sheet, Washington, D. C. 1974 .

8. U. S. Federal Energy Administration, National Energy Outlook 1976. Report FEA-N-75-713, Washington, D. C., February 1976.

9. Lotker, M. Hydrogen for Electric Utilities - Long Range Possibilities. 9th Intersociety Energy Conversion Engineering Conference, San Francisco, California, August 1974, pp. 423-428.

10. Special Studies Group. Hydrogen in the Energy System of the Netherlands. TNO - Industrial Research Organization, Apeldoorn, the Netherlands, September 1975.

11. Beller, M. Cost Tables for Brookhaven Energy System Optimization Model. BNL Memorandum, Upton, New York, September 1975.

12. Beller, M., Editor. Sourcebook for Energy Assessment, BNL-50483, Upton, New York, December 1975. 
13. Steinmetz, G. F., Baltimore Gas and Electric Company. Work of the Ad Hoc Committee evaluating the use of hydrogen as a supplement to natural gas. Paper presented at the ERDA Contractor's Review Meeting on Chemical Energy Storage and Hydrogen Energy Systems.

14. Fernandes, R. (Niagara Mohawk Power Corp.), Draft Summary Report of the Supply Task Group Communication to Members of the Ad Hoc Committee on Hydrogen as a Natural Gas Supplement. Syracuse, New York, November 12 , 1976.

15. Hoffman, K. C. Economics of Hydrogen Energy Systems. Paper presented at the 33rd Annual Meeting of the Institute of Gas Technology, Chicago, Illinois, Report BNL-19440, November 21, 1974.

16. Burger, J. M. An Energy Utility Company's View of Hydrogen Energy Fundamentals - A Symposium Course, Pp. S-4-39 to S-4-63, Miami Beach, Florida, March 3-5, 1975.

17. Salzano, F. J., Cherniavsky, E. A., Isler, R. J., Hoffman, K. C. On the Role of Hydrogen in Electric Energy Storage. Paper presented at the Hydrogen Economy Miami Energy Conference (THEME), Miami Beach, Florida, March 18-20, 1974.

18. Braun, C., Cherniavsky, E. A., Salzano, F. J. The Integration of Distillate $0 \mathrm{il} / \mathrm{Hydrogen}$ Fueled Fuel Cells into the National Energy System. Report BNL-20989, presented at the lst World Hydrogen Energy Conference, Reference (14).

19. Fernandes, R. A. Hydrogen Cycle Peak Shaving - Assessment of the Technical and Economic Feasibility for the New York State Electric Utilities. Niagara Mohawk Power Corporation, Report NMP-HCPS-2-75, Syracuse, New York, April 1975.

20. Kalhammer, F. R., Schneider, T. R. Energy Storage. Pp. 311-343 of Annual Review of Energy, J. M. Hollander, ed., Vol. 1, Palo Alto, California, April 1976.

21. Schneider, T. R., Project Manager. An Assessment of Energy Storage Systems Suitable for Use by Electric Utilities. Final Report of EPRI Project 225, EPRI EM-264, Palo Alto, California, July 1976.

22. Gileadi, E., Srinivasan, S., Salzano, F. J., Braun, C., Nuttall, L. J., LaConti, A. B. An Electrochemically Regenerative Hydrogen-Chlorine Fuel Cell as an Energy Storage System for Electric Utilities. Paper presented at the 11 th IECEC Meeting, State Line, Nevada, September 1976. BNL 21820.

23. Fernandes, R. A., Philipp, H. D. Hydrogen Cycle Peak Shaving on the New York State Grid Using Fuel Cells. Paper presented at the IEEE Power Engineering Society Summer Meeting, Portland, Oregon, July 1976. 
24. Fernandes, R. Analys is of Hydrogen Cycle Peak-Shaving for New York State. Niagara Mohawk Power Corporation, Report NMP-HCPS 2-75, Syracuse, New York, April 1975.

25. Dickson, E. M., Ryan, J. W., Smulyan, M. H. The Hydrogen Economy - A Preliminary Technology Assessment. Stanford Research Institute Project EGU-2836, Menlo Park, California, July 1975.

26. Proceedings of the First World Hydrogen Conference. Clean Energy Research Institute, University of Miami, Miami Beach, Florida, March 1976.

27. Busi, J. D. Hydrogen Technology - Foreign (U). U. S. Defense Intelligence Agency Report. DST-1850S-522-76, Washington D. C., May 1976.

28. Tsaros, C. L., Arora, J. L., Burnham, K. B. A Study of the Conversion of Coal to Hydrogen Methane and Liquid Fuels for Aircraft. Prepared for Langley Research Center, National Aeronautics and Space Administration by the Institute of Gas Technology, Chicago, Illinois, June 1976.

29. Kant, F. H. et al. Feasibility Study of Alternative Fuels for Automotive Transportation. U. S. Environmental Protection Agency Report EPA-460/3-74009, Linden, New Jersey, Exxon Research and Engineering Company, June 1974.

30. Stewart, W. F., Edeskuty, F. J. Logistics, Economics and Safety of a Liquid Hydrogen System for Automotive Transportation. Paper presented at the Intersociety Conference on Transportation, Denver, Colorado, September 1973.

31. Escher, W. J. D. Hydrogen via Electricity: A Candidate Transitional Transportation Energy System Concept. U. S. ERDA Report ERDA-77-13, Washington, D. C., February 1977.

32. Billings, R. E. A Hydrogen Powered Mass Transit System, Paper presented at the lst World Hydrogen Energy Conference, Reference (14).

33. Mauri, G., Exxon Enterprises, Florham Park, New Jersey. Private Communication to C. Braun, BNL, August 12, 1976.

34. Hord, J., Editor, Selected Topics on Hydrogen Fuel. National Bureau of Standards, Special Publication 419, Washington, D. C., May 1975.

35. Working Symposium on Liquid-Hydrogen-Fueled Aircraft, held at National Aeronautics and Space Administration, Langley Research Center, Hampton, Virginia, May 15-16, 1973 .

36. Lessard, R. D., Liquid Hydrogen as a Fuel for Future Commercial Aircraft, United Aircraft Research Laboratories, East Hartford, Connecticut. 9th Intersociety Energy Conversion Engineering Conference, San Francisco, California, August 26-30, 1974. 
37. Hallet, N. C. NASA Contractor Summary Report, Study, Cost, and System Analys is of Liquid Hydrogen Production. Prepared under Contract No. NAS 2-3894 by Air Products and Chemicals, Inc. Allentown, Pennsylvania for Mission Analysis Division, Ames Research Center, National Aeronautics and Space Administration.

38. Johnson, John E. The Economics of Liquid Hydrogen Supply for Air Transportation. Union Carbide Corporation, Linde Division, New York, New York, presented at the Cryogenic Engineering Conference, August 10, 1973, At lanta, Georgia.

39. Escher, William J. D. Prospects for Liquid Hydrogen Fueled Commercial Aircraft, Escher Technology Associates, Report PR-37, September 1973.

40. Witcofski, R. D. The Thermal Efficiency and Cost of Producing Hydrogen and Other Synthetic Aircraft Fuels from Coal. Paper presented at the lst World Hydrogen Conference, Reference (14).

41. Corneil, H. G. Report of the Subgroup on Coal Gasification to the Task Group on Supply. Ad Hoc Committee on Hydrogen as a Natural Gas Supplement Dated August 11, 1976. Included in the Minutes of the Second Meeting of the Supply Task Group, Washington, D. C., August 13, 1976.

42. The INGAS Project: A Joint Venture of Columbia Coal Gasification Corp. and Koppers Company Inc. Medium Btu Gas From Coal: Technical, Economic, and Utilization Aspects. Report submitted ERDA, September 8, 1976.

43. U. S. ERDA, Division of Coal Conversion and Utilization. Program Opportunity Notice: Developmental Integration and Evaluation of a Facility to Produce Hydrogen from the Gasification of Coal for Use in an Industrial Process. Document PON-FE-6, Washington, D. C., June 30, 1976.

44. Robin, A. M., Principal Investigator. Hydrogen Production from Coal Liquefaction Residues. Prepared by Taxaco, Inc. for the Electric Power Research Institute. EPRI Report EPRI-AF-233, Palo Alto, California, December 1976.

45. Preliminary Economic Analysis of Lurgi Plant Producing 250 Million SCFD Gas from New Mexico Coal. ERDA-76-57; FE-2083-9; UC-90C; U. S. Department of Interior, Bureau of Mines, Process Evaluation Group, Morgantown, West Virginia, March 1976.

46. An Economic Analysis - 250 Million SCFD High Btu Gas Plant - Synthane Wyodak Seam Coal. ERDA 75-15b, Revision of Report No. 75-15A, U. S. Department of Interior, Bureau of Mines, Process Evaluation Group, Morgantown, West Virginia, September 1975. 
47. Preliminary Economic Analys is of $\mathrm{CO}_{2}$ Acdeptor Process Producing 250 Million SCFD of High Btu Gas from Subbituminous Coal and Lignite. ERDA-76-58; FE 2083-7; UC-90C, U. S. Department of Interior, Bureau of Mines, Process Evaluation Group, Morgantown, West Virginia, March 1976.

48. Preliminary Economic Analysis of $B C R$ Bi-Gas Plant Producing 250 Million SCFD High Btu Gas from Montana and Western Kentucky Seam Coals. ERDA 76-48; FE-2083-2; UC-90-C, U. S. Department of Interior, Bureau of Mines, Process Evaluation Group, Morgantown, West Virginia, March 1976.

49. Preliminary Economic Analysis of IGT Hygas Plant Producing 250 Million SCFD High Btu Gas from Montana and Pittsburgh Seam Coals. ERDA 76-47; FE-2083-3; UC-90C, U. S. Department of Interior, Bureau of Mines, Process Evaluation Group, Morgantown, West Virginia, March 1976.

50. U. S. Office of Management and Budget OMB Circular No. A-94, Revised, Washington, D. C. 1969.

51. Salzano, F. J., Braun, C., editors. Hydrogen Energy Assessment - Final Draft for Review. Brookhaven National Laboratory, Upton, New York, May 1976.

52. Gregory, D. P., Pangborn, J. B., Gillis, J. C. Survey of Hydrogen Production and Utilization Methods, Institute of Gas Technology, Final Report of Project 8962, Chicago, IIlinois, August 1975.

53. Herman, S. W., Cannon, J. S. Chapter on "Hydrogen Production" from Energy Futures, Industry, and the New Technologies. An INFORM Book, 1976.

54. Scott, R. B. Technology/Uses of Liquid Hydrogen, 1964.

55. Commercial Gas Bulk Prices and Commercial Liquid Hydrogen Bulk Prices. Estimates made by the Brookhaven National Laboratory Supply and Materials Division and Accelerator Department. Private Communications to V. Gazerro, Brookhaven National Laboratory, Upton, New York, August 1975.

56. Corneil, H. G., Heinzelmann, F. J., Nicholson, E. S. Production Economics for Hydrogen Ammonia, and Methanol during the 1980-2000 Period. Paper presented at the Second Information Meeting for Contractors in the ERDA Hydrogen Energy Program. Airlie House, Airlie, Virginia, November 8-9, 1976.

57. U. S. ERDA, Office of the Assistant Administrator for Planning Analysis and Evaluation. Briefing for Assistant Administrators-Presentation of ERDA Electric Utilities Study (Revised). Washington, D. C., May 26, 1976.

58. Economic Evaluation Sub-Task Group - Ad Hoc Committee on Hydrogen as a Natural Gas Supplement. Sample Hydrogen Production Cost Analysis Included in the Minutes of the Fourth Meeting of the Ad Hoc Committee held in Chicago, Illinois, September 1976. Minutes Distributed by BNL on November 15, 1976. 
59. Wintrel, R. The K-T Process: Koppers Commercially Proven Coal and MultiFuel Gasifier for Synthetic Gas Production in the Chemical and Fertilizer Industries. Paper presented at the National Meeting of the American Institute of Chemical Engineers, Salt Lake City, Utah, August 1974.

60. U. S. Department of the Interior, Bureau of Mines. Fifteen Million SCFH Plant, Hydrogen Via Entrained Gasification of Pittsburgh Seam Coal at 30 Atmospheres. Report ERDA-76-6, Morgantown, West Virginia, August 1975.

61. Olds, F. C. The Availability of Fuels for Power Plants, Power Engineering, Pp 42-49, September 1976.

62. Bechok, M. R. Process and Environmental Technology for Producing SNG and Liquid Fuels. Report EPA 660/2-75-011, May 1975.

63. a. Jahnig, C. E., Bertrand, R. R. Environmental Aspects of Coal Gasification. Chemical Engineering Progress, pp 51-56, August 1976. This paper cites several EXXON Research and Engineering Company reports dealing with the environmental aspects of Coal Conversion. See also

b. Hittman Associates Inc. Baseline Data: Environmental Assessment of a Large Coal Conversion Complex. Volumes I and II. Report FE-1508-TI, Columbia, Maryland, May 1975.

c. Hittman Associates Inc. Environmental Effects, Impacts, and Issues Related to Large Scale Coal Refining Complex. Report FE-1508-T2, Columbia, Maryland, May 1975.

64. Sulzberger, V. T., Zemkowski The Potential for Application of Energy Storage Capacity on Electric Utility Systems in the United States: Part 1. Paper presented in the IEEE Report on Energy Development 11 . 76CH1102-3PWR, New York, New York, February 1976.

65. Reilly, J. J., Johnson, J. R. Titanium Alloy Hydrides, Their Properties and Applications. Paper presented at the First World Hydrogen Energy Conference, Miami Beach, Florida, March 1-3, 1976.

66. Beaufrere, A. H., Salzano, F. J., Isler, R. J., Yu, W. S. Hydrogen Storage via Iron-Titanium for a $26 \mathrm{MW}$ (e) Peaking Electric Plant, BNL-20902, January 1976.

67. Salzano, F. J., Braun, C., Beaufrere, A., Srinivasan, S., Strickland, G., Reilly, J. J., Waide, C. Hydrogen Storage Via Metal Hydrides for Utility and Automotive Energy Storage Applications. Report BNL 21723, presented at the 26th Canadian Society of Chemical Engineers Meeting held in Toronto, Canada, October 4-6, 1976. 
68. Steeve, E. J., Commonwealth Edison Company. Spinning Reserve for Hydrogen Production. A brief for presentation at the International Energy Agency Meeting, Brussels, Belgium, June 24, 1976.

69. Guerra, C. R., Public Service Electric and Gas Company of New Jersey. Letter to E. J. Steeve. Re: Hydrogen from Spinning Reserve, dated September 24, 1976. Included in the Minutes of the Fourth Meeting of the Task Group on Supply, the Ad Hoc Committee on Hydrogen as a Natural Gas Supplement, held in New York, New York, October 20, 1976.

70. Biederman, N. P. Wind Powered Hydrogen Electric Systems for Farm and Rural Use. Paper presented at the Second Workshop on Wind Energy Conversion Systems. Report NSF RA-N-75-050, Washington, D. C., June 1975. See also

IGT Report with the same title, written by Tison, R. R. and Biederman, N. P. Final Report of IGT Project 8967, Chicago, Illinois, April 1976.

71. Dubey, M., Lockheed - California Company. Conversion and Storage of Wind Energy as Nitrate Fertilizer. Paper presented at the ERDA Contractor's Review Meeting on Chemical Energy Storage and Hydrogen Energy Systems, Airlie House, Airlie, Virginia, November 8-9, 1976.

72. Fickett, A. P., EPRI, Palo Alto, California. Private Communication to C. Braun, BNL, September 7, 1976.

73. Proceedings of the Cornell International Symposium $\varepsilon$ Workshop on the Hydrogen Economy, August 20-22, 1973, sponsored by the National Science Foundation Research Applied to National Needs (RANN) Program in cooperation with the Cornell Energy Project, Simpson Linke, Editor. Published by Cornell University, I thaca, New York, April 1975.

74. A Hydrogen Based Energy Economy, prepared for Northeast Utilities Service Company, Report No. 69-08-10, by Elihu Fein, The Futures Group, 124 Hebron Avenue, Glastonbury, Connecticut, October 1972.

75. Gregory, D. P. The Hydrogen Economy. Scientific American, Vol. 228, pp. 13-21, 1973.

76. Debeni, G., Marchetti, C. Hydrogen, Key to the Energy Market. Euro Spectra, Vol. 9, pp. 46-50, 1970.

77. Gregory, D. P., Pangborn, J. B. Hydrogen Energy, pp. 279-310, of Annual Review of Energy, Volume I, Hollander, J. M. and Simmons, M. K., Editors. Palo Alto, California, April 1976.

78. Wentorf, R. H., Hanneman, R. E. Thermochemical Hydrogen Generation. Science, Vol. 185, pp. 311-319, July 26, 1974. A comment letter by R. Shinnar. Thermochemical Hydrogen Generation - Heat Requirements and Costs. Science, Vol. 188, pp. 1036-1037, June 6, 1975. 
79. Pangborn, J. B., Sharer, J. C. Analysis of Thermochemical Water Splitting Cycles. Hydrogen Energy: Proceedings of the Hydrogen Economy Miami

Conference, (THEME), pp. 499-516, Veziroglu, T. N., Editor, Miami Beach, Florida, March 1974.

80. Several Thermochemical Hydrogen papers were presented at the ERDA Contractor's Review Meeting on Chemical Energy Storage and Hydrogen Energy Systems, Airlie House, Airlie, Virginia, November 8-9, 1976. These include the following review papers:

a. Funk, J. E., Carty, R. H., Conger, W. L. Analysis and Evaluation of Thermochemical Hydrogen Production Processes. University of Kentucky, Lexington, Kentucky.

b. Bowman, M. G. The LASL Thermochemical Hydrogen Program: Status on October 31, 1976. Report LA-UR-76-2453, Los Alamos Scientific Laboratory, Los Alamos, New Mexico.

c. Farbman, G. H. Sulfer Cycle Water Decomposition System. Westinghouse Electric Corporation, Pittsburgh, Pennsylvania.

d. Schuster, J. R., Russell, J. L. Thermochemical Water Splitting at General Atomic. Report GA-A14114, General Atomic Company, San Diego, California.

81. Quade, R. N. HTGR and Process Evaluation. pp. 117-123 of the Proceedings of the First National Topical Meeting on Nuclear Process Heat Applications. Los Alamos Scientific Laboratory, LA-5795C, October 13, 1974.

82. Several Generic Reports on a Very High Temperature Reactor have recently been published, such as:

a. West inghouse Astronuclear Laboratory

The Very High Temperature Reactor for Process Heat

WANL-2445-1, December 1974.

b. General Atomic Company

High Temperature Nuclear Heat Source Study

GA-A 13158, December 1974.

c. West inghouse Astronuclear Laboratory

Presentation of the Results of Task III: Studies of the Use of Heat from Nuclear Sources for Hydrogen Production Processes NASA Contract NAS-3-18934, November 13, 1975.

83. Hornung, C. D., Lindal, B., El Rauly, N. Preliminary Research on Ocean Energy Industrial Complexes Phase 1. Report OR0-4915-3, April 1976. 
84. Eisenstadt, M. M., Cox, K. E. Hydrogen Production from Solar Energy. Solar Energy, Vol. 17, pp. 59-65, 1975.

See also paper by Ohta, T. Solar Hydrogen Energy System: How Will It Be

Founded. PP. 7-12, Chemical Economy and Engineering Review, June 1975.

85. Several reports dealing with the utilization of fusion reactors in the chemical process industry are listed here:

a. Steinberg, M., Beller, M., Powell, J. R. A Survey of Applications of Fusion Power Technology to the Chemical and Material Processing Industry. Informal BNL Report BNL-18866, May 1974.

b. Jordan, R. K., Steinberg, M. Applications of Controlled Thermonuclear Reactor (CTR) Fusion Power in the Steel Industry. Report BNL-19885, March 1975.

c. Steinberg, M., Dang, V. D. Use of Controlled Thermonuclear Reactor Fusion Power for the Production of Synthetic Methanol Fuel from Air Water. Report BNL-20016R, April 1975.

86. Blanchet, M. J. Scenario for Hydrogen Production from Solid Municipal Waste in Pacific Gas and Electric Service Area. A short status report submitted to C. Braun, BNL, October 1976.

87. Brewer, G. D. The Case for Hydrogen Fueled Aircraft. Paper presented at the 98th Propulsion Conference of the American Institute of Aeronautics and Astronautics, Las Vegas, Nevada, November 1973. 


\section{B I BL I OGRAPHY}

Bamberger, C. G., Braunstein, J. Hydrogen: A Versatile Element, American Scientist, Vol. 63, pp. 438-447, July-August 1975.

Bass, A. F. Curtailments of Natural Gas Service, pp. 2-13 of the Federal Energy Administration's Monthly Energy Review for January 1976.

Casazza, J. A. What Can Hydrogen Do for an Energy Company? Combustion, pp. 23-27, 1976.

Casazza, J. A., Huse, R. A., Sulzberger, V. T., Salzano, F. J. Possibilities for Integration of Electric, Gas and Hydrogen Energy Systems. Paper 31-07 presented at the International Conference on Large High Voltage Electric Systems (CIGRE), Paris, France, August 1974.

Escher, W. J. D. Hydrogen Fueled Internal Combustion Engine: A Technical Survey of Contemporary U. S. Projects. U. S. ERDA Report TEC-75/005, St. John, Michigan, September 1975.

Escher, W. J. D., Donakowski, T. D., Tison, R. R. A preliminary Systems Engineering Study of and Advanced Nuclear Electrolytic Hydrogen Production Facility. Final Report submitted to the Marshall Space Flight Center, NASA, by the Institute of Gas Technology, Chicago, Illinois, December 1975.

EURATOM, Joint Nuclear Research Center. Hydrogen Prociuction from Water. Using Nuclear Heat. Progress Report No. 5, Ispra, Italy, Annual Report ending December 1974.

Gregory, D. P. A Hydrogen-Energy System, prepared for American Gas Association by Institute of Gas Technology. Contributors: Anderson, P. J., Dufour, R. J., Elkins, R. H., Escher, W. J. D. (Consultant), Foster, R. B., Long, G. M., Wurm, J., Yie, G. G., August 1972.

Gregory, D. P., Konopka, A. J. Hydrogen Production by Electrolysis. Final Report of Project 8777 for Stevens Institute of Technology. Prepared by the Institue of Gas Technology, Chicago, 111 inois, July 1974.

Hoffman, G. A. The U. S. Fuel Industry in the 21 st Century. The University of Southern California, Industrial and Systems Engineering Department, Technical Report 75-1, January 1975.

Hughes, W. L. Allison, H. J., Ramakumar, R. G. Development of an Electrical Generator and Electrolysis Cell for Wind Energy Conversion System. Final Report NSF RANN Grant No. G1-39475, Oklahoma State University, July 10, 1975. 
Hydrogen and Other Synthetic Fuels, A Summary of the work of the Synthetic Fuels Panel, prepared for the Federal Council on Science and Technology RED Goals Study under the cognizance of the U. S. Atomic Energy Commission, Division of Reactor Development and Technology, TID-26136, September 1972.

Lotker, M., Fein, E., Salzano, F. J. The Hydrogen Economy - A Utility Perspective Paper. Presented at the IEEE Power Engineering Society Winter Meeting, New York, New York, February 1976.

Manne, A. S., Marchetti, C. Hydrogen: Mechanisms and Strategies of Market Penetration. International Institute for Applied Systems Analysis (IIASA) Research Report RR-74-4, Laxenburg; Austria, March 1974.

Marchetti, C. Geo Engineering and the Energy Island, Second Status Report of the IIASA Project on Energy Systems, Haefele, W., Editor, pp. 220-246. IIASA Research Report RR-76-1, Laxenburg, Austria, 1976.

Meyer, Charles F., Project Manager, Hausz, W., Knapp, L. H., Leeth, G. G., Luek, D. W., Steen, J. E. Phase I Study of Eco-Energy, 71TMP-44B, This study was funded jointly by the Southern California Edison Company and the General Electric Company, Tempo General Electric Company, Center for Advanced Studies, Santa Barbara, California, July 30, 1971 .

The Natural Gas Shortage: It's Worse Worse Worse. Anon., Business Week, pp. 66-72, September 27, 1976.

Nuttall,L. J. Application of SPE Water Electrolysis for Bulk Hydrogen Generation, Paper presented at the Eighth Synthetic Pipeline Gas Symposium, Chicago, Illinois, October 18-20, 1976.

Pangborn, J., Gillis, J. Alternative Fuels for Automotive Transportation - A Feasibility Study. U. S. Environmental Protection Agency Report EPA-460/3-74-012, Chicago. Institute of Gas Technology, July 1974.

Reilly, J. J., Hoffman, K. C., Strickland, G., Wiswall, R. H., Iron Titanium Hydride as a Source of Hydrogen Fuel for Stationary and Automotive Applications. Paper presented at the 26 th Annual Proceedings, Power Sources Conference, May 1974. See Also, Waide, C. H. Comparing the Electric Lead Acid Battery Vehicle with a Hydrogen Fueled Vehicle Incorporating an Fe-Ti Hydride Storage Unit. Report BNL-20950, January 1976.

Salzano, F. J., Braun, C. Water Electrolysis vs. Thermochemical Production of Hydrogen: A Parametric Assessment. Paper presented at the lst World Hydrogen Energy Conference, Miami Beach, Florida, BNL 20878, March 1976.

Savage, R. L., Blank, L., Cady, T., Cox, K., Murray, R., Williams, R. D, Editors, A Hydrogenergy Carrier, Volume I Summary, NGT 44-005-114, NASA-ASEE, September 1973. 
Swisher, J. H., The Chemical Energy Storage Program in Perspective. Paper presented at the ERDA Contractor's Review Meeting on Chemical Energy Storage and Hydrogen Energy Systems, held at Airlie House, Airlie, Virginia, November 8-9, 1976.

Tittertington, W. A. Status of GE Company SPE Water Electrolysis for Hydrogen/ Oxygen Production. Paper presented at World Energy System Conference. Hurst, Tesas, June 1974.

U. S. ERDA. National Benefits Associated with Commercial Associated with Commercial Application of Fuel Cell Power Plants. Report ERDA-76-54, Washington, D. C., February 1976.

U. S. ERDA Weekly Announcements, ERDA Considering Two Proposals for Making Hydrogen from Coal, Volume 2, No. 43, Washington D. C., November 5, 1976.

U. S. Federal Power Commission, Report on Monthly Curtailments based on FPC Form No. 17 (April, May, and June 1976. Bureau of Natural Gas Staff Report, Washington, D. C., August 1976.

Young, R. B., Tiedemann, A. F., Jr., Marianowski, L. G., Camara, E. H. Production of Methane Using Offshore Wind Energy. Report ERDA/NSF/993-75/TI, Washington, D. C., November 1975. 
APPENDIX A

HYDROGEN PRODUCTION METHODS AND COSTS

\section{A.- Introduction}

The major hydrogen production processes presently in use are catalytic steam reforming of natural gas, partial oxidation of hydrocarbons, and refinery catalytic reforming. Smaller amounts of high purity mechant hydrogen are produced commercially by water electrolysis. The various hydrogen production methods have been discussed in References $(1,2,4,6,25)$ and $(27,28,34,52,53,54)$.

As shown in (2) the average price of captive hydrogen in constant 1973 dollars has steadily declined from 1954 to 1972; this price trend is also evident in current dollars. This can be attributed to increased plant inefficiencies and the replacement of old units by new, larger production facilities. A reversal of the declining price trend has occurred since 1973 due to the sharp increase in oil prices, and the scarcity and rising price of natural gas. The average annual price of captive industrial hydrogen has been estimated as $\$ 0.6 / 10^{6}$ Btu by 1975 according to (2). Merchant high purity electrolytic hydrogen has shown the same price trend except that the current dollars prices have been increasing since 1970. The estimated average 1974 price of high purity hydrogen was $\$ 7.60 / 10^{6}$ Btu and the price of very high purity hydrogen is much higher (55). The relationship of hydrogen purity, prices, and supply is shown in Figure A-l.

The rising prices of hydrogen feedstocks (natural gas and oil) and of electricity, have created an incentive to develop other fossil raw materials as hydrogen feedstocks, to reduce the cost and improve the efficiency of water electrolysis equipment, and to investigate new production methods based on thermochemical water splitting, photosynthesis, and waste materials. The major current and future hydrogen production methods and costs are described below.

B. Natural Gas Reforming and Partial Oxidation of Hydrocarbons

The current major processes for large-scale manufacture of industrial hydrogen are natural gas reforming and partial oxidation of hydrocarbons. 


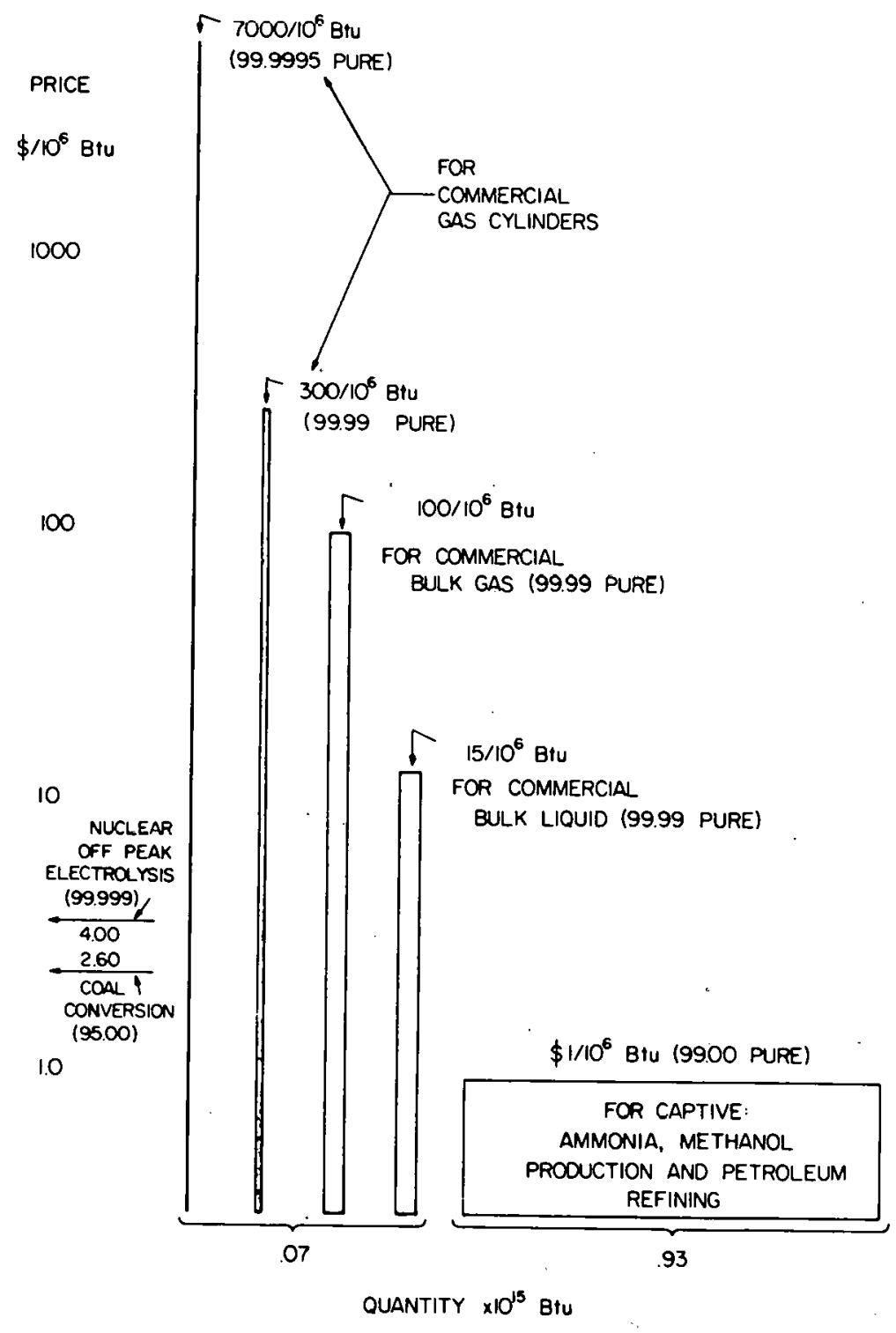

Figure A-1. Approximate current hydrogen prices (1974). 
The overall process is summarized in Figure A-2. The reaction of methane and steam is performed at $\sim 1500^{\circ} \mathrm{F}$ and the products of the first step are reacted with excess steam ("shifted") to convert the carbon monoxide to carbon dioxide and produce more hydrogen. The carbon dioxide is then scrubbed and removed. Typical hydrogen purity of $97 \%$ is obtained in this reaction at an overall energy efficiency of $68 \%$. Further cleaning with molecular sieves to $99 \%$ purity can be accomplished.

Two very similar partial oxidation processes for conversion of liquid hydrocarbons to hydrogen have been commercialized. These are the Texaco Process and the Shell Gasification Process. Heavy oil is reacted with steam and oxygen at a high pressure, and the resulting gas is rapidly quenched with water. The resulting mixture of carbon monoxide, water vapor, and hydrogen is subsequently shifted and scrubbed to yield industrial-grade hydrogen.

The partial oxidation processes are very versatile with respect to raw materials feedstocks. These processes consume large volumes of $95 \%-99 \%$ pure oxygen which increases the hydrogen production costs compared with natural gas reforming.

Another refinery process for hydrogen manufacture is catalytic reforming of petroleum components. The main reactions are isomerization and cyclization which result in dehydrogenation of the final products. The conversion of napthalenes to aromatics results in equivalent excess hydrogen production of $700 \mathrm{SCF}\left(\mathrm{H}_{2}\right)$ per barrel reformed.

A recent comparative estimate of hydrogen production prices by different processes was performed by the Exxon Company (6) and updated for recent inflationary effects on investment costs (56). A summary of the results is shown in Figure A-3. These results are reported in 1980 dollars and various escalation rates are required to convert capital, fuel, and operating expenses from 1980 to 1975 dollars. A similar comparison of hydrogen production costs by several different technologies which are expected to be commercially available by 1985 has been carried out here, and the results are shown in Table A-1. These cost computations are presented in 1975 dollars and are 
30 ATMOSPHERE PRESSURE

REFORM

SHIFT

SCRUB $1500^{\circ} \mathrm{F}$ TEMPERATURE

$\mathrm{CH}_{4}+\mathrm{H}_{2} \mathrm{O} \longrightarrow \mathrm{CO}$

co
NICKEL

CATALYST

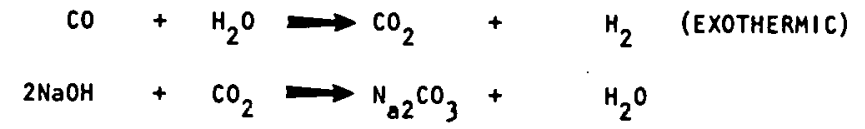

PARTIAL OXIDATION (HYDROCARBONS)

OXYGEN PLANT
PRECISE RATES
PREHEATED REACTANTS

$\mathrm{CH} 4+\mathrm{I} / 2 \mathrm{O}_{2} \longrightarrow \mathrm{CO}+2 \mathrm{H}_{2}$

Figure A-2. Current hydrogen production processes. Steam reform (natural gas/naptha)

$-70-$ 
Table A-1

COMPUTATION OF hYDROGEN PRODUCTION COSTS BY VARIOUS TECHNOLOGIES IN THE YEARS 1985 aND 2000 1975 Dollars

\begin{tabular}{|c|c|c|c|c|c|c|c|c|}
\hline \multirow[b]{2}{*}{ Performance and Cost 1 tems } & \multirow[b]{2}{*}{$\begin{array}{l}\text { Methane } \\
\text { Steam } \\
\text { Reforming } \\
\text { (1) (5) }\end{array}$} & \multirow[b]{2}{*}{$\begin{array}{l}\text { Resid } \\
\text { Partial } \\
\text { Oxidation } \\
\text { (1) (5) } \\
\end{array}$} & \multicolumn{2}{|c|}{ Coal Gasification } & \multirow{2}{*}{$\begin{array}{l}\text { Lurgi Water } \\
\text { Electrolyzer } \\
\text { Using } \\
\text { off-Peak } \\
\text { Power } \\
\text { (2) (4) }\end{array}$} & \multirow{2}{*}{$\begin{array}{l}\text { SPE New } \\
\text { Off-Peak } \\
\text { Power } \\
\text { (3) (4) }\end{array}$} & \multicolumn{2}{|c|}{ Water Electrolysis } \\
\hline & & & $\begin{array}{l}\text { Koppers } \\
\text { Totzek } \\
\text { (1) (.5) }\end{array}$ & $\begin{array}{l}\text { Improved } \\
\mathrm{K}-\mathrm{T} \\
\text { (1) (5) }\end{array}$ & & & $\begin{array}{l}\text { Spinning } \\
\text { Reserve } \\
\text { (3) (4) }\end{array}$ & $\begin{array}{l}\text { Dedicated } \\
\text { Plant } \\
\text { (3) (4) }\end{array}$ \\
\hline Plant Cost $\left(10^{6} \$\right)$ & 40.7 & 103.5 & 160.1 & 130.0 & 17.1 & 0.75 & 0.75 & 0.75 \\
\hline Plant Production & $100 \frac{\text { MSCF }}{\text { Day }}$ & $100 \frac{\text { MSCF }}{\text { Day }}$ & $100 \frac{\text { MSCF }}{\text { Day }}$ & $100 \frac{\text { MSCF }}{\text { Day }}$ & 53.3MWth & 5 MWth & 5 MWth & 5 Mwth \\
\hline Annual Operation & $330 \frac{\text { Days }}{Y_{r}}$ & $330 \frac{\text { Days }}{Y_{r}}$ & $330 \frac{\text { Days }}{Y_{r}}$ & $330 \frac{\text { Days }}{Y_{r}}$ & $55 \frac{\text { Hours }}{\text { Week }}$ & $55 \frac{\text { Hours }}{\text { Week }}$ & $7920 \frac{\text { Hours }}{\text { Year }}$ & $109 \frac{\text { Hours }}{\text { Weat }}$ \\
\hline Annual Average Load Factor & 0.904 & 0.904 & 0.904 & 0.904 & 0.33 & 032 & & \\
\hline Conversion Efficiency $(z)$ & 70.2 & 82.7 & 59.6 & 64.2 & 74 & 0.33 & 0.904 & 0.03 \\
\hline Unit Capital Cost $\$$ & & & (1) & 87.2 & 14.8 & 90.0 & 90.0 & 90.0 \\
\hline Basic Fuel Cost & - & - & - & - & 320 & 150 & 150 & 150 \\
\hline Year 1985 ( $\$ / M$ Btu) & 2.15 & 2.52 & 0.74 & 0.74 & 0.76 & 0.76 & 0.76 & 2.53 \\
\hline Year $2000(\$ / M$ Btu $)$ & 2.41 & 3.15 & 0.82 & 0.82 & 0.88 & 0.88 & 0.88 & 2.65 \\
\hline Unit Production Costs - 1985 & & & & & & & & \\
\hline Capital Cost (7) (\$/M Btu) & 0.65 & 1.64 & 2.54 & 2.06 & 5.50 & 2.58 & 0.94 & 1.31 \\
\hline Fuel Cost (\$/M Btu) & 3.06 & 3.05 & 1.24 & 1.15 & 3.08 & 2.56 & 2.56 & 8.53 \\
\hline 0 and $M \operatorname{cost}(6)(\$ / M B t u)$ & $\underline{0.50}$ & $\underline{0.50}$ & 1.34 & $\underline{1.25}$ & $\underline{0.47}$ & 0.47 & 0.47 & 0.47 \\
\hline Total Unit Cost ( $\$ / M$ Btu) & 4.21 & 5.19 & 5.12 & 4.46 & 9.05 & 5.61 & 3.97 & 10.31 \\
\hline Unit Production Costs - 2000 & & & & & & & & \\
\hline Capital Cost (7) (\$/M Btu) & 0.65 & 1.64 & 2.54 & 2.06 & 5.50 & 2.58 & 0.94 & 1.31 \\
\hline Fuel Cost $(\$ / M B t u)$ & 3.43 & 3.81 & 1.38 & 1.28 & 3.46 & 2.88 & 2.88 & 8.66 \\
\hline 0 and $M \cos t(6)(\$ / M B t u)$ & $\underline{0.50}$ & $\underline{0.50}$ & 1.34 & $\underline{1.25}$ & $\underline{0.47}$ & $\underline{0.47}$ & $\underline{0.47}$ & 0.47 \\
\hline Total Unit Cost (S/MBtu) & 4.58 & 5.95 & 5.26 & 4.59 & 9.43 & 5.93 & 4.29 & 10.44 \\
\hline
\end{tabular}


Footnotes to Table A-1

1. Plant capacity, capital cost, conversion efficiency and annual load factor are obtained from the Exxon study (6). The investment cost figures are converted from 1980 to 1975 dollars using a $9 \%$ annual discount factor, based on private communication from H. G. Corneil (Exxon Research and Engineering Company) to C. Braun, BNL, November 15, 1976.

2. Lurgi electrolyzer capacity, capital cost and conversion efficiency data obtained from the EPRI/IGT report on Utilization of Off-Peak Electric Power (4), Table || $\mid-1$ and || $\mid-2$.

3. Plant capacity, capital cost and conversion efficiency of solid polymer electrolyte water electrolysis equipment based on commun cation from R. Fernandes (Niagara Mohawk Power Company) to the Ad Hoc Committee on Hydrogen as a Natural Gas Supplement, November 2, $1976(14)$.

4. Electricity supplied to the water electrolysis plant is assumed to be provided by a LWR nuclear power plant having the following economic parameters:

(a) Capital cost of $\$ 585 / \mathrm{kW}(\mathrm{e})$ in 1974 dollars (3). Escalated to 1975 dollars assuming $5 \%$ /year escalation rate according to (57).

(b) Nuclear fuel cycle cost - $\$ 0.65 / \mathrm{M}$ Btu and $\$ 0.77 / \mathrm{M}$ Btu in 1985 and 2000 , respectively (3).

(c) Operating and maintenance costs of $1.2 \mathrm{mills} / \mathrm{kWh}$ according to Reference (3) or the equivalent of $\$ 0.11 / \mathrm{M} B t u$.

(d) Thermal efficiency of 0.33 and 0.34 in 1985 and 2000, respectively (3).

(e) Base load annual average load factor of 0.65 (3). Spinning reserve is assumed available on a year-round basis $(7920 \mathrm{hr} /$ year) at nuclear fuel cost. Off-peak and spinning reserve operation are charged only the variable, i.e., fuel and $0 \& M$ nuclear costs which amount ot 7.86 and $9.10 \mathrm{mills} / \mathrm{kWh}$ in 1985 and 2000 , respectively. 


\section{Footnotes to Table A-1 (cont'd)}

5. Fossil fuels costs including raw fuel cost and incremental fuel processing expenses obtained from (3).

6. Operating and maintenance costs of fossil-fuel based hydrogen production plants obtained from (3). Water electrolysis plants OEM costs obtained from (14).

7. Annual fixed charges on capital are assumed at $17 \%$ of investment per year $(58)$.
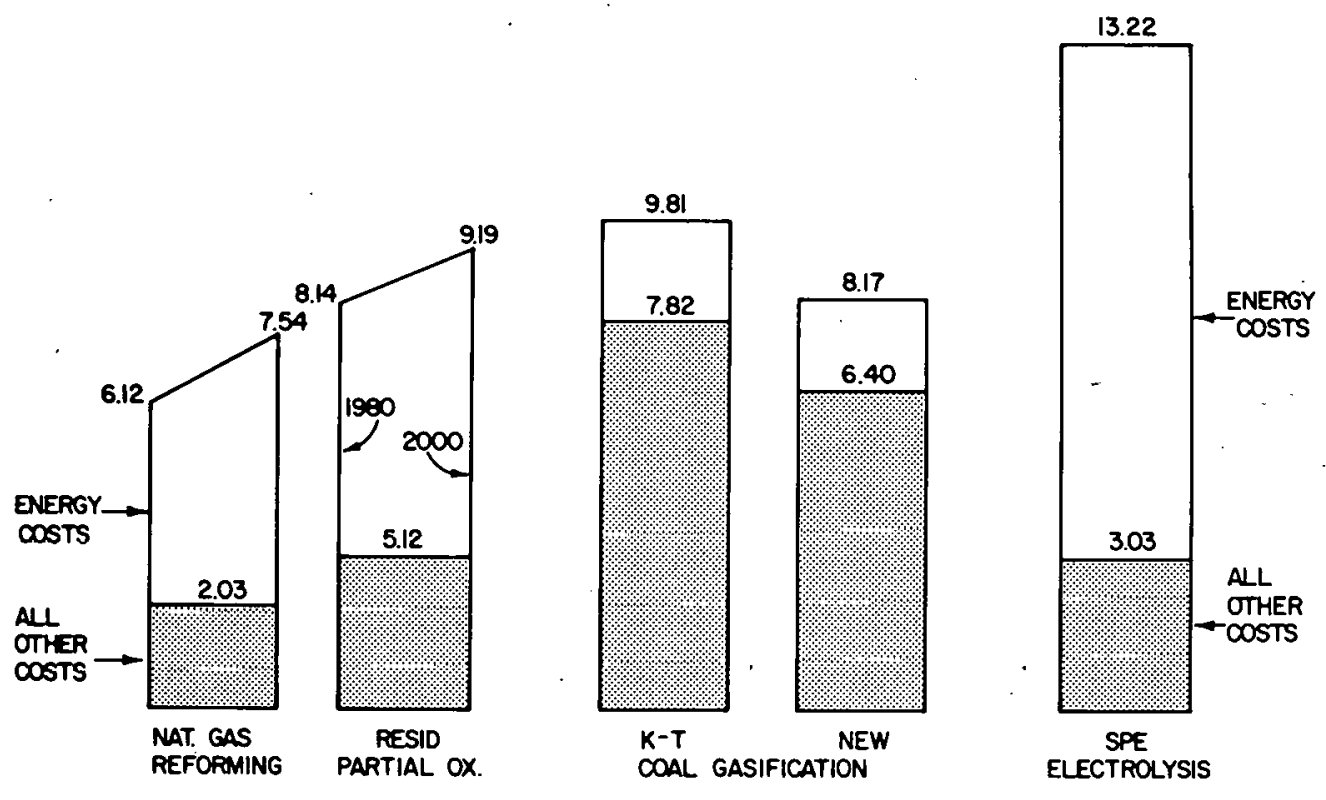

Figure A-3. Hydrogen manufacturing costs-midcontinent location. \$/MBtu - $100 \mathrm{MSCF} / \mathrm{D}$ plants - 1980 \$ operation during period $1980-2000$. 
based in part on Exxon capital cost estimates (6) (56), on ERDA fuel cost projections (3), and on SPE water electrolyzer performance expectations (14).

C. Hydrogen Production by Coal Gasification

Hydrogen is produced as an intermediate product in the gas mix from the first stage of the coal gasification process. This step consists of reacting coal with steam, oxygen, or air; the energy for the gasification reaction is obtained from the combustion of some of the coal. The raw gas product of this step typically includes $50-60 \%$ hydrogen (41).

The second step of each gasification process is the product gas purification to the desired composition and purity levels. This includes both the further reacting of intermediate products and cleaning of the final gas stream. In several gasification processes for the production of low Btu gas, the final gas mix, with an average heating value of $160 \mathrm{Btu} / \mathrm{SCF}$, does include an average hydrogen content of $17 \%$ (according to Figure 18 (42). It is possible to modify these processes to provide hydrogen-rich gas mixes or pure hydrogen.

Three coal gasification technologies that can be applied to hydrogen production have recently been evaluated by the Institute of Gas Technology (IGT) for NASA (28). These include the Koppers Totzek, U-Gas, and Steam-Iron Processes. The Koppers Totzek Process (59) is now commercially available and is most commonly used for ammonia synthesis. It is based on suspension gasification of pulverized coal by steam and oxygen at close to atmospheric pressure and $3000^{\circ} \mathrm{F}$.

A recent Exxon estimate of hydrogen production cost by pressure gasification (41), based on ERDA Research Center evaluated data (60), estimates hydrogen production costs of $\$ 3.84 / \mathrm{M}$ Btu to $\$ 4.16 / \mathrm{M}$ Btu for coal prices of $\$ 11 /$ ton to $\$ 15 /$ ton, respectively. These cost estimates are reported in 1975 dollars and are almost twice the projected coal-derived hydrogen costs reported by IGT (28).

The BNL cost projections (1975 dollars) of hydrogen from current and advanced Koppers Totzek processes are shown in Table A-1, and a parametric cost analysis is shown in Figure A-4. These costs are somewhat higher than the Exxon cost computations based on ERDA data. The pressurized gasification 
process has a $15 \%$ cost advantage over the current process. Depending on the cost projections for natural gas, residual oil and coal, the hydrogen price from the advanced Koppers Totzek process is about equal to the cost of hydrogen from steam reforming or methane. The coal gasification process is much more capital intensive; however, this is compensated for by the higher price of the scarce natural gas feedstock compared with coal. Hydrogen produced by the conventional Koppers Totzek process is found to cost slightly less than hydrogen from resid partial oxidation, which is attributed mostly to the difference in fossil fuels prices.

A comparison of the hydrogen production expenses via steam reforming of methane and advanced Koppers Totzek process using Exxon Company's data is shown in Figure A-5 (obtained from (56)). Production costs are reported in 1980 dollars and the regional impacts of plant construction and coal transportation are taken into account.

It is expected that coal-derived hydrogen costs in 1975 dollars will vary between $\$ 4.5 / M B t u$ and $\$ 5.5 / M$ Btu depending on the process technology and coal price projections. At such prices, hydrogen from coal gasification can economically penetrate the future market for industrial hydrogen, especially in the methanol and ammonia manufacturing industries. More refined comparative calculations are required for other industrial demand categories. Ultimately, however, the future large-scale demand for coal in the synthetic fuels and electric utility industries (61), and the environmental impacts associated with large-scale mining, transportation, and combustion of coal (62), (63), may limit the use of coal to provide industrial hydrogen. Consideration should be given to hydrogen production technologies associated with relatively inexhaustible resources.

\section{Hydrogen Production by Water Electrolysis}

The electrolytic method of hydrogen production is a relatively simple process by which the hydrogen and oxygen products are easily separable from the water feedstock, and no by-products or pollutants are emitted at the production site. The electrolyzer, though modularized in construction and including no moving parts, must be designed to achieve high power densities and high conversion efficiency. The main impediment to large-scale 


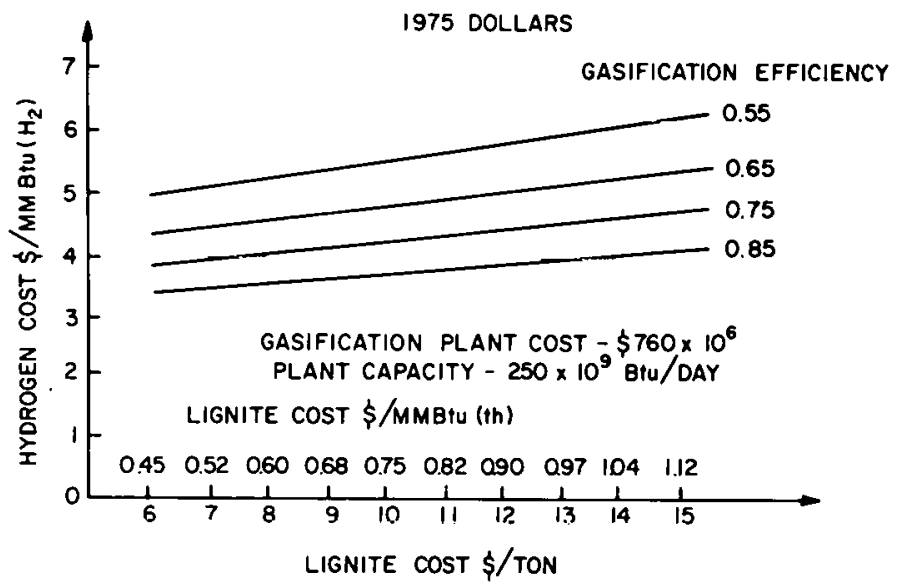

Figure A-4. Cost of coal derived hydrogen as a function of the gasification efficiency and the lignite cost.

Years 1985 and 2000 .
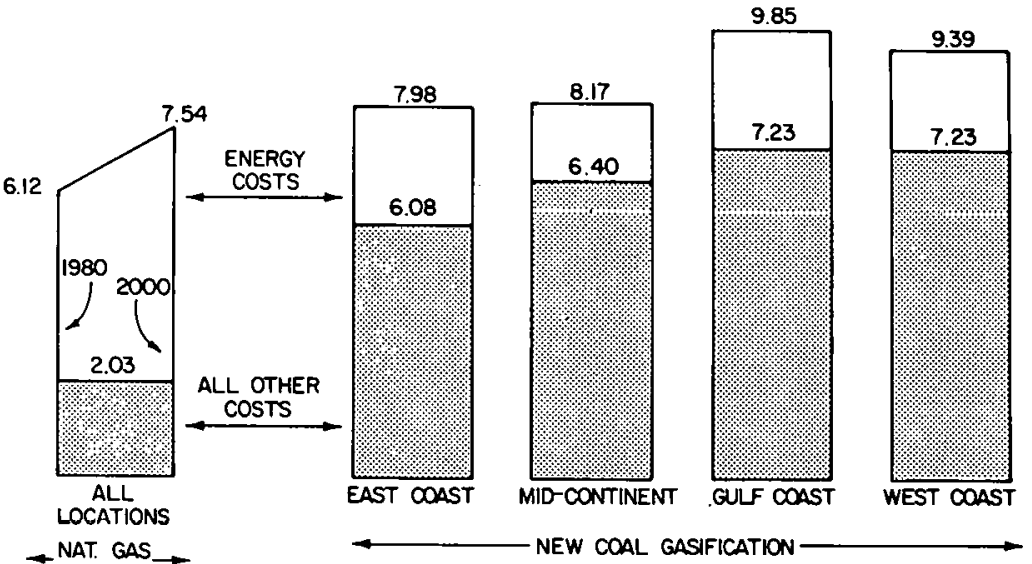

- NAT. GAS

$\rightarrow$ REFORMING

NEW COAL GASIFICATION

Figure A-5. Hydrogen manufacturing costs - new coal gasification. \$/MBtu - $100 \mathrm{MSCF} / \mathrm{D}$ plants - $1980 \$$. Plant operation during period 1980-2000. 
commercialization of this technology is the availability and cost of the input electric power. Water electrolysis is a commercially available technology.

Because electrolytic hydrogen production is determined by the availability and cost of electric power, four types of operating modes can be conceived: electricity supply from a dedicated plant, part time use of offpeak power, operation with spinning reserve electric power, and hybrid renewable off-peak concepts. Each of these operating modes will be described briefly.

(1) Electrolytic Production - Dedicated Nuclear Plant Hydrogen is produced by water electrolysis using on-peak electricity supplied by a nuclear plant which forms an integral part of the hydrogen production complex. A light water reactor is assumed as the dedicated nuclear plant.

The load factor of the electrolysis plant is assumed here as $65 \%$ since it is connected to a dedicated nuclear plant which operates at a maximum utilization factor of 0.65 (3). In this case, all the nuclear electric production costs, i.e., both capital, fuel, and 0 and $M$ are charged to the cost of the electrolytic hydrogen in addition to the electrolysis plant costs. No specific credits are assumed here for considering the dedicated electric plant as part of the spinning reserve of the local electric utility, which can shed the electrolysis load and supply power to the electric grid on short notice. As such, the nuclear plant capacity could be regarded as spinning reserve, and credit should be taken because old fossil-fired electric plants, which normally serve as spinning plants, need not be used.

(2) Electrolytic Production - off-Peak Power

In this scheme, hydrogen is produced during off-peak periods using available base load electric power. It is assumed that nuclear off-peak power or other essentially inexhaustible and consequently low fuel cost electric plant, e.g., geothermal, solar, breeder, or fusion, is driving the water electrolysis facility. Indeed, it would make little economic sense to convert coal to electricity to be used in water electrolysis. 
Direct coal gasification to produce industrial hydrogen is the more economic and efficient process of converting coal into hydrogen. Only the variable fuel and operating and maintenance expenses of the base load power plant are charged to the hydrogen production cost. Capital charges on the electric plant are paid by the electric utility which derives base load electric power from this plant. This in effect is tantamount to subsidizing the hydrogen manufacturing operation at the expense of the electric power customers. Such a cost distribution is utilized within the utility system. Should it be desirable to sell the off-peak electrolytic hydrogen to other industries, a prorated portion of the base load plant capital charges must be assigned to the hydrogen price. It is for this reason that off-peak electric production of hydrogen is considered mostly by electric or electric and gas utilities for electric energy storage or natural gas supplementation purposes. A major impediment to the use of off-peak electrolytic hydrogen in industrial applications outside the electric utilities sector is the intermittent production rate at annual average load factors varying between 0.3 and 0.5 . In fact, off-peak power availability varies over a daily, weekly and seasonal basis during the year (64). Because industrial applications may require a constant hydrogen supply rate, the use of offpeak production methods results in the hydrogen storage buffer requirement between the supply and demand points. The impact of hydrogen storage on the use and economics of off-peak electrolytic hydrogen has been extensively and thoroughly discussed in $(4,6,34,65,66)$ and (67). Storage requirements may considerably increase the cost of electrolytic hydrogen.

The dynamics of off-peak electric power availability and cost are demonstrated for a large electric power pool in Tables A-2 and A-3, obtained from (14). The seasonal variation in off-peak power cost at a constant supply level are shown in Table A-2. Cost differentials are explained by the different power plants mix that will provide off-peak power at each season. This in turn depends on the seasonal load duration curves and on the planned maintenance schedules. Table A-3 demonstrates the annual averaged variations of off-peak power costs and available capacity levels. In general, cheap off-peak power from under-utilized nuclear plants may be available for 


\section{Table A-2 \\ SYSTEM A}

PROJECTED OFF-PEAK ENERGY COSTS*

. 1975 Dollars

$M i l l s / k W h$

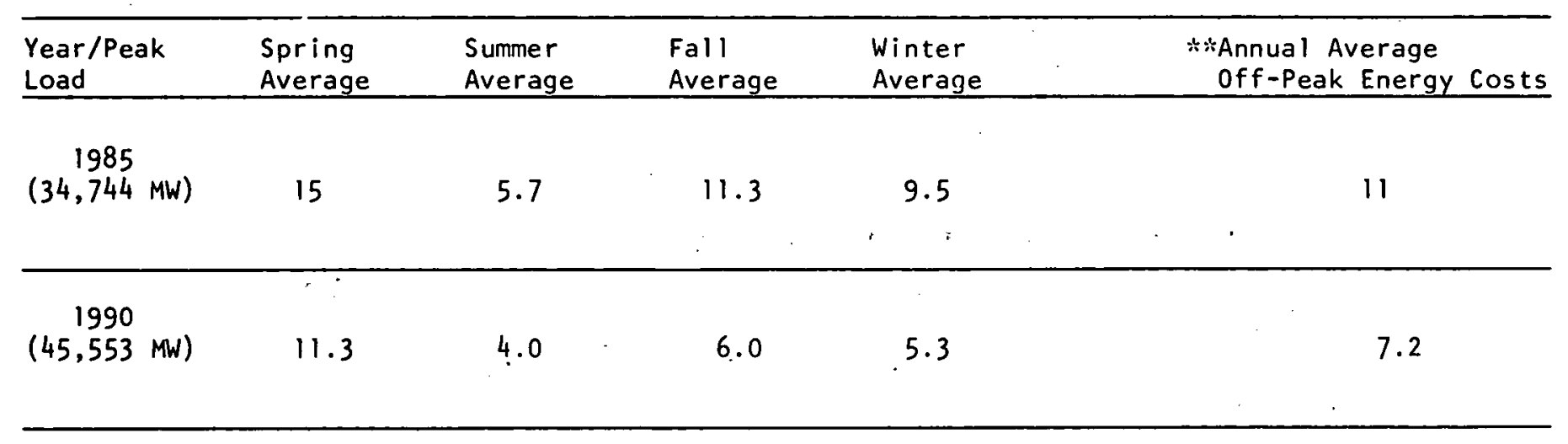

:Off-Peak Energy Computed Below 60\% Capacity

$* *$ Based on $8 \mathrm{~h} /$ weekday and $36 \mathrm{~h} /$ weekend 
Table A-3

NEW YORK POWER POOL

OFF-PEAK ENERGY COSTS VS. DEMAND LEVEL

1975 Dollars

\begin{tabular}{|c|c|c|c|c|c|}
\hline & \multirow{2}{*}{\multicolumn{2}{|c|}{$\begin{array}{l}\text { Off-Peak Capacity } \\
\text { Demand Increments }\end{array}$}} & & \multirow{3}{*}{$\begin{array}{c}\text { Off-Peak Energy Costs } \\
\text { Mills/kWh }\end{array}$} \\
\hline & & & & & \\
\hline Year & $\begin{array}{c}\text { System Peak } \\
\text { MW }\end{array}$ & $\begin{array}{l}\text { Block(\#) } \\
\text { Percent }\end{array}$ & Megawatts & Capacity Factor & \\
\hline \multirow[t]{3}{*}{1985} & 34,744 & (1) $2 \%$ & 696 & 0.40 & 3.5 \\
\hline & & (2) $4 \%$ & 1,392 & 0.45 & 11.75 \\
\hline & & (3) $3 \%$ & 1,044 & 0.50 & 14.10 \\
\hline \multirow[t]{3}{*}{1990} & 45,553 & (1) $4 \%$ & 1.820 & 0.40 & 3.50 \\
\hline & & (2) $5 \%$ & 2.275 & 0.45 & 8.50 \\
\hline & & (3) $2 \%$ & 910 & 0.50 & 10.20 \\
\hline
\end{tabular}


small amounts of time. As larger off-peak load factors are desired, additional plants having higher variable production costs are utilized, which raises the average cost of this electric power block. The expected larger penetration of nuclear power plants into the future utility system results in cheaper electric costs at the higher capacity blocks in the later time period. An economic balance must be established in each system between larger hydrogen production levels and higher electric power input prices. A parametric analysis of the impact of the rising off-peak power costs on the hydrogen manufacturing prices is shown in Figure A-6.

(3) Electrolytic Production - Spinning Reserve Power

The concept of utilizing spinning reserve power to produce electrolytic hydrogen has been suggested for study by the Commonwealth Edison Company (68). The definition and method of providing spinning reserve varies somewhat depending on what electric utility or group of utilities are considered, e.g., specific definition of capacity and cost reported in (69). In general, it is defined as the generating capacity which is held for emergency reserve, is connected to the electric system, and is available within a very short time--say 5-15 minutes. It normally provides for such unpredictable emergencies as the loss of a large generating unit, either within a utility's system, or a neighboring utility which is a member of a common power pool. In many utilities, this spinning reserve is carried part of the time by hydroelectric, coal-fired, and nuclear plants having relatively low cost fuel charges. The total spinning reserve is commonly provided in small increments by several power plants distributed through the electric utility grid.

In this production concept, the spinning reserve is now provided to the interruptible electrolyzer load which would be owned and operated by the electric utility. Control of the electrolyzer load must be under the direct supervision of the load dispatcher through either a manual or automatic arrangement to make the generating capacity serving the electrolyzers available in a very short time for emergency duty.

Normally, the spinning reserve is restored to the system as soon as possible by the addition of standby or operating reserve generating units so 
NUCLEAR FUEL CYCLE COST \$/MM BHU

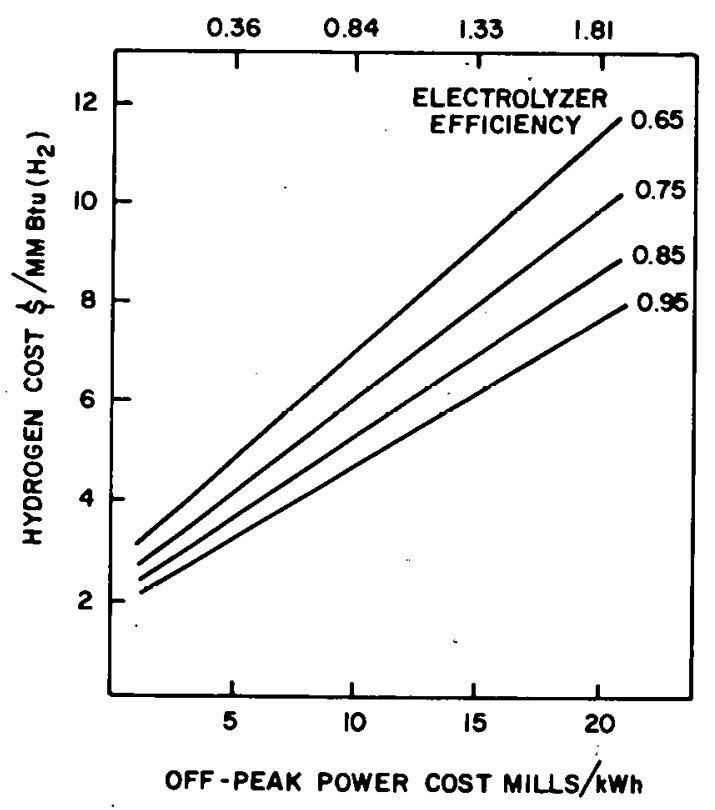

ELECTROLYZER COST - $\$ 100 / \mathrm{kW}(0)$

O AND $M$ COSTS - $0.37 \$ / M M B+U$

NUCLEAR THERMAL EFFICIENCY -0.33

\section{DOLLARS}

Figure A-6. Cost off-peak nuclear electrolytic hydrogen as a function of the of $f$-peak power cost, and the electrolyzer efficiency. (Years $1985-2000$ ) 
that electrolyzers would not normally be off the line for more than an hour or two for each operation involving spinning reserve. Assuming 100 operations a year averaging $1 \frac{1}{2}$ hours each, the electrolyzers would still have a potential availability for producing hydrogen of $8610 / 8760$ hours or $98 \%$.

The application of this concept to electrolytic hydrogen production has the advantage of having relatively low cost electric energy (the cheapest block of off-peak power) available for the electrolyzers at essentially all times. No capital charges on the electric generating plants are assessed against the hydrogen price, since these charges are covered by the electric sector's spinning reserve. The unit capital charges on the electrolyzers are minimized since very high utilization factors can be achieved. The concept of using spinning reserve to produce electrolytic hydrogen has the potential of combining the best economic advantages of the off-peak concept (low electricity cost) and the dedicated plant method (high utilization factors).

The cost of spinning reserve in the Commonwealth Edison service territory in 1975 varies between 7 to $10 \mathrm{mills} / \mathrm{kWh}$, (69). Average spinning reserve power costs vary between $10-14 \mathrm{mills} / \mathrm{kWh}$ for the Pennsylvania-JerseyMaryland (PJM) power pool (69). Using PJM definitions, 200 MWe of spinning reserve are available in 1976 on 10 hours/day, 300 days/year, within the 42,000 MWe power pool capacity, at the above quoted prices. Thus, spinning reserve forms $4.9 \%$ of the PJM installed capacity. Detailed daily and seasonal distribution of spinning reserve costs within the New York Power Pool (NYPP) are provided in (14) and (69). The annual average cost by 1985 is expected to be $7.5 \mathrm{mills} / \mathrm{kWh}$ in 1975 dollars. Assuming that the large-scale nuclear base load plant construction program of NYPP progresses on schedule, the year 1990 spinning reserve cost is projected to decrease below the 1985 value quoted above. Thus, spinning reserve appears to offer the potential of very low cost electrolytic hydrogen production within electric utility systems. In terms of hydrogen use potential this production method is most applicable to combined electric and gas utilities. Application within an all electric utility may increase the hydrogen price due to the required installation of storage facilities to act as a buffer between the production and use points within the electric utility network. 
(4) Electrolytic Production - Hybrid Renewable Resource Off-Peak Power In this concept an electrolyzer plant is powered by a renewable resource energy concerter such as a wind generator, solar vapor cycle, or photovoltaic cell array. A conventional electric power source is also connected to the electrolyzer through an automatic selective switch. This renewable source is connected as the primary energy source and powers the electrolyzer whenever sun or wind energy is available. During off-peak periods when wind or solar energy is not available, the switch is closed and the conventional electric supply powers the electrolyzer. This concept has been suggested by $E$. J. Steeve of Commonweal th Edison Company.

This hybrid system increases the use factor of the electrolyzer system at a minimum expense (i.e., the rectifier or converter and the selective switch). The hybrid concept could possibly offer the best opportunity for economic hydrogen production, when the cost of the solar generator is reduced, since solar/wind energy and off-peak power tend to complement each other in filling the avallable time for powering the electrolyzer.

The wind generator appears to be the most economic near-term renewable resource device to be utilized for hydrogen production. The feasibility of using wind generators to produce electrolytic hydrogen has recently been investigated (70) and (71).

The possibility of a gas/electric utility using this concept could be enhanced by the addition of an alternate supply of a conventional electric source. The alternate source could power the electrolyzer during calm periods when surplus cheap electric power is available. The hybrid power source system could replace some of the existing hydrogen production facilities, thus releasing a certain amount of natural gas or residual oil for other applications within the energy system.

(5) Electrolytic Production - Economic Analysis

Recent analyses of the cost of electrolytic hydrogen production using off-peak or spinning reserve power within a utility environment (14) are shown in Table A-4 for electrolyzer characteristics described in Table A-5. Similar computations also using 1975 dollars and somewhat different electrolyzer cost and performance goals are shown in Table A-6. The BNL projections of the cost 
Table A-4

HYDROGEN PRODUCTION COSTS 1975 DOLLARS

Operating Mode

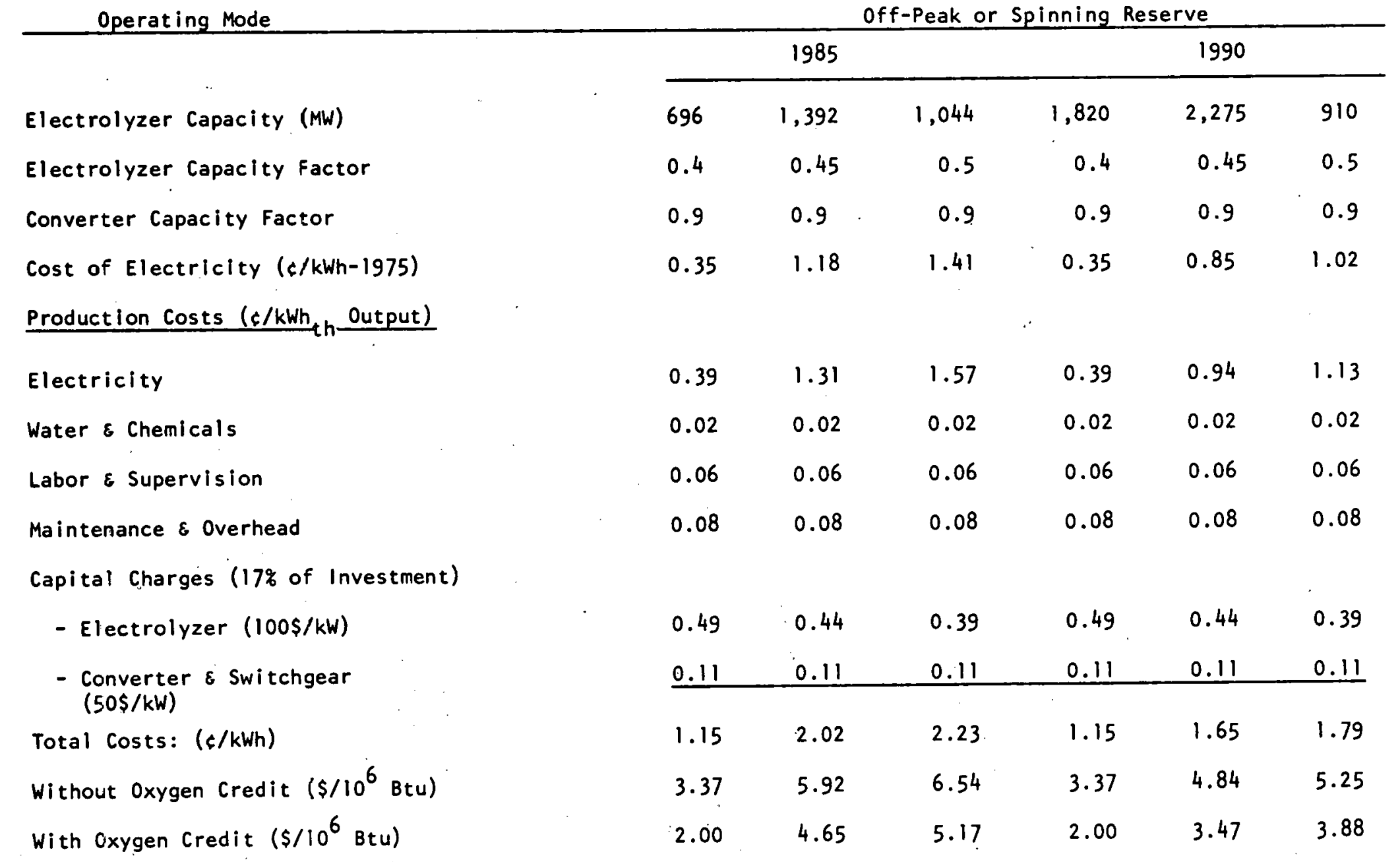


Table A-5

ELECTROLYTIC HYDROGEN PRODUCTION COSTS

1975 DOLLARS

1. General Assumptions

$\begin{array}{ll}\text { Plant: } & \begin{array}{c}\text { Solid Polymer Electrolyzer with Forced } \\ \text { Commutated Converter Interface }\end{array} \\ \text { Location: } & \begin{array}{l}\text { Northeast USA } \\ \text { Mode of Operation: }\end{array} \\ \text { Utilization Factor: } & \begin{array}{c}\text { Electrolyzer } 0.4,0.45,0.5 \\ \text { Converter } 0.9\end{array} \\ \text { Plant Size: } & 5 M W_{\text {th } \text { (Output) }} \\ \text { Production Efficiency: } & 90 \% \text { (Hydrogen Thermal Output) } \\ \text { Hydrogen Pressure: } & 450 \text { psig } \\ \text { Construction Period: } & 1 \text { year }\end{array}$

11. Investment Costs

$\$ / \mathrm{kW}$ out $\quad 10^{3} \$$ ( $P$ lant)

Electrolysis Modules
Plant Auxiliaries
Power Conversion \& Switchgear
Installation
Offsites
Contingency

20

100

23

115

45

225

22

110

15

75

TOTAL

25

$\underline{125}$

150

750 
Table A-6

GENERAL ELECTRIC SPE ELECTROLYSIS SYSTEM HYDROGEN PRODUCT COST FOR VARIOUS OPERATING MODES

Utility Financing, 1985 Operation, 1975 \$

Investment

Electrolysis Modules

Power Conversion and Switchgear

0 ther Process Equipment

Installation

off-sites

Cont ingency

Total

\section{Operating Mode}

Cost of Electricity, \$/kWhr

Operating hours per day

Operation hours per year

MBtu product per year $\times 10^{6}$

Working Capital, M\$

\section{Annual Production Costs, M\$ \\ Electricity \\ Water and Chemicals \\ Labor and Supervision}

Annual Production Costs

Maintenance ( $4 \%$ of on-sites)

General Overhead (2.6\% of on-sites)

Capital Charges (17\% of total invest.)

Working Capital Charges (21\% of work cap.)

Total Annual Costs

\section{Total Cost, \$/MBtu}

Without Oxygen Credit

With Oxygen Credit
$\$ / \mathrm{kW}$ out

$\begin{array}{rll}9 & & 0.460 \\ 46 & & 2.351 \\ 19 & & 0.571 \\ 9 & & 0.460 \\ 20 & & 1.022 \\ 31 & & 1.584 \\ 134 & & 6.448\end{array}$

$$
\begin{array}{cc} 
& \frac{M S}{} \text { On-Sites } \\
\text { Off-Sites } & \frac{1.093}{1.355} \\
\text { Total } & 6.448
\end{array}
$$

Off-Peak or Spinning Reserve

$\begin{array}{cccc}0.010 & 0.010 & 0.010 & 0.010 \\ 24 & 18 & 12 & 6 \\ 7920 & 5940 & 3960 & 1980 \\ 1.378 & 1.034 & 0.689 & 0.345 \\ 0.920 & 0.700 & 0.480 & 0.260\end{array}$

Dedicated

0.021

24

7920

1.378

1.876

\begin{tabular}{lllll}
5.211 & 3.908 & 2.606 & 1.303 & 10.944 \\
0.075 & 0.056 & 0.038 & 0.019 & 0.075 \\
$\frac{0.236}{5.522}$ & $\frac{0.236}{4.200}$ & $\frac{0.236}{2.880}$ & $\frac{0.236}{1.558}$ & $\frac{0.236}{11.255}$ \\
0.204 & 0.204 & 0.204 & 0.204 & 0.204 \\
0.132 & 0.132 & 0.132 & 0.132 & 0.132 \\
1.096 & 1.096 & 1.096 & 1.096 & 1.096 \\
$\frac{0.193}{7.147}$ & $\frac{0.147}{5.779}$ & $\frac{0.101}{4.413}$ & $\frac{0.055}{3.045}$ & 0.394 \\
\hline 13.081
\end{tabular}

$\begin{array}{lcccc}5.19 & 5.59 & 6.41 & 8.83 & 9.49 \\ 3.62 & - & - & - & 7.92\end{array}$

Plant - GE SPE Electrolysis
Plant Capacity - $51.1 \mathrm{MW}$ Hydrogen Output $=0.5417 \times 10^{6} \mathrm{sCF} / \mathrm{hr}=174 \times 10^{6} \mathrm{Btu} / \mathrm{hr}$

Thermal Efficiency - $77.6 \%$ Operating Days per year - 330

Electrical Requirement - $65.8 \mathrm{MW}$

Note: The contingency is $30 \%$ of the estimate for on-sites + off-sites. These investments include cost of funds during construction. 
of electrolytic hydrogen derived from current electrolysis technology operating in the dedicated plant, off-peak power and spinning reserve modes, are shown in Table $A-1$. Note that for an advanced electrolysis technology operating with off-peak power the cost of the product hydrogen varies between $\$ 5.5 / \mathrm{M} \mathrm{Btu}$ to $\$ 6.5 / M B t u$, in Tables $A-1, A-4$, and $A-6$, respectively. Hydrogen production costs with dedicated plants are higher--about $\$ 10 / M B t u$ as seen in Tables $A-1$ and $A-6$. The cost of spinning reserve electrolytic hydrogen production vary between $\$ 4 / \mathrm{MBtu}$ and $\$ 5.5 / \mathrm{MBtu}$, depending on the assumed availability and cost of electric power. The dynamics of off-peak power supply shown in Table A-3 are also repeated in Table A-4. The economics of electrolytic hydrogen production depend on the balance between the increasing cost of electric power input and the decreasing capital charges with improved electrolyzer use. In comparing part-time operation with off-peak power against continuous hydrogen production with a dedicated base load plant, the variation between the on-peak and off-peak power availability and the cost should be investigated for each local situation to identify the best mode of electrolyzer operation. The circumstances may arise whereby electrolytic hydrogen production with a dedicated plant becomes as economic as part-time operation with off-peak power, when a continuous hydrogen supply is not required. This point has been raised by A. Fickett of EPRI (72) and was also considered in (4).

A more detailed comparison between current and advanced electrolysis technology was performed in (4) and (6). A sample cost analysis performed in the Exxon study (56), using 1980 dollars is shown in Figure A-7. Both Figure $A-1$ and the results in Table $A-1$ indicate the potential reduction in electrolytic hydrogen cost from the commercialization of advanced water electrolysis technology. Table A-I shows that using Lurgi electrolysis technology, current electrolytic hydrogen prices are much higher than hydrogen production costs, using fossil fuel feedstocks. Advanced water electrolysis has the potential of reducing electrolytic hydrogen prices to levels similar to resid partial oxidation and conventional Koppers Totzek manufacturing methods. Comparison of advanced coal gasification with advanced water electrolysis technology indicates that electrolysis is more expensive by about one dollar per million Btu, assuming off-peak production. The spinning reserve concept of electrolytic 


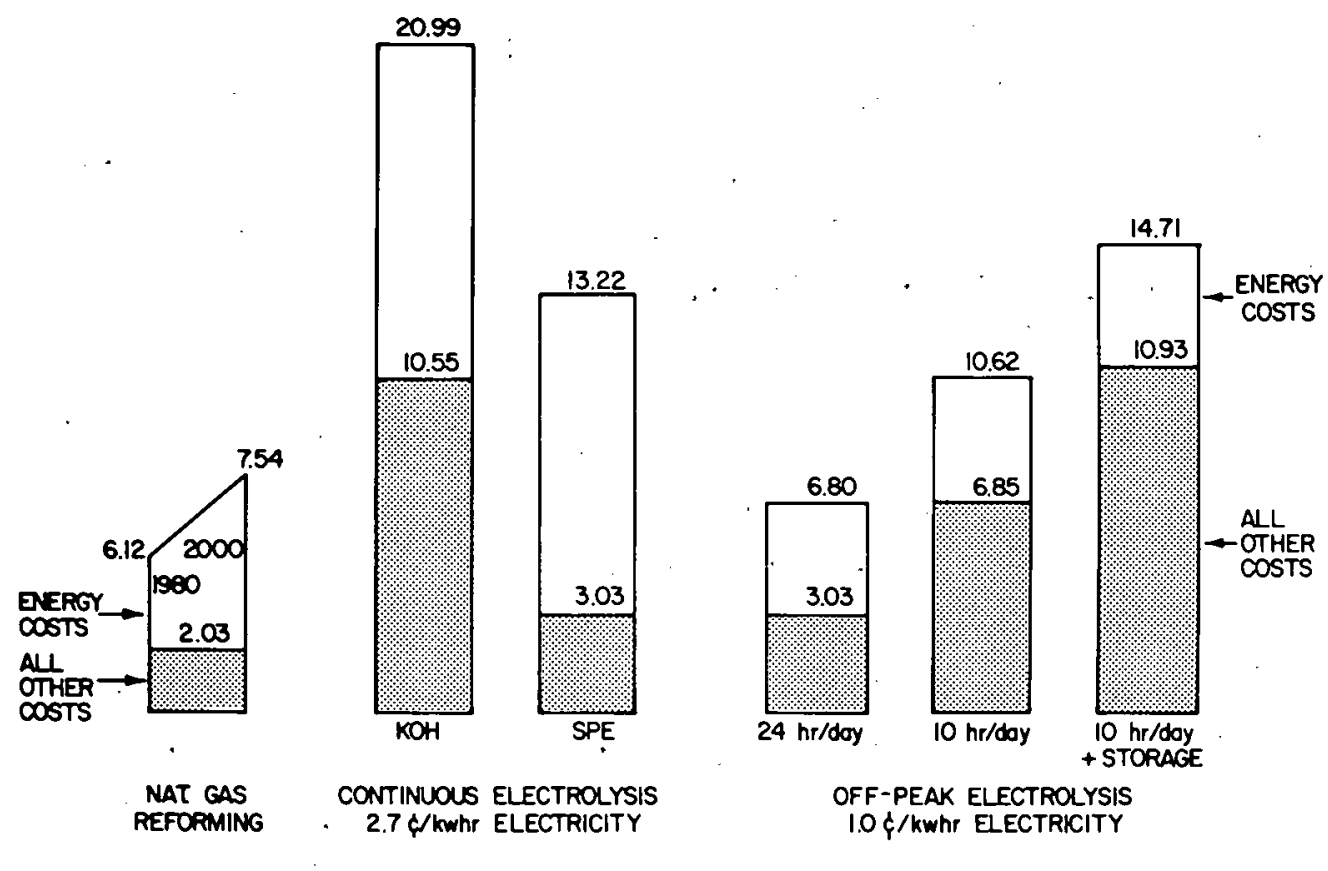

Figure A-7. Hydrogen manufacturing costs - electrolysis $\$ /$ MBtu - $1980 \$$ 
hydrogen production is projected to be cheaper than advanced Koppers Totzek gasification. Both advanced technologies may be commercialized by 1985 given sufficient RDED funding.

Although electrolytic hydrogen production may compete economically with advanced coal gasification in favorable situations, the potential implementation of the electrolysis method will be quite limited by the availability of relatively cheap electric power. The possible requirement for hydrogen storage which is concomitant with off-peak electrolytic production for industrial applications will reduce the economic incentive of this process vis-a-vis coal-derived hydrogen as seen in Figure A-7.

\section{E. Thermochemical Hydrogen Production}

Thermochemical methods of hydrogen production have been reviewed extensively in $(1,52,73,77)$ and $(78-80)$.

The general method of thermochemical water splitting is to drive a series of chemical reactions by supplying energy, usually heat, and thereby accomplish hydrogen and oxygen release in separate chemical steps. The objectives are to avoid the high temperatures (above $2500^{\circ} \mathrm{C}$ ) of direct thermal decomposition of water and to reduce the electricity requirements for water electrolysis. Water splitting constitutes a heat engine because the free energy available from the product hydrogen is the thermodynamic equivalent of work. Therefore, second-law requirements apply to these processes to the extent that heat or entropy is converted to chemical free energy (which is a part of the enthalpy of hydrogen).

If the series of chemical reactions is cyclical, that is, all intermediate compounds are recycled within the process, the procedure is called closed-loop thermochemical hydrogen production. Most of the research programs today have concluded that some high temperature heat source is needed for operation of efficient cycles and, therefore, the high-temperature (gas-cooled) nuclear reactors (HTR's) will be required for nuclear-driven cycles, (81) and (82). Alternatively, high-temperature solar heat could be used; or at later periods, nuclear fusion reactors might be applicable. Studies have also shown that for closed-loop thermochemical cycles efficiency advantages for thermochemistry over electrolysis occurs only if heat can be supplied at temperatures over about $700^{\circ} \mathrm{C}$. 
The more promising thermochemical closed-loop hydrogen processes have been reviewed in (1), (77), (52), and (80). It is generally assumed that process chemistry for an advanced concept may become available after 1985. No detailed industrial chemical process design is currently available and pilot plant testing that will indicate realistic cost goals may be carried out under favorable circumstances during the 1990's. Another major uncertainty affecting the eventual commercialization of thermochemical water production is the fate of the HTGR, HTR, and VHTR high-temperature nuclear reactor programs.

F. Additional Hydrogen Production Methods

Beyond the hydrogen production processes discussed so far, additional manufacturing methods are now being investigated for possible commercializacion toward the end of the century. These processes mostly involve the use of renewable energy resources and include production by photosynthesis, by various solar electrolytic routes, e.g., in ocean thermal energy conversion plants (83) and (84), and by direct thermal decomposition of water. The utilization of such different energy sources as fusion reactors (85) and waste materials (86) for hydrogen manufacture has been considered.

$-91-$ 
APPENDIX B

COST EQUATIONS USED IN ESTIMATING HYDROGEN PRODUCTION COSTS

The following equations were utilized in the computation of the hydrogen cost and in the sensitivity analysis computations. Sample cost data used in an earlier draft of the Hydrogen Assessment Report are included here as a basic numerical example:

1. Off-Peak Electric Production

$$
H C\left[\frac{\$}{M M B t u\left(H_{2}\right)}\right]=\frac{C_{E} \cdot 0 \cdot 15}{29 \cdot 92 \cdot L F_{E} \cdot E F F_{E}}+\frac{O M}{E F F_{E}}+\frac{F C}{E F F_{N} \cdot E F F_{E}}
$$

where

MM Btu is $10^{6}$ Btu

$\mathrm{HC}$ is the hydrogen cost in [\$/MM Btu $\left.\left(\mathrm{H}_{2}\right)\right]$

$C_{E}$ is the electrolyzer cost [in $\left.\$ / k W(e)\right]$

0.15 is the annual fixed charges rate in fraction per year $\left[\mathrm{Yr}^{-1}\right.$ ]

29.92 is the conversion factor for [MM Btu(e)/kW(e)-Yr]

$L F$ is the electrolyzer load factor

$E_{E F}$ is the electrolysis efficiency [MM Btu $\left(\mathrm{H}_{2}\right) / M M$ Btu(e)]

$E_{N}$ is the nuclear thermal efficiency in $[M M B t u(e) / M M B t u(t h)]$

$O M$ is the nuclear operating and maintenance cost in [\$/MM Btu(e)]

FC is the nuclear fuel cycle cost in [\$/MM Btu(th)]

The following nominal values for the different variables were used

in the base case of the sensitivity analysis computations.

$C_{E}=\$ 100 / \mathrm{kW}(\mathrm{e})$

$L F_{E}=0.3$

EFF $_{E}=0.75$ in 1985 and 0.90 in 2000

FC $=\$ 0.30 / M M B t u(t h)$ in 1985 and $\$ 0.50 / M M B t u(t h)$ in 2000

$O M=\$ 0.37 / M M$ Btu(e)

$E F F_{N}=0.33$. 
These, as well as most of the other base case values reported in this Appendix, were obtained from Reference (1).

2. Electrolytic Hydrogen with Dedicated Nuclear Plant

$H C\left[\frac{\$}{M M B t U}\left(H_{2}\right)\right]=\frac{C_{N} \cdot 0 \cdot 15}{29 \cdot 92 \cdot L_{N} \cdot E F F_{E}}+\frac{C_{E} \cdot 0 \cdot 15}{29 \cdot 92 \cdot L F_{E} \cdot E F F_{E}}+\frac{O M}{E_{E F F}}+\frac{F C}{E_{E F F} \cdot E F F_{E}}$

where

$C_{N}$ is the nuclear plant capital cost in $[\$ / k W(e)]$

${ }^{L F}$ is the nuclear plant annual average load factor

All the other variables have been defined above.

The following nominal values are used in the computations: (only values which differ from those mentioned above are reported here).

$C_{N}=\$ 520 / \mathrm{kW}(\mathrm{e})$ in 1985 and $\$ 550 / \mathrm{kW}(\mathrm{e})$ in 2000

$L F_{N} \quad=0.8$

$L F_{E} \quad=0.8$

EFF $_{N}=0.33$ in 1985 and 0.40 in 2000

3. Thermochemical Hydrogen Production

The nominal thermochemical hydrogen cost was set equal to the nominal cost of electrolytic hydrogen. Thermochemical hydrogen cost variations were computed from the following equation:

$$
H C\left[\frac{\$}{M M B t U\left(H_{2}\right)}\right]=\frac{C_{N T P} \cdot E F F_{N} \cdot 0.15}{29.92 \cdot L_{N} \cdot E F F_{T}}+C_{T P}+\frac{O M \cdot E F F_{N}}{E F F_{T}}+\frac{F C}{E F F_{T}}
$$

where

$C_{\text {NTP }}$ - the cost of the nuclear thermal plant in $\$ k W(t h)$

$C_{N T P}$ is computed from the nominal nuclear plant cost $C_{N}$ in

[ $\$ / \mathrm{kW}(\mathrm{e})]$ using the following equation 


$$
C_{N T P}=C_{N}\left[1-F R_{E L}\right] \cdot E F F_{N}
$$

where

$F R_{E L}$ is the fraction of the nuclear plant capital cost related to electricity producing equipment. All other variables were defined before.

$E_{T}$ is the thermochemical process efficiency in units of [MM Btu $\left(\mathrm{H}_{2}\right)$ / MM Btu(th)].

$C_{T P}$ is the thermochemical process plant capital cost, expressed in [\$/MM Btu $\left.\left(\mathrm{H}_{2}\right)\right]$.

The following nominal values were used in the computations or obtained from equating the costs of electrolytic and thermochemical hydrogen.

$F R_{E L}=0.337$

$C_{\text {NTP }}=\$ 145.9 / \mathrm{kW}(\mathrm{th})$ or $\$ 2.29 / \mathrm{MM} \mathrm{Btu}\left(\mathrm{H}_{2}\right)$

$C_{T P}=\$ 2.38 / M M B t u\left(H_{2}\right)$

$\mathrm{EFF}_{\mathrm{T}}=0.40$

4. Coal-Derived Hydrogen

$$
H C\left[\frac{\$}{M M B t u\left(H_{2}\right)}\right]=\frac{C_{G} \cdot 0.15}{H_{G} \cdot 365 \cdot L F_{G} \cdot[}\left[\begin{array}{ll}
0.65 \\
E F F_{G}
\end{array}\right]+\frac{C C}{21.4 \cdot E_{G}}+O M
$$

where

$C_{G}$ is the cost of the coal gasification plant in dollars [\$]

$H_{G}$ is the gasification plant capacity in MM Btu $\left(H_{2}\right) /$ Day

365 is days/year

$L_{G}$ is the gasification plant annual average load factor

$E_{G}$ is the gasification efficiency in [MM Btu $\left.\left(\mathrm{H}_{2}\right) / M M B t u(t h)\right]$

$C C$ is the coal cost in ( $\$ /$ ton)

21.4 is the coal heat content in [MM Btu(th)/ton]

OM is the gasification plant operating and maintenance cost in [\$/MM Btu $\mathrm{H}_{2}$ )]

The following nominal values were used in the computations

$C_{G}=\$ 760.10^{6}$

$H_{G}=250.10^{3}$ MM Btu $\left(H_{2}\right) /$ day 
$L F_{G}=0.9$

$E F F_{G}=0.65$

LC $=\$ 8.0 /$ ton lignite

$O M=\$ 0.25 / M M$ Btu $\left(\mathrm{H}_{2}\right)$

5. Natural Gas Reforming

The cost of hydrogen produced from natural gas reforming is computed from data presented in a graph in Reference (2).

6. Unit Conversions

The off-peak electric cost can be converted to variable fuel cost using the following equation:

$$
F C=O P C \cdot \frac{E F F_{N}}{3.413}-O M \cdot E F F_{N}
$$

where

FC is variable fuel cost in [\$/MM $B t u /(t h)]$

$E F F_{N}$ is nuclear plant thermal efficiency [MM Btu(e)/MM Btu(th)]

$O P C$ is off-peak power cost in [Mills/kW(e)hr]

3.413 is conversion factor [MM Btu(e) Mills/kW(e) $\mathrm{hr}, \$$ ]

$O M$ is operating and maintenance cost in [\$/MM Btu(e)]

The coal cost in $(\$ / M M B t u(t h))$ is obtained by dividing the coal cost in $(\$ /$ ton) by the coal heat content in [MM Btu(th)/ton]

\section{References}

(1) Beller, M. Cost Tables for Brookhaven Energy System Optimization Model, BNL Memorandum, Upton, New York, September 1975.

(2) Hord, J. Selected Topics in Hydrogen Fuel. National Bureau of Standards Special Publication No. 419, Washington, D.C., May 1975. 